\title{
Catalyst-free Hydrodefluorination of Perfluoroarenes with $\mathrm{NaBH}_{4}$
}

Timothy D. Schoch, Mukulesh Mondal, and Jimmie D. Weaver*

Department of Chemistry, Oklahoma State University, Stillwater, OK 74078

jimmie.weaver@okstate.edu

\section{Supporting Information}

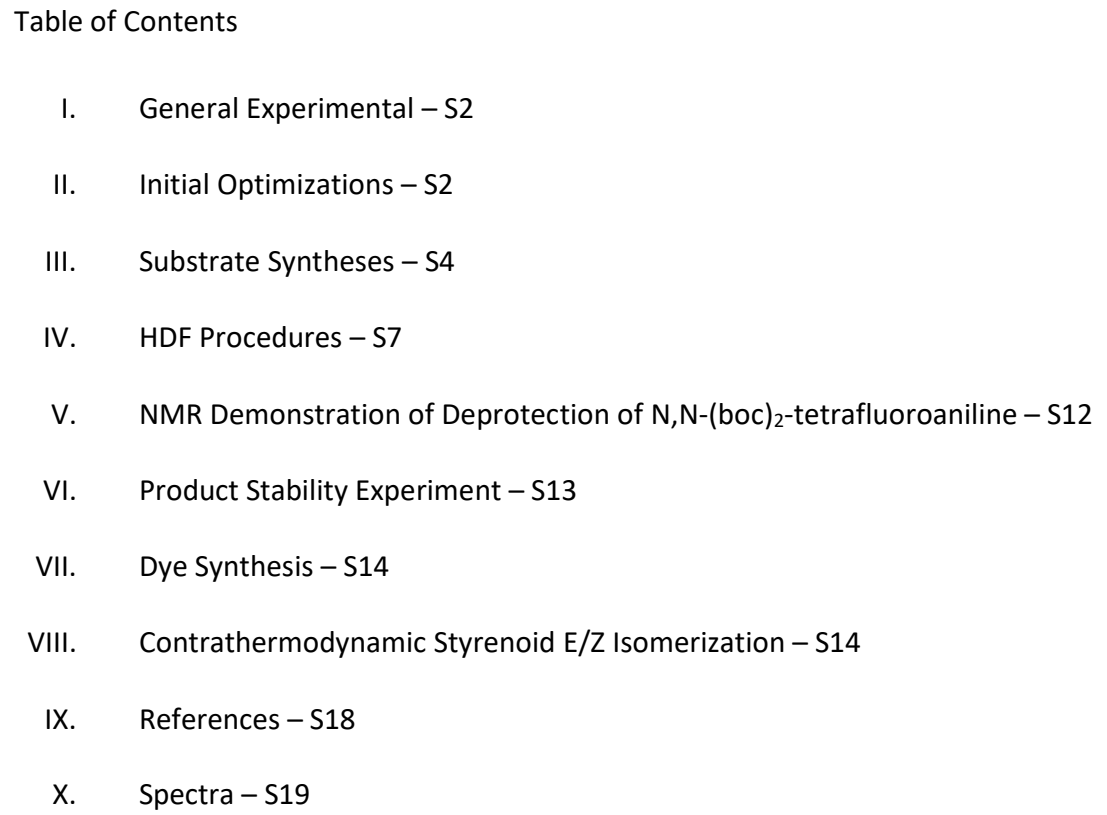


General Experimental : - All reagents were obtained from commercial suppliers (Aldrich, VWR, TCl chemicals, Oakwood chemicals, Alfa Aesar) and used without further purification unless otherwise noted. Reactions were monitored by thin layer chromatography (TLC), obtained from sorbent technology Silica XHL TLC Plates, w/UV254, glass backed, $250 \mu \mathrm{m}, 20 \times 20 \mathrm{~cm}$ visualized with ultraviolet light, and GC-MS (QP 2010S, Shimadzu equipped with auto sampler), also by aliquots subjected to ${ }^{19} \mathrm{~F}$ NMR described below. Contrathermodynamic isomerization was set up in a light bath equipped with a linear vertical array of $1 \mathrm{~W} 447 \mathrm{~nm}$ LEDs. Solvents were used as received, stored over 4 Å molecular sieves except DMSO and THF, which were first distilled from $\mathrm{CaH}_{2}$ and $\mathrm{Na}$ metal respectively and stored under argon. Flash chromatography was carried out with Merck $60 \AA$, mesh 230-400 silica gel; all compounds that were purified by flash chromatography utilized a gradient of hexanes and ethyl acetate (or DCM) unless otherwise noted. NMR spectra were obtained on $400 \mathrm{MHz}$ Bruker Avance III spectrometer or a Bruker NEO $600 \mathrm{MHz}$ spectrometer equipped with BBO BBF-H-D-05 SmartProbe. ${ }^{1 \mathrm{H}},{ }^{19} \mathrm{~F}$ and ${ }^{13} \mathrm{C}$ NMR chemical shifts are reported in ppm relative to the residual proteo solvent peak (with ${ }^{19} \mathrm{~F}$ spectra referencing the residual solvent indirectly using the tabulated IUPAC standard ratio, $\equiv$, derived from $\left.\mathrm{CFCl}_{3}\right) .{ }^{1}$ Fluorescence spectroscopy was performed with a Cary Eclipse Fluorescence Spectrophotometer and UV-vis absorbance spectroscopy was performed with a Shimadzu UV2600 UV-vis spectrophotometer. HRMS was obtained with a Thermo Scientific Orbitrap Fusion Tribrid Mass Spectrometer, utilizing the quadrupole mass analyzer.

\section{Initial Optimizations}

\section{Scheme 1. Solvent Optimization}

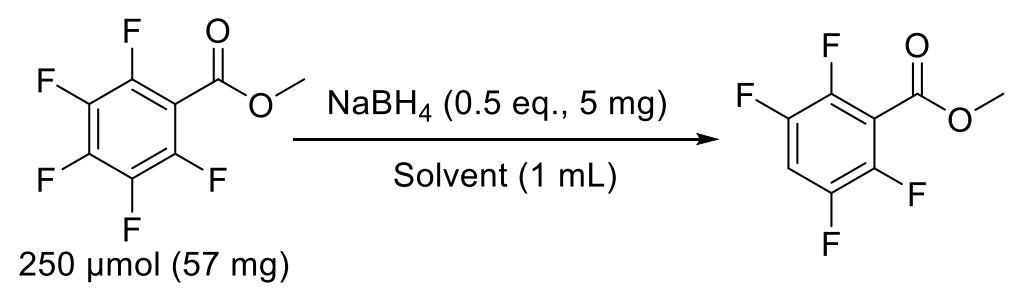

$6 \mathrm{NMR}$ tubes were each charged with a benzene $\mathrm{d}^{6}$ capillary, $125 \mu \mathrm{mol}(5 \mathrm{mg})$ of $\mathrm{NaBH}_{4}$, and $1 \mathrm{~mL}$ of methanol, ethanol, 1,2-dimethoxyethane, tetrahydrofuran, dimethylsulfoxide, or dimethylformamide respectively. Each tube was agitated under sonication until it became a homogeneous solution of $\mathrm{NaBH}_{4}$; however, tetrahydrofuran and 1,2dimethoxyethane did not completely dissolve and remained suspensions. To each tube was then carefully added $250 \mu \mathrm{mol}(57 \mathrm{mg}$ ) of methyl pentafluorobenzoate (MPFB), which caused some effervescence in the samples with methanol and to a lesser degree, ethanol. The tubes were left sitting at room temperature for 10 hours before the addition to each of fluorobenzene $(10 \mu \mathrm{L}, 106 \mu \mathrm{mol})$ as an internal standard for subsequent ${ }^{19} \mathrm{FNMR}$ spectra to quantify residual MPFB for NMR conversion and to quantify the product methyl 2,3,5,6-tetrafluorobenzoate for NMR yield. 
Table 1. Solvent Optimization

$\begin{array}{cccccc}\text { entry } & \text { Equiv. } \mathrm{NaBH}_{4} & \text { Solvent } & \text { Time (hours) } & \text { \% NMR Yield } & \text { \% Conversion MPFB } \\ 1 & 0.50 & \text { MeOH } & 10 & 0 & \sim 100 \\ 2 & 0.50 & \text { EtOH } & 10 & 6 & 72 \\ 3 & 0.50 & \text { THF } & 10 & <2 & <2 \\ 4 & 0.50 & \text { DME } & 10 & 46 & 46 \\ 5 & 0.50 & \text { DMSO } & 10 & 97 & 98 \\ 6 & 0.50 & \text { DMF } & 10 & 70 & 72\end{array}$

Scheme 2. $\mathrm{NaBH}_{4}$ loading variation

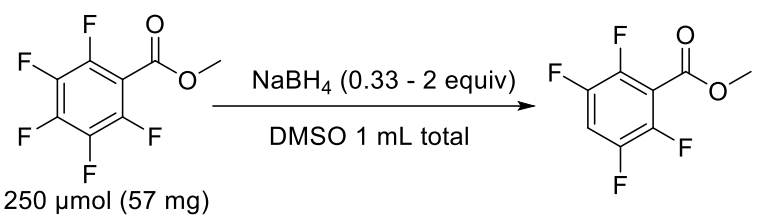

4 NMR tubes were each charged with a benzene- $d^{6}$ filled capillary and $57 \mathrm{mg}(250 \mu \mathrm{mol})$ MPFB. A $0.5 \mathrm{M}$ stock solution of $\mathrm{NaBH}_{4}$ in dimethylsulfoxide was prepared by dissolving $1 \mathrm{mmol}(38 \mathrm{mg}) \mathrm{NaBH}_{4}$ in $2 \mathrm{~mL}$ dimethylsulfoxide. This stock solution along with pure dimethylsulfoxide was dispensed into the 4 NMR tubes according to table 2 (below) such that each tube contained a total of $1 \mathrm{~mL}$ of solution. The tubes were allowed to sit at room temperature for 2 hours before being charged with $10 \mu \mathrm{L}(106 \mu \mathrm{mol})$ fluorobenzene internal standard and having their ${ }^{19} \mathrm{FNMR}$ spectra collected for methyl 2,3,5,6-tetrafluorobenzoate quantitation (\% NMR yield).

Table 2. $\mathrm{NaBH}_{4}$ Loading Variation

\begin{tabular}{ccccc}
\hline entry & Volume $0.5 \mathrm{M}$ stock solution of $\mathrm{NaBH}_{4}$ & Volume DMSO & Eq. $\mathrm{NaBH}_{4}$ & \% NMR Yield \\
1 & $165 \mu \mathrm{L}$ & $835 \mu \mathrm{L}$ & 0.33 & 23 \\
2 & $330 \mu \mathrm{L}$ & $660 \mu \mathrm{L}$ & 0.66 & 43 \\
3 & $500 \mu \mathrm{L}$ & $500 \mu \mathrm{L}$ & 1.00 & 99 \\
4 & $1000 \mu \mathrm{L}$ & $0 \mu \mathrm{L}$ & 2.00 & 99
\end{tabular}


<smiles>CC(C)(C)OC(=O)c1c(F)c(F)c(F)c(F)c1F</smiles><smiles>Fc1c(F)c(Br)c(F)c(/C=C/c2ccccc2)c1F</smiles><smiles>NC(=O)c1c(F)c(F)c(F)c(F)c1F</smiles><smiles>O=S(=O)(O)c1c(F)c(F)c(F)c(C#Cc2ccccc2)c1F</smiles><smiles>[Y16]C(=O)c1c(F)c(F)c(F)c(F)c1C(=O)NCc1ccc(F)cc1</smiles><smiles>Fc1c(F)c(F)c(C2OCCO2)c(F)c1F</smiles><smiles>O=[N+]([O-])c1c(F)c(O)c(F)c(F)c1F</smiles><smiles></smiles><smiles>O=[W]c1c(F)c(Cl)c(F)c(F)c1[N+](=O)[O-]</smiles>

Figure 1. Substrates above were prepared for HDF.

Synthesis of tert-butyl pentafluorobenzoate $2 a$<smiles>O=C(O)c1c(F)c(F)c(F)c(F)c1Br</smiles>

Into a $100 \mathrm{~mL}$ round-bottom flask equipped with a magnetic stir bar was loaded pentafluorobenzoic acid ( $2 \mathrm{~g}, 9.4 \mathrm{mmol})$, di-tert-butyl dicarbonate $(4.1 \mathrm{~g}, 18.9 \mathrm{mmol})$, 4-(dimethylamino)pyridine $(116 \mathrm{mg}, 0.95 \mathrm{mmol})$, and $30 \mathrm{~mL}$ of tert-butanol. The flask was heated to $40{ }^{\circ} \mathrm{C}$ for 20 hours with stirring before being quenched with $1 \mathrm{M} \mathrm{HCl}(20 \mathrm{~mL})$ followed by subsequent extraction with EtoAc ( $3 \times 20 \mathrm{~mL}$ ). The combined organic layers were washed with saturated sodium carbonate solution and then brine, dried over $\mathrm{MgSO}_{4}$, and concentrated under reduced pressure. The residue was purified by silica gel chromatography using $2 \%$ EtoAC in Hexanes as eluent to afford the desired product ( $1.9 \mathrm{~g}, 76 \%$ yield). The ${ }^{1} \mathrm{H} \mathrm{NMR},{ }^{19} \mathrm{~F}$ NMR and mass spectra match the literature. ${ }^{2}$

\section{Synthesis of pentafluorobenzamide $3 a$}

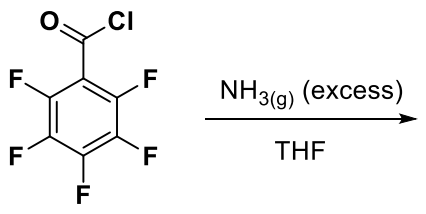<smiles>NC(=O)c1c(F)c(F)c(F)c(F)c1F</smiles>

\section{3a}

Into a dry $125 \mathrm{~mL}$ Erlenmeyer flask is added pentafluorobenzoyl chloride (647 mg, $2.8 \mathrm{mmol}$ ) in $30 \mathrm{~mL}$ THF. Using a glass diffuser connected by rubber tubing to a separate vessel of ammonium chloride and $\mathrm{NaOH}$ pellets, a large excess of ammonia gas is bubbled through the THF solution over 2 minutes, or until the exotherm subsides (determined by touching the outside of the flask). The THF solution containing the product is then eluted through a silica plug, thoroughly rinsing the precipitated ammonium chloride with more THF $(2 \times 20 \mathrm{~mL})$. The THF filtrate was concentrated under reduced pressure, and the resulting white solid ( $434 \mathrm{mg}, 73 \%$ yield) was used without further purification. The mass spectrum was found to match the literature. ${ }^{3} 19 \mathrm{~F} \mathrm{NMR}\left(376 \mathrm{MHz}, \mathrm{CDCl}_{3}\right) \delta-139.63--139.73(\mathrm{~m}, 2 \mathrm{~F}),-149.54(\mathrm{tt}, \mathrm{J}=20.1,3.5 \mathrm{~Hz}, 1 \mathrm{~F})$, $159.7--159.84(\mathrm{~m}, 2 \mathrm{~F}) . \quad 1 \mathrm{H} \operatorname{NMR}\left(400 \mathrm{MHz}, \mathrm{CDCl}_{3}\right) \delta 6.37-6.05$ (brs, $\left.1 \mathrm{H}\right), 6.18-5.84$ (brs, $\left.1 \mathrm{H}\right)$. 
Synthesis of N-(4-fluorobenzyl)pentafluorobenzamide $4 a$<smiles>CCN(CC)CCO</smiles>

To an ice-cooled solution of parafluorobenzylamine $(0.35 \mathrm{~mL}, 3.05 \mathrm{mmol})$ in $\mathrm{CH}_{2} \mathrm{Cl}_{2}(10 \mathrm{~mL})$ is added dropwise a solution of pentafluorobenzoyl chloride $(640 \mathrm{mg}, 2.77 \mathrm{mmol})$ in $\mathrm{CH}_{2} \mathrm{Cl}_{2}(2 \mathrm{~mL})$ followed by triethylamine $(1.2 \mathrm{~mL}, 8.31 \mathrm{mmol})$. The ice bath was removed after 30 minutes and the reaction was allowed to continue for 2 hours before being quenched with cold water and diluted with $\mathrm{CH}_{2} \mathrm{Cl}_{2}(60 \mathrm{~mL})$. The organic layer was washed with water and subsequently brine, dried over $\mathrm{MgSO}_{4}$. Removal of solvent and purification by silica gel flash chromatography (Hexane : EtOAc ramp) afforded 4a as pale orange-white needles $\left(726 \mathrm{mg}, 82 \%\right.$ yield). The $\mathrm{mp} 156-157^{\circ} \mathrm{C} ; 19 \mathrm{~F} \mathrm{NMR}\left(376 \mathrm{MHz}, \mathrm{C}_{6} \mathrm{D}_{6}\right) \delta-114.13(\mathrm{tt}, \mathrm{J}=8.6,5.2 \mathrm{~Hz}, 1 \mathrm{~F})$, $-140.27--140.41(\mathrm{~m}, 2 \mathrm{~F}),-150.26(\mathrm{tt}, \mathrm{J}=20.8,3.2 \mathrm{~Hz}, 1 \mathrm{~F}),-159.73--159.84(\mathrm{~m}, 2 \mathrm{~F})$. $1 \mathrm{H} \mathrm{NMR}\left(400 \mathrm{MHz}^{\mathrm{C}} \mathrm{CDCl}_{3}\right) \delta 7.35-$ $7.28(\mathrm{~m}, 2 \mathrm{H}), 7.09-7.02(\mathrm{~m}, 2 \mathrm{H}), 6.34-6.09(\mathrm{brs}, 1 \mathrm{H}), 4.62(\mathrm{~d}, \mathrm{~J}=5.7 \mathrm{~Hz}, 2 \mathrm{H}) .{ }^{13} \mathrm{C} \mathrm{NMR}\left(151 \mathrm{MHz}\right.$, Acetone- $\left.d_{6}\right) \delta 163.8$, 162.2, 157.9, 144.8 (dddt, $J=249.0,12.6,8.5,4.1 \mathrm{~Hz}$ ), 142.7 (dtt, $J=253.2,12.9,4.9 \mathrm{~Hz}$ ), 138.4 (dddd, $J=250.3,17.2,12.4$, $4.8 \mathrm{~Hz}$ ), 135.4 (d, $J=3.2 \mathrm{~Hz}), 130.4$ (d, $J=8.1 \mathrm{~Hz}$ ), 116.07 (d, $J=21.6 \mathrm{~Hz}$ ), 43.6. Calculated HRMS(ESI) for (C14H7F6NO $(\mathrm{M}+\mathrm{H})+$ is 320.0510 observed 320.0512 .

Synthesis of N,N-di-n-butylpentafluorobenzamide $5 a$

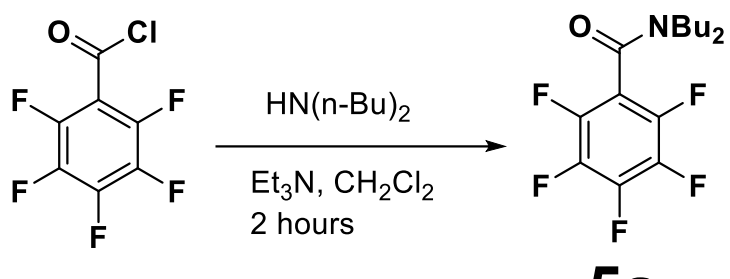

\section{$5 a$}

Into a stirring ice-cooled solution of $N, N$-di-n-butylamine $(0.51 \mathrm{~mL}, 3.05 \mathrm{mmol})$ in DCM (10 mL) is added dropwise a solution of pentafluorobenzoyl chloride $(640 \mathrm{mg} 2.77 \mathrm{mmol})$ in DCM $(1 \mathrm{~mL})$ and then triethylamine $(1.2 \mathrm{~mL}, 8.31 \mathrm{mmol})$. The cooling bath was removed after 30 minutes and the stirring continued for 2 hours before quenching with cold water. The quenched reaction was diluted with $\mathrm{DCM}(60 \mathrm{~mL})$ and washed with water $(20 \mathrm{~mL})$ and then brine $(20 \mathrm{~mL})$. The combined organic layers were dried over $\mathrm{MgSO}_{4}$ and concentrated in vacuo prior to silica gel column purification using EtOAc : hexane ramp to afford the desired product ( $843 \mathrm{mg}, 94 \%$ yield). 19F NMR (376 MHz, Chloroform-d) $\delta-140.94--141.10$ (m, 2F), -152.64 $--152.85(\mathrm{~m}, 1 \mathrm{~F}),-159.94--160.17(\mathrm{~m}, 2 \mathrm{~F})$. 1H NMR (400 MHz, Chloroform-d) $3.56-3.48(\mathrm{~m}, 2 \mathrm{H}), 3.16-3.10(\mathrm{~m}, 2 \mathrm{H})$, $1.69-1.58(\mathrm{~m}, 2 \mathrm{H}), 1.53-1.44(\mathrm{~m}, 2 \mathrm{H}), 1.38(\mathrm{sext}, \mathrm{J}=7.3,2 \mathrm{H}), 1.19(\mathrm{sext}, \mathrm{J}=7.3,2 \mathrm{H}), 0.96(\mathrm{t}, \mathrm{J}=7.3,3 \mathrm{H}), 0.83(\mathrm{t}, \mathrm{J}=7.3$, 3H). ${ }^{13} \mathrm{C}$ NMR (101 MHz, Chloroform -d) $\delta$ 158.3, 142.8 (dddt, J = 249.4, 12.4, 8.4, 4.0 Hz), 141.7 (dtt, J = 256.3, 13.3, 4.7), $137.8(\mathrm{~d}, \mathrm{~J}=253.3 \mathrm{~Hz}$ ), $112.3(\mathrm{t}, \mathrm{J}=22.1 \mathrm{~Hz}), 48.6,45.0,30.6,29.4,20.2,19.8,13.9,13.7 . \mathrm{GC} / \mathrm{MS}$ (m/z, relative intensity) 323 (M+, 10), 304 (4), 294 (5), 280 (13), 195 (100). Calculated HRMS(ESI) for (C15H18F5NO (M+H) + is 324.1387 observed 324.1379 
Synthesis of di-BOC-pentafluorobenzamide $10 a$

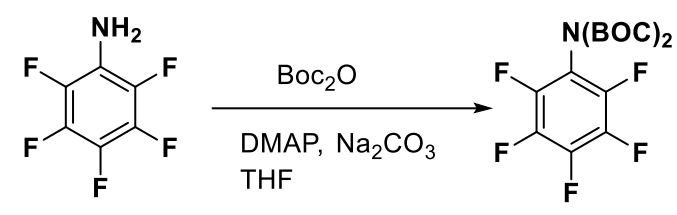

\section{$10 a$}

The procedure reported by Bissember et al. ${ }^{4}$ was followed scaled to $500 \mathrm{mg}$ of pentafluoroaniline, ultimately affording a $48 \%$ yield of 10 a as a colorless solid.

Synthesis of E-styrylpentafluorobenzene $8 a$

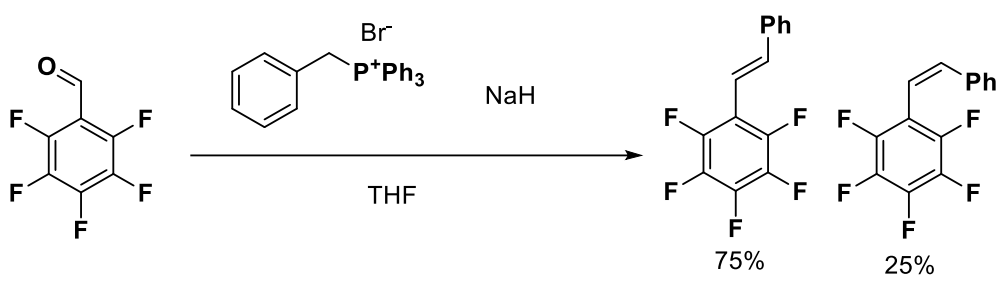

$8 \mathbf{a}$

To a stirring suspension of sodium hydride (111 $\mathrm{mg}$ of $60 \%$ paraffin dispersion, $2.77 \mathrm{mmol}$ ) in $5 \mathrm{~mL} \mathrm{THF}$ at $0{ }^{\circ} \mathrm{C}$ is added benzyltriphenylphosphonium bromide $(1 \mathrm{~g}, 2.315 \mathrm{mmol})$ in THF $(5 \mathrm{~mL})$. The solution was allowed to gradually warm to room temperature and then stir for 2 hours. To the solution is then added pentafluorobenzaldehyde $(0.285 \mathrm{~mL}, 2.315$ $\mathrm{mmol}$ ) which is then allowed to continue stirring overnight prior to a quench with minimal ice water. The solution was concentrated in vacuo and the residue diluted with EtOAc before being washed sequentially with water and then brine. The organic layer was dried over $\mathrm{MgSO}_{4}$ and concentrated in vacuo. The residue is subjected to silica gel column chromatography with $100 \%$ hexane to afford the desired product as a 3:1 mixture of $\mathrm{E}$ - and Z-isomers (930 mg, $74 \%$ yield). ${ }^{1} \mathrm{H} N M R,{ }^{19} \mathrm{~F} N \mathrm{NR}$, and mass spectra match the literature. ${ }^{5}$

\section{Synthesis of pentafluoro(phenylethynyl)benzene $9 a$}

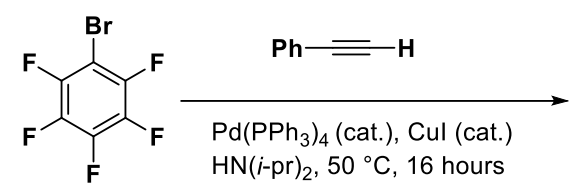<smiles>Fc1c(F)c(F)c(C#Cc2ccccc2)c(F)c1F</smiles>

\section{$9 a$}

To a deaerated, stirring solution of bromopentafluorobenzene $(0.88 \mathrm{~mL}, 6.82 \mathrm{mmol})$ and phenylacetylene $(465 \mathrm{mg}, 4.55$ $\mathrm{mmol})$ in diisopropylamine $(20 \mathrm{~mL})$ is added Cul $(43 \mathrm{mg}, 227 \mu \mathrm{mol})$ and $\mathrm{Pd}(\mathrm{PPh})_{3}(262 \mathrm{mg}, 227 \mu \mathrm{mol})$. The mixture is heated to $50{ }^{\circ} \mathrm{C}$ and left overnight under an argon atmosphere. The mixture was then cooled to room temperature and diluted with diethyl ether before filtering through celite and concentrating in vacuo. The residue was subjected to silica column chromatography in pure hexane to afford the desired product (400 mg, 33\% yield). Melting point, ${ }^{1} \mathrm{H}$ NMR and ${ }^{19} \mathrm{~F}$ NMR match the literature. ${ }^{6} \mathrm{GC} / \mathrm{MS}$ (m/z, relative intensity) $268(\mathrm{M}+, 5), 253(5), 252(40), 224(5), 210(100)$. 
Synthesis of 2-(perfluorophenyl)-1,3-dioxolane 11a

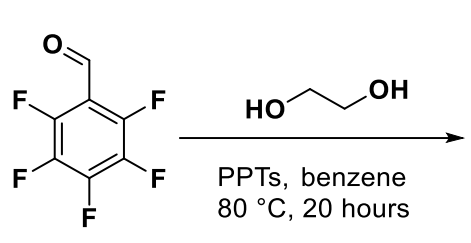<smiles>Fc1c(F)c(F)c(F)c(F)c1F</smiles>

The procedure reported by Kambe et al. ${ }^{7}$ was followed and scaled to $500 \mathrm{mg}$ ( $2.55 \mathrm{mmol}$ ) of pentafluorobenzaldehyde, affording an $83 \%$ yield of desired product. 19F NMR (376 MHz, CDCl $\left.{ }_{3}\right) \delta-143.80--144.06(\mathrm{~m}, 2 \mathrm{~F}),-152.56--152.88(\mathrm{t}, \mathrm{J}$ $=20.9 \mathrm{~Hz}, 1 \mathrm{~F}),-161.92--162.27(\mathrm{~m}, 2 \mathrm{~F}) .1 \mathrm{H} \mathrm{NMR}\left(400 \mathrm{MHz}, \mathrm{CDCl}_{3}\right) \delta 6.21-6.18(\mathrm{~s}, 1 \mathrm{H}), 4.25-4.15(\mathrm{~m}, 2 \mathrm{H}), 4.09-3.99$ $(\mathrm{m}, 2 \mathrm{H})$.

Synthesis of 2-methyl-2-(perfluorophenyl)-1,3-dioxolane 12a

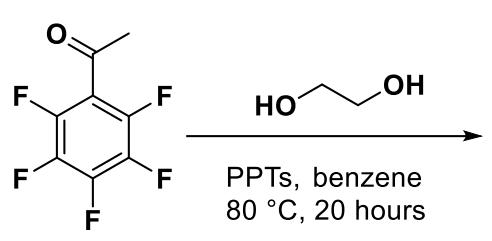<smiles>CC1(c2c(F)c(F)c(F)c(F)c2F)OCCO1</smiles>

The procedure reported by Kambe et al. ${ }^{7}$ was followed and scaled to $500 \mathrm{mg}(2.38 \mathrm{mmol})$ of pentafluoroacetophenone. An additional step was required at the end. Namely, the product residue was dissolved in $0{ }^{\circ} \mathrm{C} \mathrm{EtOH}(6 \mathrm{~mL}) \mathrm{with} \mathrm{NaBH}_{4}(45$ $\mathrm{mg}, 1.19 \mathrm{mmol}$ ), and allowed to stir for 2 hours to convert residual pentafluoroacetophenone to a more easily separated alcohol. The solution was quenched with cold water, extracted with EtOAc, the organic layer washed with brine, dried over $\mathrm{MgSO}_{4}$, and concentrated in vacuo. Silica column chromatography using a ramp of EtOAc: hexane afforded the desired product (375 mg, 62\% yield) as a colorless liquid. ${ }^{19} \mathrm{~F}$ NMR (376 MHz, Chloroform-d) $\delta-142.10--142.29$ (m, $2 \mathrm{~F}$ ), -155.02 $(\mathrm{tt}, \mathrm{J}=21.4,3.0,1 \mathrm{~F}),-161.90--162.08(\mathrm{~m}, 2 \mathrm{~F}) .{ }^{1} \mathrm{H}$ NMR (400 MHz, Chloroform-d) $\delta 64.18-4.15(\mathrm{~m}, 2 \mathrm{H}), 3.95-3.83(\mathrm{~m}$, $2 \mathrm{H}), 1.83-1.77(\mathrm{~s}, 3 \mathrm{H}) .{ }^{13} \mathrm{C}$ NMR $(101 \mathrm{MHz}$, Chloroform-d) $\delta 144.6$ (dddd, J = 252.0, 11.8, 7.9, 4.0 Hz), 140.8 (dtt, J = 254.6, 13.5, 5.2 Hz), $137.9\left(\mathrm{~m}, \mathrm{~J}_{\mathrm{C}-\mathrm{F}}=252.5 \mathrm{~Hz}\right), 116.7$ (tdt, J = 13.9, 4.6, $\left.2.9 \mathrm{~Hz}\right), 107.5,65.0,26.7$ (t, J = 1.9 Hz)

\section{Synthesis of p-chloro-tetrafluoronitrobenzene $20 a$}<smiles>O=[N+]([O-])c1c(F)c(F)c(F)c(F)c1F</smiles>

The procedure described by Weaver et al. was followed. ${ }^{8}$ Pentafluoronitrobenzene $(426 \mathrm{mg}, 2 \mathrm{mmol})$, benzyltributylammonium chloride $(250 \mathrm{mg}, 0.8 \mathrm{mmol}), \mathrm{TMSCl}(261 \mathrm{mg}, 2.4 \mathrm{mmol})$, and $3 \mathrm{~mL}$ THF are added to a microwave vial charged with a magnetic stir bar and sealed. The reaction was heated in an oil bath at $80{ }^{\circ} \mathrm{C}$ overnight before concentration in vacuo and subjection to silica column chromatography with hexane to afford the desired product $20 \mathrm{a}$ (365 mg, 80\%) yield.

\section{General Procedure A for HDF of Perfluoroarenes}

To stirring a solution of fluoroarene in dimethylsulfoxide $(0.2 \mathrm{M})$ was slowly added $\mathrm{NaBH}_{4}$ dissolved in equal volume of DMSO. CAUTION: some of the reactions effervesce hydrogen gas, especially when the solvent is not dry! Care should be taken to use dry DMSO and ensure that the gas can safely escape the reaction vessel! The reactions were monitored by removing aliquots and subjecting them to ${ }^{19} \mathrm{FNMR}$. When complete, the mixtures were diluted with ethyl acetate (10-fold) and carefully quenched with aqueous brine solution over 10 minutes. The organic layers were washed five times with brine to remove the $\mathrm{DMSO}$, dried over $\mathrm{MgSO}_{4}$, then concentrated in vacuo to afford the desired products without any further purification. If NMR yields were to be obtained (for products too volatile for concentration in vacuo), 20 microliters ( 213 $\mu \mathrm{mol})$ fluorobenzene internal standard would be added to aliquots of crude reaction mixture in lieu of dilution with ethyl acetate and workup. This procedure was used on $0.1-22.1 \mathrm{mmol}$ scale, including $1.0 \mathrm{mmol}$. See $18 \mathrm{~b}$ and $19 \mathrm{~b}$ for details. 
<smiles>COC(=O)c1c(F)c(F)c([14CH3])c(F)c1F</smiles><smiles>CCCCOC(=O)c1c(F)c(F)cc(F)c1F</smiles>

$2 \mathbf{b}$<smiles>NC(=O)c1c(F)c(F)cc(F)c1F</smiles>

$3 \mathbf{b}$

methyl 2,3,5,6-tetrafluorobenzoate $1 \mathrm{~b}$

General Procedure A was followed using methyl pentafluorobenzoate ( $90 \mathrm{mg}, 400 \mu \mathrm{mol})$ and 1 equiv $\mathrm{NaBH}_{4}$ (16 mg, 400 micromol) in $2 \mathrm{~mL}$ DMSO. The desired product $\mathbf{1 b}$ was obtained as a colorless oil $(72 \mathrm{mg}, 87 \%$ yield). A known compound, characteristic NMR spectra match the literature. ${ }^{8}{ }^{19} \mathrm{~F} \mathrm{NMR}(376 \mathrm{MHz}$, Chloroform-d) $\delta-137.45--137.60(\mathrm{~m}, 2 \mathrm{~F}),-139.48--139.63(\mathrm{~m}, 2 \mathrm{~F}) .{ }^{1} \mathrm{H}$ NMR (400 MHz, Chloroform-d) $\delta$ $7.20(\mathrm{tt}, \mathrm{J}=9.4,7.2 \mathrm{~Hz}, 1 \mathrm{H}), 4.00-3.97(\mathrm{~s}, 3 \mathrm{H})$

\section{tert-butyl 2,3,5,6-tetrafluorobenzoate $2 b$}

General Procedure A was followed using tert-butyl pentafluorobenzoate ( $54 \mathrm{mg}, 200 \mu \mathrm{mol}$ ) and $\mathrm{NaBH}_{4}(8$ $\mathrm{mg}, 200 \mu \mathrm{mol})$ in $2 \mathrm{~mL}$ DMSO. The desired product $\mathbf{2 b}$ was obtained as a colorless oil ( $42 \mathrm{mg}, 85 \%$ yield). A known compound, characteristic NMR spectra match the literature. ${ }^{8}{ }^{19} \mathrm{~F}$ NMR (376 MHz, Chloroform-d) $\delta$ $137.82--138.03(\mathrm{~m}, 2 \mathrm{~F}),-141.07--141.23(\mathrm{~m}, 2 \mathrm{~F}) .{ }^{1} \mathrm{H}$ NMR (400 MHz, Chloroform-d) $\delta 7.13$ (tt, J = 9.5, 7.2 $\mathrm{Hz}, 1 \mathrm{H}), 1.61-1.58(\mathrm{~s}, 9 \mathrm{H})$.

\section{2,3,5,6-tetrafluorobenzamide $3 b$}

General Procedure A was followed using pentafluorobenzamide (40 mg, $190 \mu \mathrm{mol}$ ) and $\mathrm{NaBH}_{4}(5 \mathrm{mg}, 190$ $\mu \mathrm{mol}$ ) in $1 \mathrm{~mL}$ DMSO. The desired product $\mathbf{3 b}$ was obtained as a white powder ( $30 \mathrm{mg}, 88 \%$ yield). A known compound, ${ }^{19} \mathrm{~F}$ NMR spectrum and melting point are in accord with the literature. ${ }^{9}{ }^{19} \mathrm{~F} \mathrm{NMR}(564 \mathrm{MHz}$, DMSO-d $\left.d_{6}\right) \delta-138.51--138.78(\mathrm{~m}),-142.97--143.12(\mathrm{~m}) .{ }^{1} \mathrm{H}$ NMR $\left(599 \mathrm{MHz}, \mathrm{DMSO}-d_{6}\right) \delta 8.32(\mathrm{~s}, 1 \mathrm{H})$, $8.14(\mathrm{~s}, 1 \mathrm{H}), 7.96(\mathrm{tt}, J=10.4,7.5 \mathrm{~Hz}, 1 \mathrm{H}) .{ }^{13} \mathrm{C} \mathrm{NMR}\left(151 \mathrm{MHz}, \mathrm{DMSO}-d_{6}\right) \delta 159.2(\mathrm{t}, J=1.8 \mathrm{~Hz}), 145.2$ (dddd, $J=246.6,14.2,10.3,3.7 \mathrm{~Hz}$ ), 142.3 (dddd, $J=247.2,15.1,6.5,3.9 \mathrm{~Hz}), 118.3(\mathrm{t}, J=21.5 \mathrm{~Hz}$ ),

107.4 (t, $J=23.4$ Hz). GC/MS (m/z, relative intensity) 193 (M+, 95), 177 (100), 150 (36), 149 (89), 99 (80).<smiles>O=C(NCc1ccc(F)cc1)c1c(F)c(F)cc(F)c1F</smiles>

\section{2,3,5,6-tetrafluoro-N-(4-fluorobenzyl)benzamide $4 b$}

General Procedure A was followed using pentafluoro-N-(4-fluorobenzyl)benzamide (64 mg, 200 $\mu \mathrm{mol})$ and $\mathrm{NaBH}_{4}(8 \mathrm{mg}, 200 \mu \mathrm{mol})$ in $2 \mathrm{~mL}$ DMSO. The desired product $\mathbf{4 b}$ was obtained as a white, crystalline solid (60 mg, 99\% yield). The mp 135-136 ${ }^{\circ} \mathrm{C}{ }^{19} \mathrm{~F}$ NMR (376 MHz, Chloroform-d) $\delta-114.20$ - -114.31 (m, 1F), -136.86--137.09 (m, 2F), -141.10--141.31 (m, 2F). ${ }^{1} \mathrm{H}$ NMR (400 MHz, Chloroformd) $\delta 7.27-7.21(\mathrm{~m}, 2 \mathrm{H}), 7.06(\mathrm{tt}, \mathrm{J}=9.4,7.3 \mathrm{~Hz}, 1 \mathrm{H}), 7.01-6.93(\mathrm{~m}, 2 \mathrm{H}), 6.38-6.20(\mathrm{brs}, 1 \mathrm{H}), 4.56-$ $4.51(\mathrm{~d}, \mathrm{~J}=5.75 \mathrm{~Hz}, 2 \mathrm{H})$.

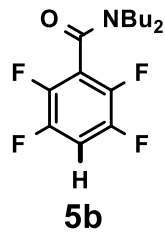

\section{$\mathrm{N}, \mathrm{N}$-dibutyl-2,3,5,6-tetrafluorobenzamide $5 \mathrm{~b}$}

General Procedure A was followed using N,N-dibutyl-pentafluorobenzamide 5a (32 mg, $100 \mu \mathrm{mol}$ ) and $\mathrm{NaBH}_{4}(8 \mathrm{mg}, 200 \mu \mathrm{mol})$ in $1 \mathrm{~mL}$ DMSO. The desired product $\mathbf{5 b}$ was obtained as a colorless oil $(29 \mathrm{mg}, 85 \%$ yield). ${ }^{19} \mathrm{~F}$ NMR (376 MHz, Chloroform-d) $\delta-137.18--137.48(\mathrm{~m}, 2 \mathrm{~F}),-141.60--141.88(\mathrm{~m}, 2 \mathrm{~F}) .{ }^{1} \mathrm{H}$ NMR (400 $\mathrm{MHz}$, Chloroform-d) $\delta 7.09(\mathrm{tt}, \mathrm{J}=9.5,7.2 \mathrm{~Hz}, 1 \mathrm{H}), 3.56-3.50(\mathrm{~m}, 2 \mathrm{H}), 3.16-3.10(\mathrm{~m}, 2 \mathrm{H}), 1.69-1.60(\mathrm{~m}$, $2 \mathrm{H}$ ), $1.53-1.44(\mathrm{~m}, 2 \mathrm{H}), 1.39$ (sext, J = 7.3 Hz, 2H), 1.18 (sext, J = 7.3 Hz, 2H), 0.97 (t, J = 7.3 Hz, 3H), $0.81(\mathrm{t}$, $\mathrm{J}=7.3 \mathrm{~Hz}, 3 \mathrm{H}$ ) GC/MS (m/z, relative intensity) 305 (M+, 9), 287 (5), 276 (6), 262 (15), 177 (100).

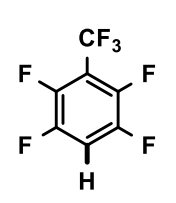

$6 \mathbf{b}$

\section{1,2,4,5-tetrafluoro-3-(trifluoromethyl)benzene $6 \mathrm{~b}$}

General Procedure A was followed using octafluorotoluene (100 mg, $466 \mu \mathrm{mol})$ and $\mathrm{NaBH}_{4}(16 \mathrm{mg}, 470 \mu \mathrm{mol})$ in $5 \mathrm{~mL}$ DMSO. When the reaction was complete, $500 \mu \mathrm{L}$ of reaction mixture ( $10 \%$ of the total volume) was taken into an NMR tube charged with a benzene- $d^{6}$ capillary and fluorobenzene $(20 \mu \mathrm{L}, 213 \mu \mathrm{mol})$ as internal standard. The aliquot was calculated to contain $44 \mu \mathrm{mol}$ of $6 \mathrm{~b}$ corresponding to a $93 \%$ yield. Mass spectrum was found consistent with literature. ${ }^{8}{ }^{19} \mathrm{~F} \mathrm{NMR} \mathrm{(376} \mathrm{MHz,} \mathrm{DMSO)} \delta-55.15--55.30$ (td, J = 21.6, 3.1 Hz, 3F), $136.29--136.47(\mathrm{~m}, 2 \mathrm{~F}),-141.12--141.49(\mathrm{~m}, 2 \mathrm{~F}) .{ }^{1} \mathrm{H}$ NMR (400 MHz, DMSO) $\delta 8.37-8.24(\mathrm{~m}, 1 \mathrm{H})$.

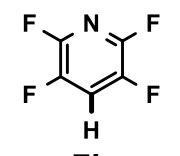

\section{2,3,5,6-tetrafluoropyridine $7 b$}

General Procedure A was followed using pentafluoropyridine (100 mg, $592 \mu \mathrm{mol})$ and $\mathrm{NaBH}_{4}(23 \mathrm{mg}, 600$ $\mu \mathrm{mol}$ ) in $5 \mathrm{~mL}$ DMSO. When the reaction was complete, $500 \mu \mathrm{L}$ of reaction mixture ( $10 \%$ of the total volume) was taken into an NMR tube charged with a benzene- $\mathrm{d}^{6}$ capillary and fluorobenzene $(20 \mu \mathrm{L}, 213 \mu \mathrm{mol})$ as internal standard. The aliquot was calculated to contain $54 \mu \mathrm{mol}$ of $7 \mathbf{b}$ corresponding to an $89 \%$ yield. Mass spectrum was found consistent with the literature. ${ }^{8}{ }^{19} \mathrm{~F} \mathrm{NMR}(376 \mathrm{MHz}$, Chloroform-d) $\delta-87.95--88.26$ (m,

2F), $-135.36-135.60$ (m, 2F). ${ }^{1} \mathrm{H}$ NMR (400 MHz, Chloroform-d) $\delta 8.67-8.55(\mathrm{~m}, 1 \mathrm{H})$. 


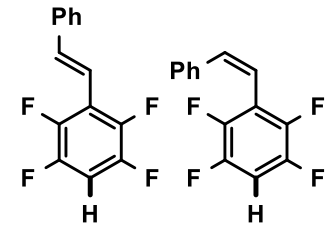

8b $(3: 1 E: Z)$

\section{1,2,4,5-tetrafluoro-3-styrylbenzene $8 \mathrm{~b}$}

To a stirring solution of $8 \mathrm{a}$ ( $50 \mathrm{mg}, 185 \mu \mathrm{mol}, 3: 1 \mathrm{E}: \mathrm{Z}$ isomeric mix) in THF (500 $\mu \mathrm{L}$ ) is added $\mathrm{NaBH}_{4}(7 \mathrm{mg}, 185 \mu \mathrm{mol})$ in DMSO $(500 \mu \mathrm{L})$. The reaction mixture is left to stir 24 hours before it is quenched by dilution with EtOAc $(5 \mathrm{~mL})$ and 5 consecutive washes with saturated brine solution ( $1 \mathrm{~mL}$ each). The organic layer is dried over $\mathrm{MgSO}_{4}$ and concentrated in vacuo to afford the product $\mathbf{8 b}$ as a white solid $(40 \mathrm{mg}, 86 \%$ yield). Melting point matches that found by Stephens et.al. ${ }^{10}{ }^{13} \mathrm{C}$ NMR and mass spectra were found to match the literature. ${ }^{5}{ }^{1} \mathrm{H}$ NMR (599 $\mathrm{MHz}$, Chloroform-d) $\delta \mathrm{E}: 7.58(\mathrm{~m}, 2 \mathrm{H}), 7.53(\mathrm{~d}, \mathrm{~J}=16.8 \mathrm{~Hz}, 1 \mathrm{H}), 7.43(\mathrm{~m}, 2 \mathrm{H}), 7.37(\mathrm{~m}, 1 \mathrm{H}), 7.11(\mathrm{~d}, \mathrm{~J}=16.8 \mathrm{~Hz}, 1 \mathrm{H}), 6.97(\mathrm{tt}$, $\mathrm{J}=9.5,7.5 \mathrm{~Hz}, 1 \mathrm{H}) . \mathrm{Z}: 7.43(\mathrm{~m}, 1 \mathrm{H}), 7.27(\mathrm{~m}, 2 \mathrm{H}), 7.17(\mathrm{~m}, 2 \mathrm{H}), 7.01(\mathrm{~m}, 2 \mathrm{H}), 6.35(\mathrm{~d}, \mathrm{~J}=12.1 \mathrm{~Hz}, 1 \mathrm{H})$.

\section{1,2,4,5-tetrafluoro-3-(phenylethynyl)benzene $9 b$}<smiles>Fc1ccc(F)c(C#Cc2ccccc2)c1F</smiles>

$9 b$

Aryl alkyne 9a (53 mg, $197 \mu \mathrm{mol}$ ) was added to a stirring suspension of $\mathrm{NaBH}_{4}(7 \mathrm{mg}, 200 \mu \mathrm{mol})$ in $1 \mathrm{~mL}$ of 1,2-dimethoxyethane and left to stir overnight. The reaction was worked up by dilution with ethyl acetate $(10 \mathrm{~mL})$ and quenching with brine $(1.5 \mathrm{~mL})$. The organic layer was washed with brine $(3 \times 1 \mathrm{~mL})$ and dried over $\mathrm{MgSO}_{4}$ before being concentrated in vacuo to afford $9 \mathrm{~b}$ as a white solid ( $49 \mathrm{mg}, 99 \%$ yield). The melting point, ${ }^{1} \mathrm{H},{ }^{13} \mathrm{C}$, and ${ }^{19} \mathrm{~F}$ NMR match with the literature. ${ }^{11}{ }^{19} \mathrm{~F}$ NMR $(376.48 \mathrm{MHz}$, Chloroform-d) $\delta$-136.63 - $136.77(\mathrm{~m}, 2 \mathrm{~F}),-138.96--139.11(\mathrm{~m}, 2 \mathrm{~F}) .{ }^{1} \mathrm{H}$ NMR (400 MHz, Chloroform-d) $\delta 7.63-7.55(\mathrm{~m}, 2 \mathrm{H}), 7.44-$ $7.35(\mathrm{~m}, 3 \mathrm{H}), 7.10-6.99(\mathrm{tt}, \mathrm{J}=9.8,7.3 \mathrm{~Hz}, 1 \mathrm{H}) .{ }^{13} \mathrm{C}$ NMR $(151 \mathrm{MHz}$, Chloroform-d) $\delta 146.8$ (ddt, $J=251.9$, 14.3, $3.3 \mathrm{~Hz}$ ), 145.9 (dddd, $J=248.1,13.6,10.8,4.2 \mathrm{~Hz}), 132.1,129.8,128.7,121.8,106.2(\mathrm{t}, J=22.8 \mathrm{~Hz}$ ), $105.6(\mathrm{tt}, J=17.6,2.6 \mathrm{~Hz}), 102.0(\mathrm{t}, J=3.8 \mathrm{~Hz}), 74.5(\mathrm{t}, J=4.4 \mathrm{~Hz}) . \mathrm{GC} / \mathrm{MS}(\mathrm{m} / \mathrm{z}$, relative intensity) $250(\mathrm{M}+, 100)$

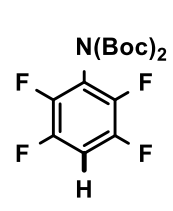

$10 b$

\section{tert-butyl (tert-butoxycarbonyl)(2,3,5,6-tetrafluorophenyl)carbamate 10b}

General Procedure A was followed using tert-butyl (tert-butoxycarbonyl)(pentafluorophenyl)carbamate (192 $\mathrm{mg}, 500 \mu \mathrm{mol})$ and $\mathrm{NaBH}_{4}(57 \mathrm{mg}, 1.5 \mathrm{mmol})$. The starting substrate was dissolved in $1.5 \mathrm{~mL}$ THF rather than DMSO since it was only sparing soluble in pure DMSO. The $\mathrm{NaBH}_{4}$ was still added as a solution in $1.5 \mathrm{~mL}$ DMSO. The reaction was heated to $60^{\circ} \mathrm{C}$ after the reagents were all mixed. The desired product $10 \mathrm{~b}$ was obtained as a white solid (173 mg, 95\% yield). The mp 56-57 ${ }^{\circ} \mathrm{C} ;{ }^{19} \mathrm{~F} \mathrm{NMR} \mathrm{(376} \mathrm{MHz,} \mathrm{Chloroform-d)} \delta-139.45--139.70$ (m, 2F), $-146.25-146.50$ (m, 2F). ${ }^{1} \mathrm{H}$ NMR (400 MHz, Chloroform-d) $\delta 7.15-7.03$ (tt, J = 9.8, 7.2, $1 \mathrm{H}$ ), $1.45-1.43$ $(\mathrm{s}, 18 \mathrm{H})$. Mass spectrum obtained following conversion to 2,3,5,6-tetrafluoroaniline via trifluoroacetic acid (S12) is consistent with the literature. ${ }^{3}$<smiles>Fc1cc(F)c(C2OCCO2)c(F)c1F</smiles>

11b<smiles>O=[N+](F)c1c(F)c(F)cc(F)c1C1(O)OCCO1</smiles>

$12 b$

\section{2-(2,3,5,6-tetrafluorophenyl)-1,3-dioxolane 11b}

General Procedure A was followed using 2-(pentafluorophenyl)-1,3-dioxolane (46 mg, $200 \mu \mathrm{mol}$ ) and $\mathrm{NaBH}_{4}$ (20 mg, $530 \mu \mathrm{mol}$ ) in $2 \mathrm{~mL} \mathrm{DMSO}$ heated to $50{ }^{\circ} \mathrm{C}$. A known compound, ${ }^{12}$ the desired product 11b was obtained as a colorless oil (35 mg, 82\% yield). ${ }^{19} \mathrm{~F} \mathrm{NMR} \mathrm{(376} \mathrm{MHz,} \mathrm{Chloroform-d)} \delta-138.99--139.15(\mathrm{~m}, 2 \mathrm{~F})$, $-144.43--144.60(\mathrm{~m}, 2 \mathrm{~F}) .{ }^{1} \mathrm{H}$ NMR (400 MHz, Chloroform-d) $\delta 7.12-7.03$ (tt, J = 9.5, 7.2, 1H), $6.26-6.23(\mathrm{~s}$, $1 \mathrm{H}), 4.26-4.17(\mathrm{~m}, 2 \mathrm{H}), 4.10-4.00(\mathrm{~m}, 2 \mathrm{H})$. GC/MS (m/z, relative intensity) $222(\mathrm{M}+, 55), 221\left(\mathrm{M}-\mathrm{H}^{-}, 80\right)$, 203 (40), 177 (90), 162 (100).

\section{2-methyl-2-(2,3,5,6-tetrafluorophenyl)-1,3-dioxolane 12b}

General Procedure A was followed using 2-methyl-2-(pentafluorophenyl)-1,3-dioxolane (51 mg, $200 \mu \mathrm{mol}$ ) and $\mathrm{NaBH}_{4}(16 \mathrm{mg}, 420 \mu \mathrm{mol})$ in DMSO $(2 \mathrm{~mL})$ heated to $50{ }^{\circ} \mathrm{C}$. The desired product $12 \mathrm{~b}$ was obtained as a colorless oil (38 mg, 80\% yield). ${ }^{19} \mathrm{~F}$ NMR (376 MHz, Chloroform-d) $\delta-138.75--138.90$ (m, 2F), -142.62 - $142.77(\mathrm{~m}, 2 \mathrm{~F}) .{ }^{1} \mathrm{H}$ NMR (400 MHz, Chloroform-d) $\delta 7.06-6.97(\mathrm{tt}, \mathrm{J}=9.5,7.2,1 \mathrm{H}), 4.17-4.07(\mathrm{~m}, 2 \mathrm{H}), 3.95$ $-3.86(\mathrm{~m}, 2 \mathrm{H}), 1.84-1.80(\mathrm{~s}, 3 \mathrm{H})$. GC/MS (m/z, relative intensity) $221\left(\mathrm{M}-\cdot \mathrm{CH}_{3}, 100\right), 187(11), 177(100)$, 149 (23), 99 (22).

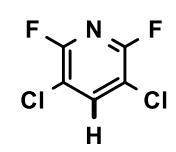

3,5-dichloro-2,6-difluoropyridine 13b

General Procedure A was followed using 3,5-dichloro-2,4,6-trifluoropyridine (101 mg, $500 \mu \mathrm{mol}$ ) and $\mathrm{NaBH}_{4}$ (19 mg, $500 \mu \mathrm{mol}$ ) in $3 \mathrm{~mL}$ DMSO. Product 13b was obtained as a pale-yellow, high-vapor-pressure solid (62 $\mathrm{mg}, 75 \%$ yield - some mass was lost under high vacuum). NMR spectra collected were a match for the literature. ${ }^{13}{ }^{19} \mathrm{~F}$ NMR $\left(376 \mathrm{MHz}\right.$, Chloroform-d) $\delta-72.00--72.26(\mathrm{~d}, \mathrm{~J}=7.5,2 \mathrm{~F}) .{ }^{1} \mathrm{H} \mathrm{NMR}(400 \mathrm{MHz}$, Chloroform-d) $\delta 7.98-7.92(t, J=7.5,1 \mathrm{H})$. 
<smiles></smiles>

2,2',3,3',5,5',6,6'-octafluoro-1,1'-biphenyl 14b

General Procedure A was followed using decafluorobiphenyl $(67 \mathrm{mg}, 200 \mu \mathrm{mol})$ and $\mathrm{NaBH}_{4}(23 \mathrm{mg}, 600$ $\mu \mathrm{mol})$ in $1 \mathrm{~mL}$ DMSO heated to $45^{\circ} \mathrm{C}$. The desired product $14 \mathrm{~b}$ was obtained as a white powder $(60 \mathrm{mg}, 84 \%$ yield). Melting point, ${ }^{13} \mathrm{C}$ and mass spectrum matched the literature. ${ }^{14,15}{ }^{19} \mathrm{~F} \mathrm{NMR}$ (376 MHz, Chloroform-d) $\delta$-137.68--137.92 (m, 4F), -138.24- -138.45 (m, 4F). ${ }^{1} \mathrm{H}$ NMR (400 MHz, Chloroform-d) $\delta 7.44-7.35$ (m, $2 \mathrm{H})$.

\section{1,2,4,5,6,8-hexafluoronaphthalene $15 b$}

Octafluoronaphthalene ( $544 \mathrm{mg}, 2 \mathrm{mmol}$ ) was taken into $8 \mathrm{~mL}$ THF and set stirring in a $50 \mathrm{~mL}$ round-bottom flask. To this was added $\mathrm{NaBH}_{4}(182 \mathrm{mg}, 4.8 \mathrm{mmol})$ in $12 \mathrm{~mL}$ of DMSO. The reaction mixture was heated to $45^{\circ} \mathrm{C}$ and continued to stir for 2 hours. The reaction mix was diluted with $180 \mathrm{~mL}$ EtOAc and quenched with brine. The organic layer was separated and washed five times with brine before being dried over $\mathrm{MgSO}_{4}$ and concentrated under reduced pressure. The residue was subjected to silica gel flash chromatography eluting with pure hexane to afford an intractable mixture of $\mathbf{1 5 b}$ and $\mathbf{1 5 c}$ with a relative ratio of $8: 1$ respectively, for a combined yield of $423 \mathrm{mg}(90 \%)$, corresponding to an $80 \%$ yield $\mathbf{1 5 b}$ and $10 \%$ yield $\mathbf{1 5 c}$. The melting point, mass, ${ }^{19} \mathrm{~F}$ NMR and ${ }^{1} \mathrm{H}$ NMR spectra match the literature. ${ }^{14,16,17}{ }^{19} \mathrm{~F} \mathrm{NMR}(564 \mathrm{MHz}, \mathrm{Chloroform}-\mathrm{d}) \delta$ $117.02--117.24(m, 2 F),-135.84--135.98(m, 2 F),-148.46--148.73(m, 2 F) .{ }^{1} H$ NMR (599 MHz, Chloroform-d) $\delta 7.24-$ $7.16(\mathrm{~m}, 2 \mathrm{H})$.<smiles>Fc1c(F)c(F)c2c(F)ccc(F)c2c1F</smiles>

$15 c$

\section{1,2,3,4,5,8-hexafluoronaphthalene 15c}

See entry for 15b for procedure. ${ }^{19} \mathrm{~F}$ NMR (564 MHz, Chloroform-d) $\delta-115.19--115.28(\mathrm{~m}, 2 \mathrm{~F}),-132.88-$ $132.97(\mathrm{~m}, 2 \mathrm{~F}),-150.10--150.21(\mathrm{~m}, 2 \mathrm{~F}) .{ }^{1} \mathrm{H}$ NMR (599 MHz, Chloroform-d) $\delta 7.14-7.08(\mathrm{~m}, 2 \mathrm{H})$.<smiles>[13CH3]c1c(F)c(F)c(C#N)c(F)c1F</smiles>

\section{2,3,5,6-tetrafluorobenzonitrile $16 b$}

Into a reaction vial is placed pentafluorobenzonitrile $(97 \mathrm{mg}, 500 \mu \mathrm{mol})$ and $\mathrm{NaBH}_{4}(19 \mathrm{mg}, 500 \mu \mathrm{mol})$ suspended in $2 \mathrm{~mL}$ of THF, set stirring with a magnetic stir bar. When the reaction was found to be complete by ${ }^{19} \mathrm{~F}$ NMR the THF was removed under reduced pressure and the residue extracted with hexanes, affording 16b as a colorless oil (77 mg, 88\% yield). Mass spectrum matched the literature, ${ }^{18}$ as well as the ${ }^{13} \mathrm{C} \mathrm{NMR.}{ }^{14}$ ${ }^{19} \mathrm{~F}$ NMR (376 MHz, Chloroform-d) $\delta$-131.77- -131.92 (m, 2F), -134.81--134.99 (m, 2F). ${ }^{1} \mathrm{H}$ NMR (400 MHz, Chloroform-d) $\delta 7.45-7.35(\mathrm{tt}, \mathrm{J}=9.4,7.3,1 \mathrm{H})$.

\section{1,3-difluoro-5-nitrobenzene $17 b$}<smiles>O=[N+]([O-])c1ccc(F)cc1F</smiles>

$17 \mathrm{~b}$ To a stirring suspension of $\mathrm{NaBH}_{4}(34 \mathrm{mg}, 900 \mu \mathrm{mol})$ in $3 \mathrm{~mL}$ of THF, cooled to $0{ }^{\circ} \mathrm{C}$, is added $\mathrm{H}_{2} \mathrm{O}(15 \mathrm{mg}, 900$ $\mu \mathrm{mol}$ ) and pentafluoronitrobenzene $(64 \mathrm{mg}, 300 \mu \mathrm{mol})$. The reaction mixture is allowed to gradually warm to room temperature and is carefully monitored by ${ }^{19} \mathrm{~F}$ NMR. When complete, the reaction is quenched by dilution with EtOAc, which precipitates the reactive salts, and the solution is decanted into a round-bottom flask. The decanted solution is dry loaded onto silica and subjected to silica gel flash chromatography to afford the product $\mathbf{1 7 b}$ as a yellow oil (38 mg). ${ }^{1} \mathrm{H}$ and ${ }^{19} \mathrm{~F}$ NMR suggested trace contamination of 10 mol\% trifluoroaniline isomers and 3 mol\% ethyl acetate, making the isolated yield $71 \% .{ }^{19} \mathrm{~F} \mathrm{NMR} \mathrm{(376.48} \mathrm{MHz,} \mathrm{Chloroform-d)} \delta-105.08$ (dd, J = 8.1, $6.5 \mathrm{~Hz}, 2 \mathrm{~F}) .{ }^{1} \mathrm{H}$ NMR (400 MHz, Chloroform-d) $\delta 7.83-7.77$ (dd, J = 6.5, $2.3 \mathrm{~Hz}, 2 \mathrm{H}$ ), $7.22-7.17(\mathrm{tt}, \mathrm{J}=8.1,2.3,1 \mathrm{H})$. $\mathrm{GC} / \mathrm{MS}$ (m/z, relative intensity) $159(\mathrm{M}+, 60), 129$ (7), $113(100), 101$ (19).<smiles>N#Cc1c(F)ccc(F)c1C#N</smiles>

$18 b$

\section{3,4,6-trifluorophthalonitrile $18 \mathrm{~b}$}

To a stirring suspension of $\mathrm{NaBH}_{4}(38 \mathrm{mg}, 1 \mathrm{mmol})$ and $\mathrm{H}_{2} \mathrm{O}(20 \mathrm{mg}, 1.1 \mathrm{mmol})$ in THF $(20 \mathrm{~mL})$ at $0{ }^{\circ} \mathrm{C}$ is added tetrafluorophthalonitrile $(200 \mathrm{mg}, 1 \mathrm{mmol})$. This mixture is stirred for 30 minutes before quenching with trifluoroacetic acid $(200 \mu \mathrm{L})$ and concentrating under reduced pressure onto silica for flash chromatography using hexane/DCM for elution. Product 18b was obtained as a pale-yellow oil (133 mg, $73 \%$ yield). Yield for this substrate was found to be highly time-dependent, with the product being highly prone to subsequent chemistry if left for longer than 30 minutes; moreover, it does not store well (highly moisture- 
sensitive). ${ }^{19} \mathrm{~F}$ NMR (564 MHz, Chloroform-d) $\delta-101.71$ (ddd, J = 12.9, 9.3, 8.0 Hz, 1F), -117.02 (dt, J = 20.9, 9.0 Hz, 1F), 128.85 (ddd, J = 20.9, 12.9, 6.3 Hz, 1F). ${ }^{1} \mathrm{H}$ NMR (599 MHz, Chloroform-d) $\delta 7.45$ (td, J = 8.4, 6.3 Hz, 1H). ${ }^{13} \mathrm{C} \mathrm{NMR} \mathrm{(151}$ $\mathrm{MHz}$, Chloroform-d) $\delta 159.7$ (ddd, J = 263.4, 10.9, 3.3 Hz), 153.8 (dt, J = 266.5, $12.6 \mathrm{~Hz}$ ), 149.4 (ddd, 264.6, 15.5, 4.0 Hz), 112.5 (dd, J = 25.6, 21.3 Hz), $109.3(t, J=2.4 \mathrm{~Hz}), 109.0(\mathrm{t}, \mathrm{J}=3.7 \mathrm{~Hz}), 106.7(\mathrm{dt}, \mathrm{J}=16.1,3.4 \mathrm{~Hz}), 100.8(\mathrm{dd}, \mathrm{J}=20.2,4.8$ $\mathrm{Hz})$. GC/MS (m/z, relative intensity) $182(\mathrm{M}+, 100)$.

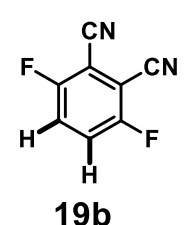

\section{3,6-difluorophthalonitrile 19b}

To a stirring suspension of $\mathrm{NaBH}_{4}(82 \mathrm{mg}, 2.2 \mathrm{mmol})$ in THF $(10 \mathrm{~mL})$ cooled to $0{ }^{\circ} \mathrm{C}$ is added $\mathrm{H}_{2} \mathrm{O}(40 \mathrm{mg}, 2.2$ $\mathrm{mmol})$ and subsequently tetrafluorophthalonitrile $(200 \mathrm{mg}, 1 \mathrm{mmol})$ as a solution in THF $\left(20 \mathrm{~mL}, 0^{\circ} \mathrm{C}\right)$. The reaction mixture warmed to room temperature and is monitored by ${ }^{19} \mathrm{~F}$ NMR. After 3 hours, the reaction is complete and concentrated onto silica for flash column chromatography using $\mathrm{CH}_{2} \mathrm{Cl}_{2}$ : hexane (ramp) for elution to afford $19 \mathrm{~b}$ (95 $\mathrm{mg}, 58 \%$ yield). Similar to $\mathbf{1 8 b}$, this reaction product degrades readily under ambient laboratory conditions (moisture-sensitive) and stores poorly. ${ }^{13} \mathrm{C}$ NMR was found to match the literature. ${ }^{14}{ }^{19} \mathrm{~F}$ NMR (376 MHz, Chloroform-d) $\delta-106.57--106.62$ (m, 2F). ${ }^{1} \mathrm{H}$ NMR (400 MHz, Chloroform-d) $\delta 7.58-7.54$ (m, 2H). GC/MS $(\mathrm{m} / \mathrm{z}$, relative intensity) $164(\mathrm{M}+, 100)$.<smiles>O=[N+]([O-])c1cc(F)c(Cl)c(F)c1</smiles>

20b

\section{2-chloro-1,3-difluoro-5-nitrobenzene 20b}

To a stirring suspension of $\mathrm{NaBH}_{4}(28 \mathrm{mg}, 740 \mu \mathrm{mol})$ in $3 \mathrm{~mL}$ of THF is added 1-chloro-2,3,5,6-tetrafluoro-4nitrobenzene $20 \mathrm{a}(92 \mathrm{mg}, 400 \mu \mathrm{mol})$. When the reaction was deemed complete by ${ }^{19} \mathrm{~F} \mathrm{NMR}$, the mixture was concentrated in vacuo and quenched by dilution with pentane, which precipitated out insoluble species. The remaining solution was filtered and concentrated in vacuo to afford the product 20b as an orange oil ( $65 \mathrm{mg}, 77 \%$ yield). Product appears to be moisture sensitive. ${ }^{19} \mathrm{~F} \mathrm{NMR} \mathrm{(376} \mathrm{MHz,} \mathrm{Chloroform-d)}$ $\delta-107.10-107.16(\mathrm{~m}, 2 \mathrm{~F}) .{ }^{1} \mathrm{H}$ NMR $(400 \mathrm{MHz}$, Chloroform-d) $\delta 7.94-7.88(\mathrm{~m}, 2 \mathrm{H}) . \mathrm{GC} / \mathrm{MS}(\mathrm{m} / \mathrm{z}$, relative intensity) $195(\mathrm{M}+2,13), 193(\mathrm{M}+, 40)$.

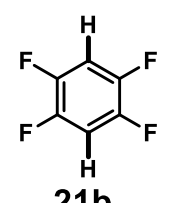

21b

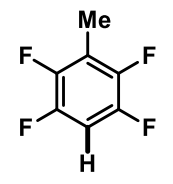

$22 b$

\section{1,2,4,5-tetrafluorobenzene 21b}

General Procedure A was followed using hexafluorobenzene $(100 \mathrm{mg}, 537 \mu \mathrm{mol})$ and $\mathrm{NaBH}_{4}(100 \mathrm{mg}, 2.6$ $\mathrm{mmol}$ ) in $5 \mathrm{~mL}$ of DMSO. When the reaction was complete, $1 \mathrm{~mL}$ of reaction mixture (20\% of the total volume) was taken into an NMR tube charged with a benzene- $d^{6}$ capillary and fluorobenzene $(20 \mu \mathrm{L}, 213 \mu \mathrm{mol})$ as internal standard. The aliquot was calculated to contain $87 \mu \mathrm{mol}$ of $7 \mathbf{b}$ corresponding to an $81 \%$ yield. Mass spectrum was found to be in accord with the literature. ${ }^{3}{ }^{19} \mathrm{~F} \mathrm{NMR}$ (564 MHz, DMSO) $\delta-134.78-134.84$ (t, J $=9.0,4 \mathrm{~F})$.

\section{1,2,4,5-tetrafluoro-3-methylbenzene 22b}

General Procedure A was followed using 1,2,3,4,5-pentafluoro-6-methylbenzene (100 mg, $550 \mu \mathrm{mol})$ and $\mathrm{NaBH}_{4}(104 \mathrm{mg}, 2.6 \mathrm{mmol})$ in $5 \mathrm{~mL}$ of DMSO heated to $80^{\circ} \mathrm{C}$. When the reaction was complete, $500 \mu \mathrm{L}$ of reaction mixture was taken into an NMR tube charged with a benzene-d ${ }^{6}$ capillary and fluorobenzene $(20 \mu \mathrm{L}$, $213 \mu \mathrm{mol}$ ) as internal standard. The aliquot was calculated to contain $39 \mu \mathrm{mol}$ of $\mathbf{2 2} \mathbf{b}$ corresponding to a $72 \%$ yield. The mass spectrum was a match for the literature. ${ }^{3}{ }^{19} \mathrm{~F} \mathrm{NMR}$ (564 MHz, DMSO) $\delta-140.03(\mathrm{~m}, 2 \mathrm{~F})$, $-143.23(\mathrm{~m}, 2 \mathrm{~F})$.<smiles></smiles>

$1 \mathrm{~b}$ methyl 2,3,5,6-tetrafluorobenzoate 16 (5 g scale)

General Procedure A was followed using methyl pentafluorobenzoate $(5.00 \mathrm{~g}, 22.1 \mathrm{mmol})$ and 1 equiv $\mathrm{NaBH}_{4}(837 \mathrm{mg}, 22.1 \mathrm{mmol})$ in $75 \mathrm{~mL}$ DMSO. The desired product 1b was obtained as a colorless oil (4.15 g, $90 \%$ yield). A known compound, characteristic NMR spectra match the literature. ${ }^{8}{ }^{19} \mathrm{~F} \mathrm{NMR}(376 \mathrm{MHz}$, Chloroform-d) $\delta-137.45--137.60(\mathrm{~m}, 2 \mathrm{~F}),-139.48--139.63(\mathrm{~m}, 2 \mathrm{~F}) .{ }^{1} \mathrm{H}$ NMR (400 MHz, Chloroform-d) $\delta$ $7.20(\mathrm{tt}, \mathrm{J}=9.4,7.2 \mathrm{~Hz}, 1 \mathrm{H}), 4.00-3.97(\mathrm{~s}, 3 \mathrm{H})$ 


\section{NMR Demonstration of Deprotection of $\mathrm{N}, \mathrm{N}$-(boc) $)_{2}$-tetrafluoroaniline $10 \mathrm{~b}$}

To demonstrate the facility of converting $10 \mathrm{~b}$ to the corresponding 2,3,5,6-tetrafluoroaniline, $16 \mathrm{mg}(44 \mu \mathrm{mol})$ of $10 \mathrm{~b}$ were taken into an NMR tube charged with benzene- $\mathrm{d}^{6}(500 \mu \mathrm{L})$ and trifluoroacetic acid (15 mg, $\left.132 \mu \mathrm{mol}\right)$. NMR spectra collected prior to and following a one-hour thermal treatment at $60{ }^{\circ} \mathrm{C}$ showed complete conversion to $2,3,5,6$ tetrafluoroaniline (Figure 2), consistent with the literature spectrum in benzene- $d^{6}{ }^{19}$

Figure 2. NMR Spectra of 10b Before and After Heating in TFA Solution

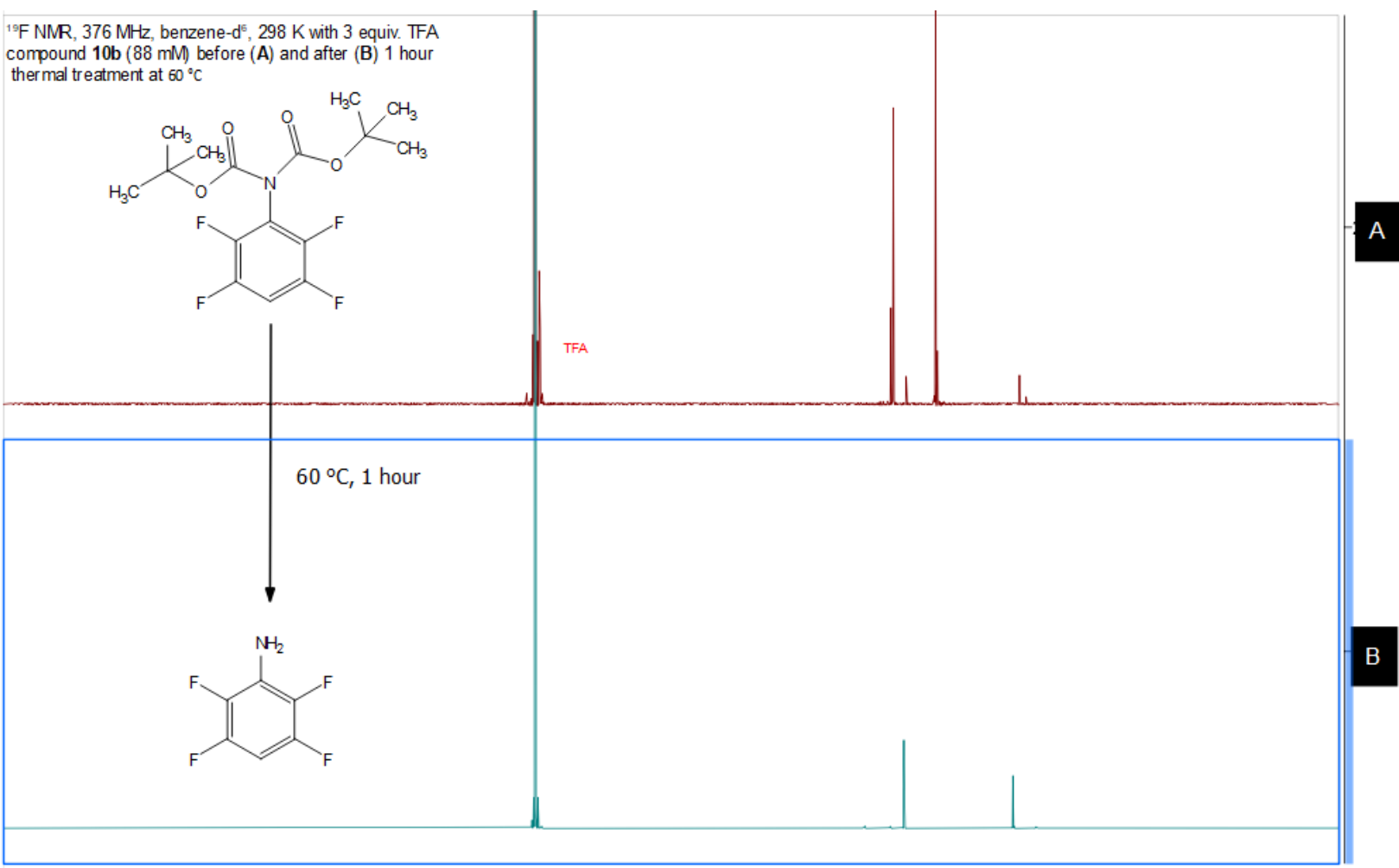

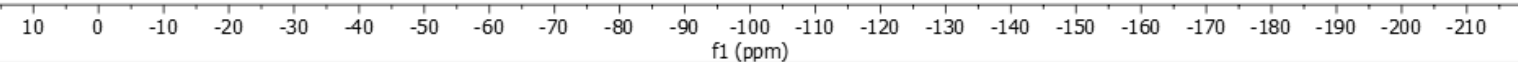

${ }^{1} \mathrm{H}$ NMR, $400 \mathrm{MHz}$, benzene- $\mathrm{d}^{5}, 298 \mathrm{~K}$

compound $10 \mathrm{~b}(88 \mathrm{mM})$ after 1 hour ther mal treatment at $60^{\circ} \mathrm{C}$ with 3 equiv. TFA

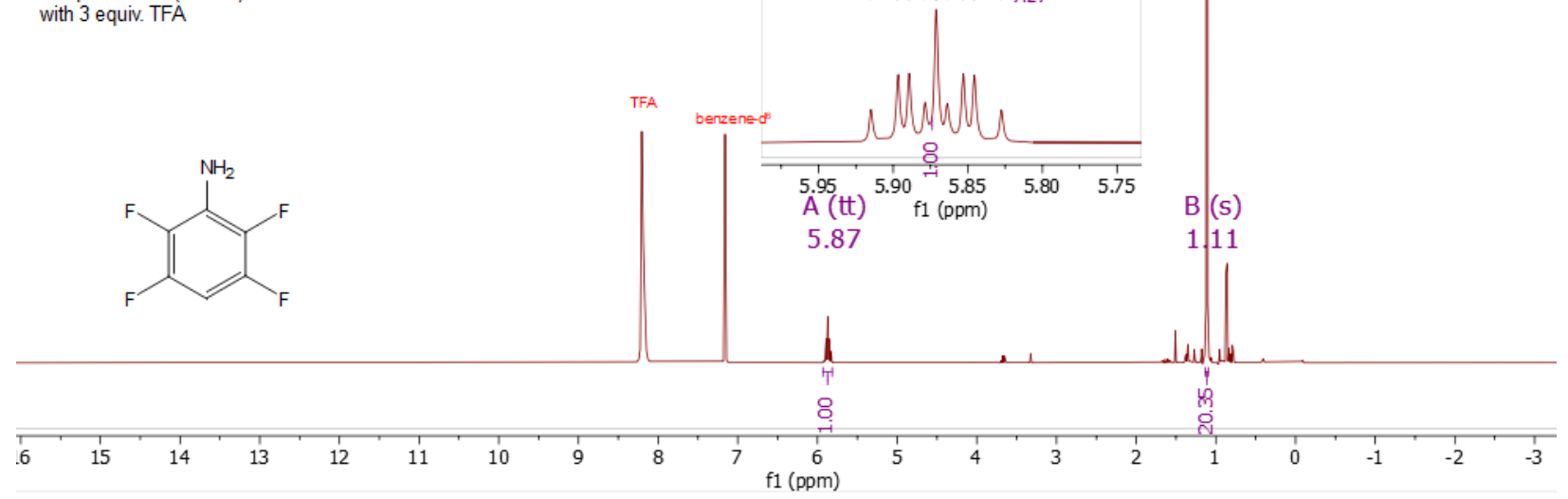




\section{Stability Test Using Methyl Pentafluorobenzoate}

In order to make a statement regarding the stability of substrates like $\mathbf{1 b}$ under reaction conditions over extended periods, a $1 \mathbf{~ m m o l}$ scale synthesis of $\mathbf{1 b}$ was set up according to General Procedure A (in $5.00 \mathrm{~mL}$ of DMSO) and left to stir for a period of time in excess of 40 hours. Periodic monitoring of the reaction by GCMS indicated complete consumption of the starting material within 4 hours, and no evidence for the formation of undesired side-products. After approximately 40 hours, aliquots subjected to GCMS still showed primarily methyl 2,3,5,6-tetrafluorobenzoate.

Finally, a $1 / 10$ volume sample from the reaction mixture was taken into an NMR tube charged with a benzene- $d^{6}$ capillary and fluorobenzene as an internal standard (20 microliters, 213 micromoles) for an expedient ${ }^{19} \mathrm{~F}$ NMR yield of $94 \%$. No attempt was made to characterize any trace side products or the fate of the remaining 3 equivalents of hydrides, although a distinct odor of dimethylsulfide suggested that the complex hydride side products preferentially react with the solvent over the methyl 1,3,5,6-tetrafluorobenzoate.

It is important to note that several of the other tested substrates were very much less stable under reaction conditions, requiring careful monitoring and timely workup to mitigate subsequent functional group reduction (17b, 18b, 19b, and 20b)

$19 F$ NMR at $376.48 \mathrm{MHz}$ in DMSO<smiles>COC(=O)c1c(F)c(F)cc(F)c1F</smiles>

$(188.17+189.45) \div 4 \times 10=944$ umoles methyl-2,3,5,6-tetrafluorobenzoate

$94 \%$ yield

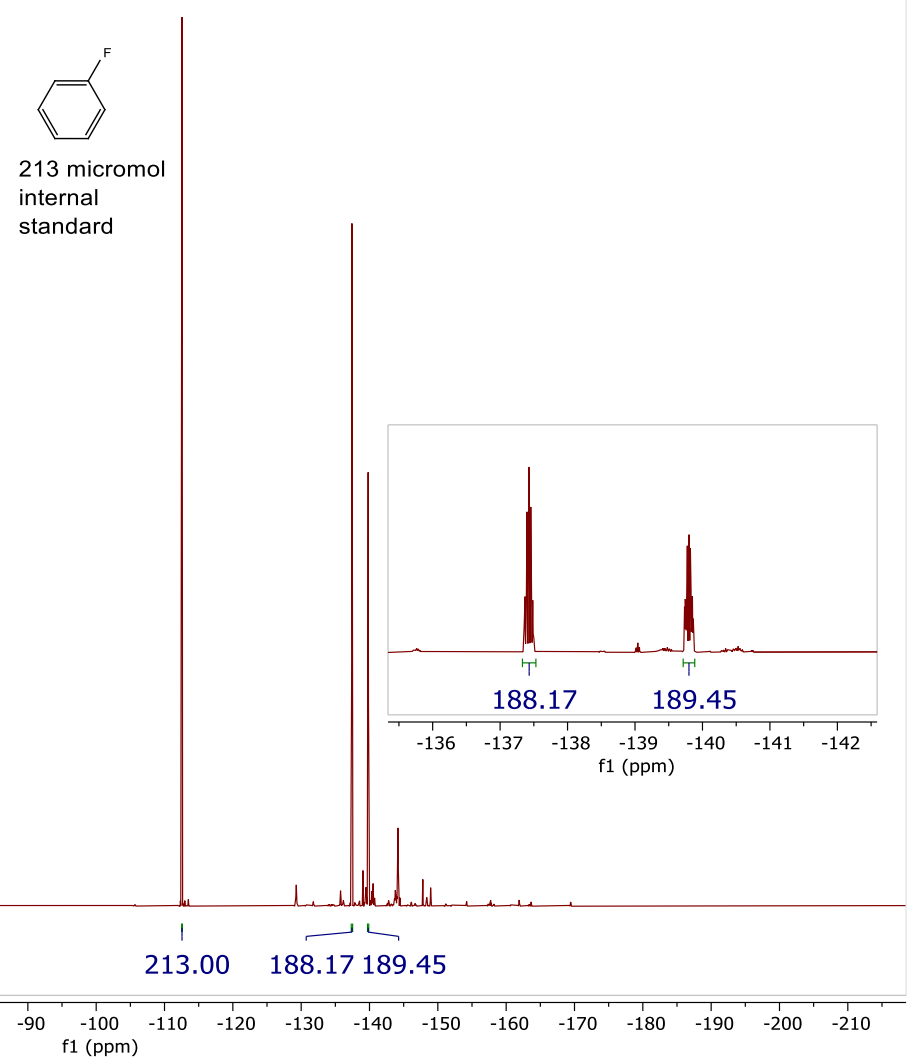


Synthesis of 3,6-di(9H-carbazol-9-yl)phthalonitrile 19c

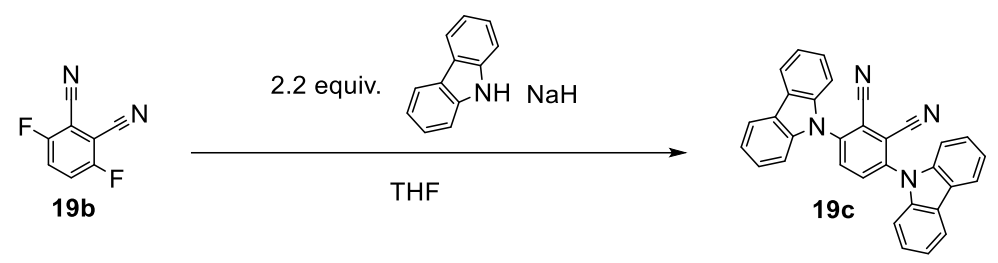

Following the procedure of Adachi et al., ${ }^{20} \mathrm{NaH}$ (110 mg 60\% paraffin dispersion, $2.7 \mathrm{mmol}$ ) was added portion-wise to a stirring solution of carbazole $(450 \mathrm{mg}, 2.7 \mathrm{mmol})$ in dry THF $(3 \mathrm{~mL})$ under argon. The stirring was continued until the exotherm and effervescence had entirely subsided, then the suspension was carefully transferred via syringe to another stirring $3 \mathrm{~mL}$ THF solution of 3,6-difluorophthalonitrile $19 \mathrm{~b}(200 \mathrm{mg}, 1.22 \mathrm{mmol})$. The $\mathrm{S}_{N} A r$ reaction was essentially diffusion controlled but allowed to stir for 30 minutes before being quenched in ice water and extracted with $\mathrm{CH}_{2} \mathrm{Cl}_{2}$ until the extractions no longer fluoresced under $365 \mathrm{~nm}$ irradiation. The organic layer was dried over $\mathrm{MgSO}_{4}$ and subjected to silica gel flash chromatography eluting with $60 \% \mathrm{CH}_{2} \mathrm{Cl}_{2} 40 \%$ hexane affording $455 \mathrm{mg}$ of $19 \mathrm{c}$ ( $81 \%$ yield) as a bright yellow, fluorescent powder. ${ }^{1} \mathrm{H}$ NMR $\left(599 \mathrm{MHz}\right.$, Benzene- $\left.d_{6}\right) \delta 7.97(\mathrm{~d}, J=7.7 \mathrm{~Hz}, 4 \mathrm{H}), 7.36(\mathrm{t}, J=7.6 \mathrm{~Hz}, 6 \mathrm{H}), 7.27(\mathrm{t}, J=7.4$ $\mathrm{Hz}, 4 \mathrm{H}), 7.03(\mathrm{~d}, J=8.1 \mathrm{~Hz}, 4 \mathrm{H}), 6.72(\mathrm{~s}, 2 \mathrm{H}) .{ }^{13} \mathrm{C} N M R\left(151 \mathrm{MHz}\right.$, Benzene- $\left.d_{6}\right) \delta 140.86,140.51,134.48,126.89$, $124.87,122.18,121.26,117.81,113.10,110.07$

\section{Scheme 3. Contrathermodynamic Isomerization of E-23a}

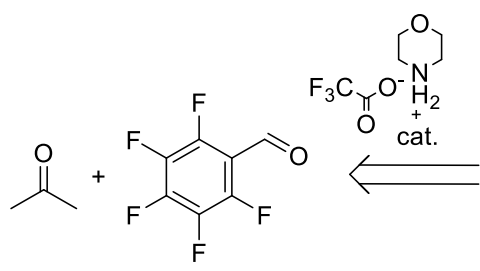

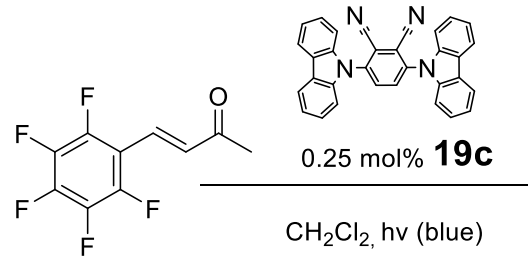

E-23a

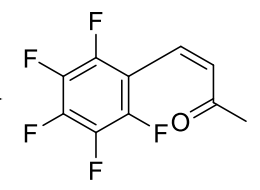

Z-23b

\section{9c-Photocatalyzed Synthesis of (Z)-4-(perfluorophenyl)but-3-en-2-one (Z-23b)}

The procedure reported by Sun et al. ${ }^{21}$ was followed scaled to $980 \mathrm{mg}$ of pentafluorobenzaldehyde, affording E-23a in $80 \%$ yield. $100 \mathrm{mg}(424 \mu \mathrm{mol})$ of E-23a was placed into glass culture tube charged with $19 \mathrm{c}$ in $\mathrm{CH}_{2} \mathrm{Cl}_{2}(4 \mathrm{~mL}, 280 \mu \mathrm{M})$, which was subsequently placed in the $447 \mathrm{~nm}$ light bath described in the general experimental at $0{ }^{\circ} \mathrm{C}$ for 1 hour. The solution was concentrated in vacuo and subjected to silica gel chromatography with hexane/EtOAc to afford Z-23b $(70 \mathrm{mg}$ combined, $70 \%$ combined yield as a mixture of $8: 1$ Z-23b : E-23a). ${ }^{19} \mathrm{~F} \mathrm{NMR}(564 \mathrm{MHz}$, chloroform-d) $\delta-138.99(\mathrm{~m}, 2 \mathrm{~F}),-154.47$ (t, J $=20.7 \mathrm{~Hz}, 1 \mathrm{~F}),-162.78(\mathrm{~m}, 2 \mathrm{~F}) .{ }^{1} \mathrm{H} \mathrm{NMR}(599 \mathrm{MHz}$, chloroform-d) $\delta 6.58(\mathrm{~d}, \mathrm{~J}=11.9 \mathrm{~Hz}, 1 \mathrm{H}), 6.49(\mathrm{dq}, \mathrm{J}=11.9,1.5 \mathrm{~Hz}, 1 \mathrm{H})$, 2.27 (s, 3H). ${ }^{13} \mathrm{C}$ NMR (151 MHz, chloroform-d) $\delta 197.72(\mathrm{~s}), 144.12$ (dddt, J = 249.0, 11.2, 7.4, $3.8 \mathrm{~Hz}$,), 141.22 (dtt, J = 255.6, 13.9, $5.4 \mathrm{~Hz}), 137.37\left(\mathrm{~m}, \mathrm{~J}_{\mathrm{C}-\mathrm{F}}=251.2 \mathrm{~Hz}\right), 133.96(\mathrm{~s}, 1 \mathrm{C}), 122.65(\mathrm{~s}), 110.98(\mathrm{td}, \mathrm{J}=17.7,4.1 \mathrm{~Hz}), 30.63(\mathrm{~s})$. 
$E-23 a$ and Z-23b

$19 \mathrm{~F} \mathrm{NMR}$ at $563.61 \mathrm{MHz}$ in $\mathrm{CDCl} 3$
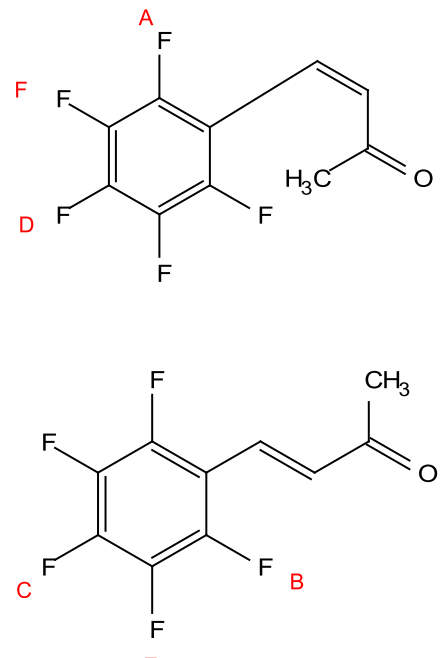

$E$

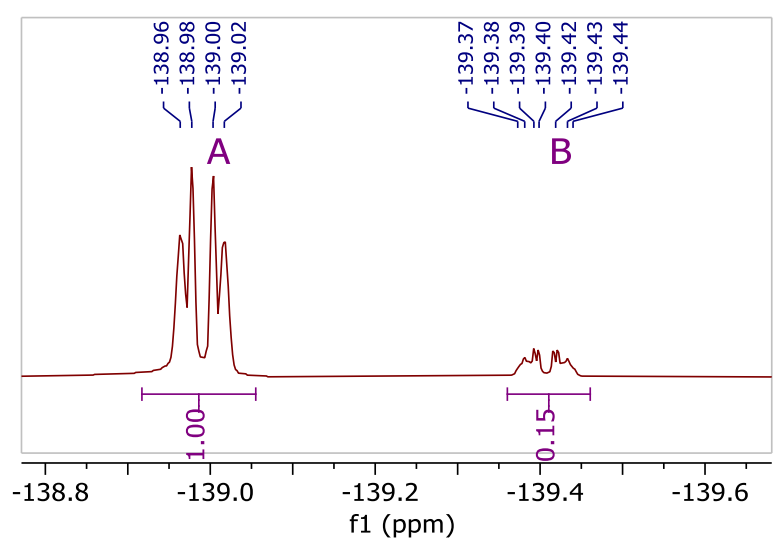

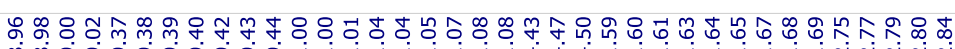
क्⿹

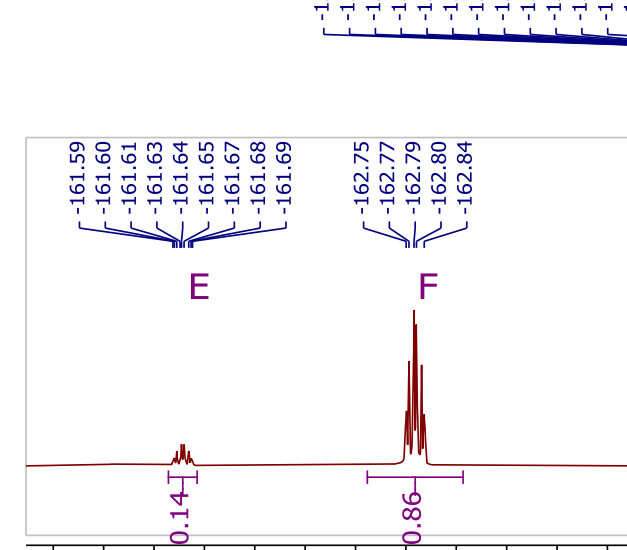

$\begin{array}{llllll}161.0 & -161.5 & -162.0 & -162.5 & -163.0 & -163.5\end{array}$ f1 (ppm)

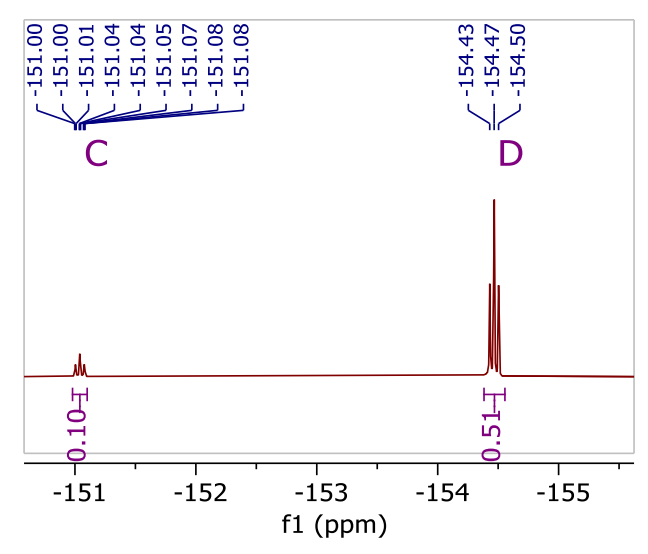

ठ내

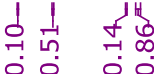

\begin{tabular}{lllllllllllllllllllllllll}
\hline & 0 & 0 & -10 & -20 & -30 & -40 & -50 & -60 & -70 & -80 & -90 & -100 & -110 & -120 & -130 & -140 & -150 & -160 & -170 & -180 & -190 & -200 & -2
\end{tabular}




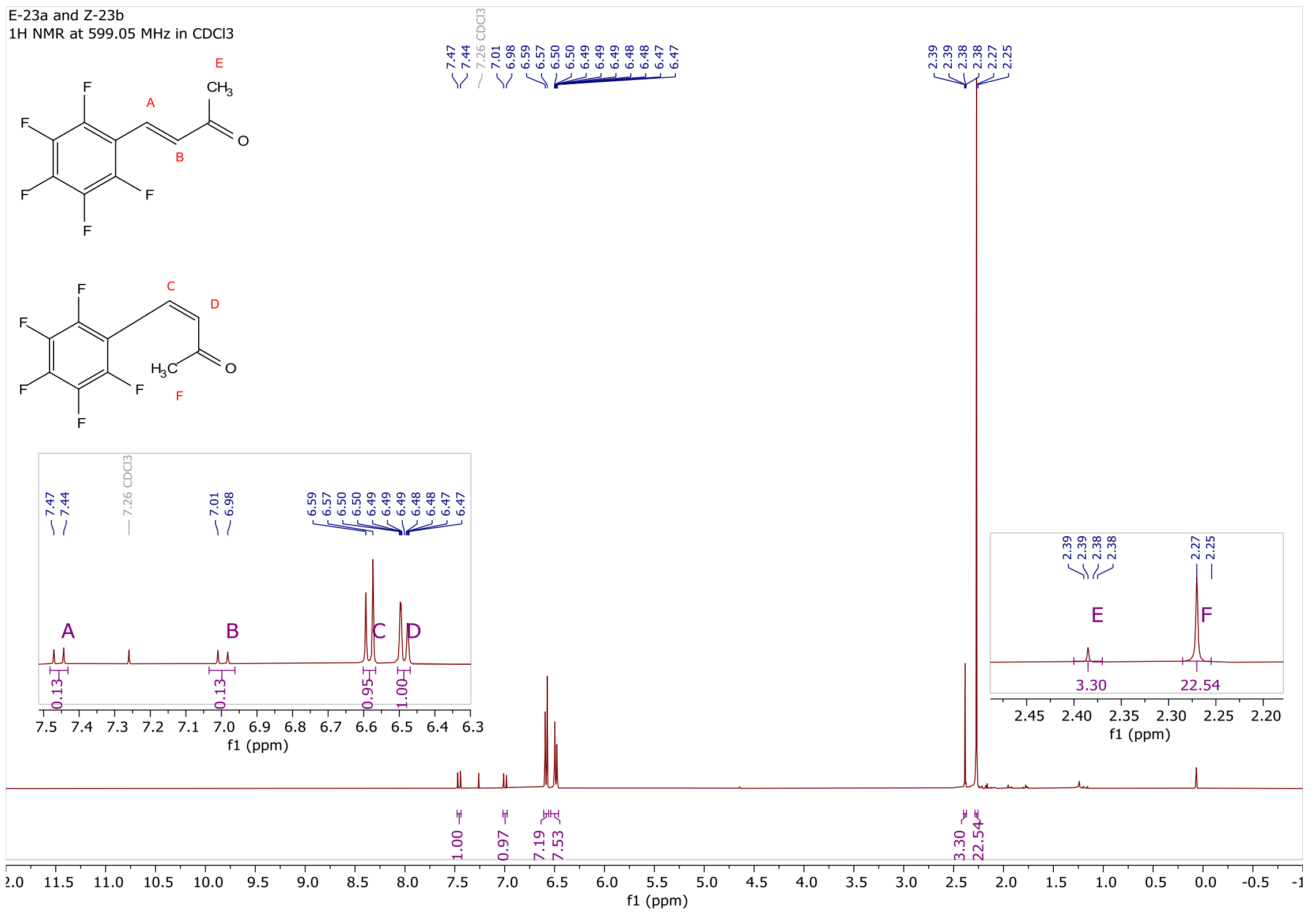




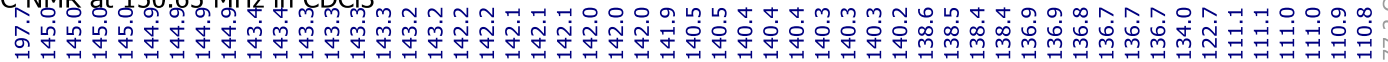

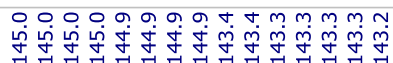

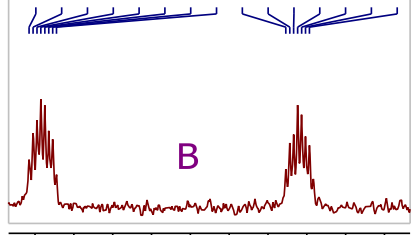

145.01445144 .01435143 .0

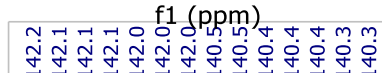

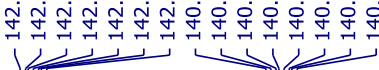

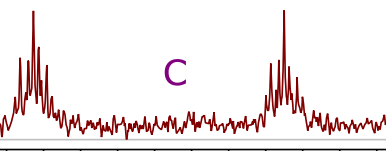

142.0141 .5141 .0140 .5140 .0
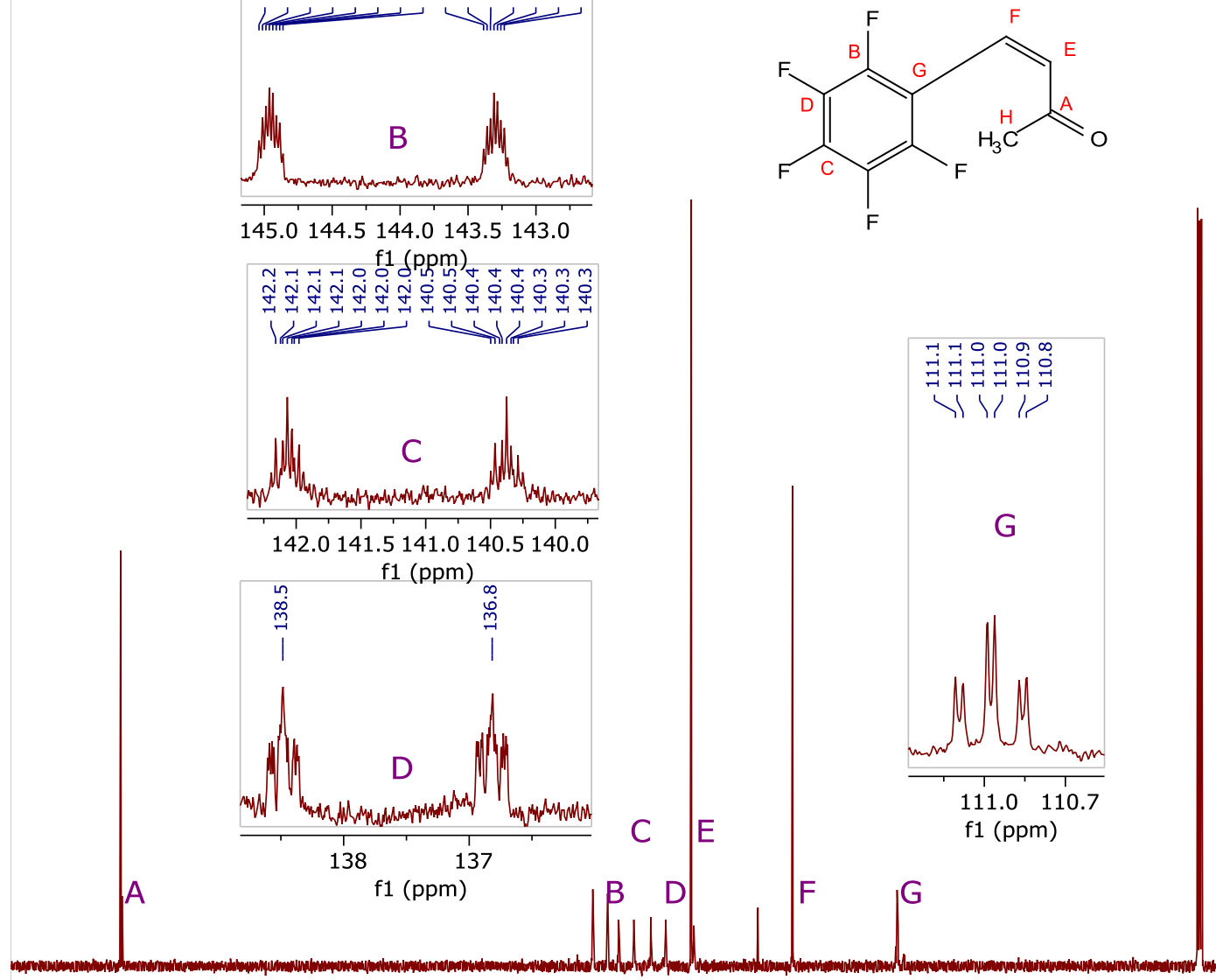

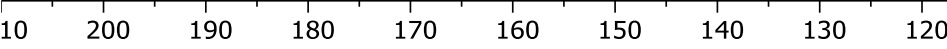

$110 \quad 100$

90

80

70

60

50

40

$30 \quad 20$ 


\section{REFERENCES}

(1) Harris, R.; Becker, E. D.; Cabral de Menezes, S. M.; Goodfellow, R.; Granger, P. NMR Nomenclature. Nuclear Spin Properties and Conventions for Chemical Shifts. Pure Appl. Chem. 2001, 73 (11), 1795-1818.

(2) Davies, L. C.; Friedlos, F.; Hedley, D.; Martin, J.; Ogilvie, L. M.; Scanlon, I. J.; Springer, C. J. Novel Fluorinated Prodrugs for Activation by Carboxypeptidase G2 Showing Good in Vivo Antitumor Activity in Gene-Directed Enzyme Prodrug Therapy. J. Med. Chem. 2005, 48 (16), 53215328. https://doi.org/10.1021/jm0502182.

(3) Wallace, W. E.; NIST Mass Spectrometry Data Center. "Mass Spectra." In NIST Chemistry WebBook, NIST Standard Reference Database Number 69; Linstrom, P. J., Mallard, W. G., Eds.; National Institute of Standards and Technology: Gaithersburg MD, $20899,2018$. https://doi.org/10.18434/T4D303.

(4) Nicholls, T. P.; Robertson, J. C.; Gardiner, M. G.; Bissember, A. C. Identifying the Potential of Pulsed LED Irradiation in Synthesis: CopperPhotocatalysed C-F Functionalisation †. Chem. Commun 2018, 54, 4589. https://doi.org/10.1039/c8cc02244e.

(5) Zhang, X.; Fan, S.; He, C.-Y.; Wan, X.; Min, Q.-Q.; Yang, J.; Jiang, Z.-X. Pd(OAc) 2 Catalyzed Olefination of Highly Electron-Deficient Perfluoroarenes. J. Am. Chem. Soc. 2010, 132 (13), 4506-4507. https://doi.org/10.1021/ja908434e.

(6) Matsuyama, N.; Kitahara, M.; Hirano, K.; Satoh, T.; Miura, M. Nickel- and Copper-Catalyzed Direct Alkynylation of Azoles and Polyfluoroarenes with Terminal Alkynes under O2 or Atmospheric Conditions. Org. Lett. 2010, 12 (10), 2358-2361. https://doi.org/10.1021/ol100699g.

(7) Iwasaki, T.; Min, X.; Fukuoka, A.; Zhu, L.; Qiu, R.; Yang, T.; Ehara, M.; Sudalai, A.; Kambe, N. Ni-Catalyzed Dimerization and Hydroperfluoroarylation of 1,3-Dienes. J. Org. Chem. 2018, 83, 9267. https://doi.org/10.1021/acs.joc.8b01266.

(8) Senaweera, S. M.; Singh, A.; Weaver, J. D. Photocatalytic Hydrodefluorination: Facile Access to Partially Fluorinated Aromatics. J. Am. Chem. Soc. 2014, 136, 3002. https://doi.org/10.1021/ja500031m.

(9) Laev, S. S.; Shteingarts, V. D. Reductive Dehalogenation of Polyfluoroarenes by Zinc in Aqueous Ammonia. J. Fluor. Chem. 1999, 96 (2), 175185. https://doi.org/10.1016/S0022-1139(99)00082-2.

(10) Aroskar, E. V.; Brown, P. J. N.; Plevey, R. G.; Stephens, R. Aromatic Polyfluoro-Compounds. PArt XLI.1 Some Reactions of Pentafluorobenzaldehyde. J. Chem. Soc. C 1966, 1569-1575. https://doi.org/10.1039/J39680001569.

(11) Wiles, M. R.; Massey, A. G. Synthesis of 1-Phenylethynyl- 4-Substituted Tetrafluorobenzenes. Tetrahedron Lett. 1967, 8 (51), 5137-5138. https://doi.org/10.1016/S0040-4039(01)89629-5.

(12) Krebs, F. C.; Jensen, T. Fluorinated Molecules Relevant to Conducting Polymer Research. J. Fluor. Chem. 2003, 120 (1), 77-84. https://doi.org/10.1016/S0022-1139(02)00289-0.

(13) Chambers, R. D.; Hall, C. W.; Hutchinson, J.; Millar, R. W. Polyhalogenated Heterocyclic Compounds. Part 42. Fluorinated Nitrogen Heterocycles with Unusual Substitution Patterns. J. Chem. Soc. - Perkin Trans. 1 1998, No. 10, 1705-1713. https://doi.org/10.1039/a709291a.

(14) Kikushima, K.; Grellier, M.; Ohashi, M.; Ogoshi, S. Transition-Metal-Free Catalytic Hydrodefluorination of Polyfluoroarenes by Concerted Nucleophilic Aromatic Substitution with a Hydrosilicate. Angew. Chemie - Int. Ed. 2017, 56 (51), 16191-16196. https://doi.org/10.1002/anie.201708003

(15) Deacon, G. B.; Phillips, R. J. Organothallium Compounds. XIV. Thermal Decomposition of Some Polyfluorobenzoatobis(Polyfluorophenyl)Thallium(III) Compounds. Aust. J. Chem 1978, 31, 1709-1724. https://doi.org/10.1071/CH9781709.

(16) Facundo, A. A.; Aré, A.; Fundora-Galano, G.; Flores-A 'lamo, M.; Orgaz, E.; Garcí, J. J. Hydrodefluorination of Functionalized Fluoroaromatics with Triethylphosphine: A Theoretical and Experimental Study †. New J. Chem 2019, 43, 6897. https://doi.org/10.1039/c9nj00721k.

(17) Yow, S.; Gates, S. J.; White, A. J. P.; Crimmin, M. R. Zirconocene Dichloride Catalyzed Hydrodefluorination of C Sp 2]F Bonds. Angew. Chemie Int. Ed. 2012, 51 (50), 12559-12563. https://doi.org/10.1002/anie.201207036.

(18) Senaweera, S. M.; Singh, A.; Weaver, J. D. Photocatalytic Hydrodefluorination; Facile Access to Partially Fluorinated Aromatics-SI; 2014.

(19) Andreevskaya, O. I.; Furin, G. G.; Yakobson, G. G. AROMATIC FLUORO-SUBSTITUTED DERIVATIVES. LXXV. BENZIDINE REARRANGEMENT OF $2,2^{\prime}, 3,3^{\prime}, 5,5^{\prime}, 6,6^{\prime}$-OCTAFLUOROHYDRAZOBENZENE AND WALLACH REARRANGEMENT OF $2,2^{\prime}, 3,3^{\prime}, 5,5^{\prime}, 6,6^{\prime}$-OCTAFLUOROAZOXYBENZENE IN ULTRASTRONG ACIDS. Zhurnal Org. Khimii 1977, 13, 1648-1693. https://doi.org/10.1002/chin.197748097.

(20) Uoyama, H.; Goushi, K.; Shizu, K.; Nomura, H.; Adachi, C. Highly Efficient Organic Light-Emitting Diodes from Delayed Fluorescence. Nature 2012, 492 (7428), 234-238. https://doi.org/10.1038/nature11687.

(21) Song, X.; Zhu, X.; Li, T.; Liang, C.; Zhang, M.; Shao, Y.; Tao, J.; Sun, R. Dehydrozingerone Inspired Discovery of Potential Broad-Spectrum Fungicidal Agents as Ergosterol Biosynthesis Inhibitors. J. Agric. Food Chem. 2019, 67 (41), 11354-11363. https://doi.org/10.1021/acs.jafc.9b04231. 
UV-Vis absorption spectra were collected at reaction concentration (approximately $1 \mathrm{mM}$ ) and at $54 \mu \mathrm{M}$ for the organodye $19 \mathrm{c}$ as part of the substance characterization.

Figure 4. UV-Vis Absorption Spectrum for organodye 19c

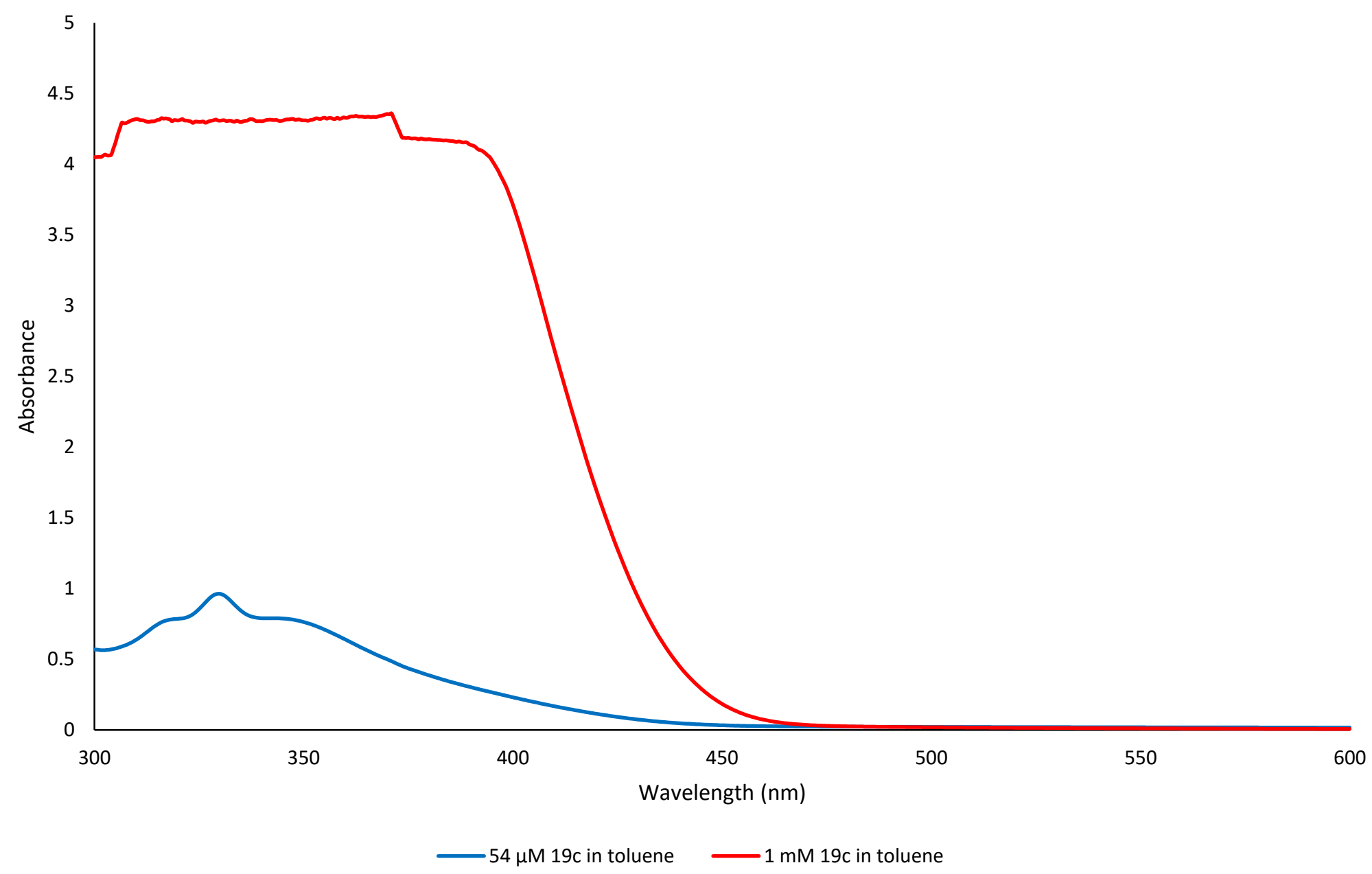


$1 b$

19F NMR at $376.48 \mathrm{MHz}$ in $\mathrm{CDCl} 3$

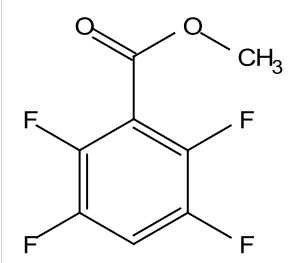

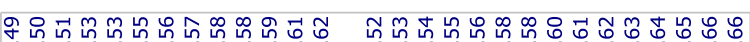

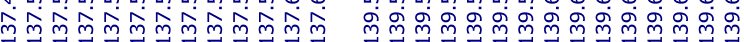

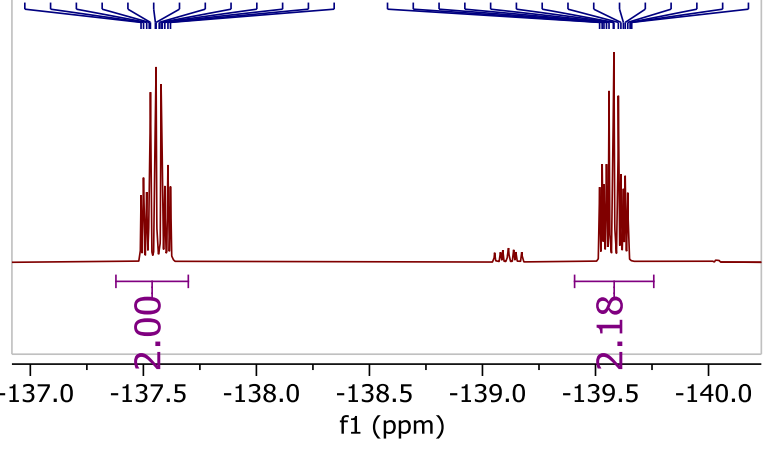

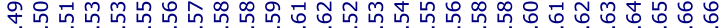

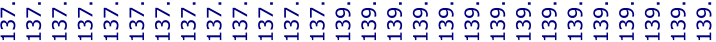

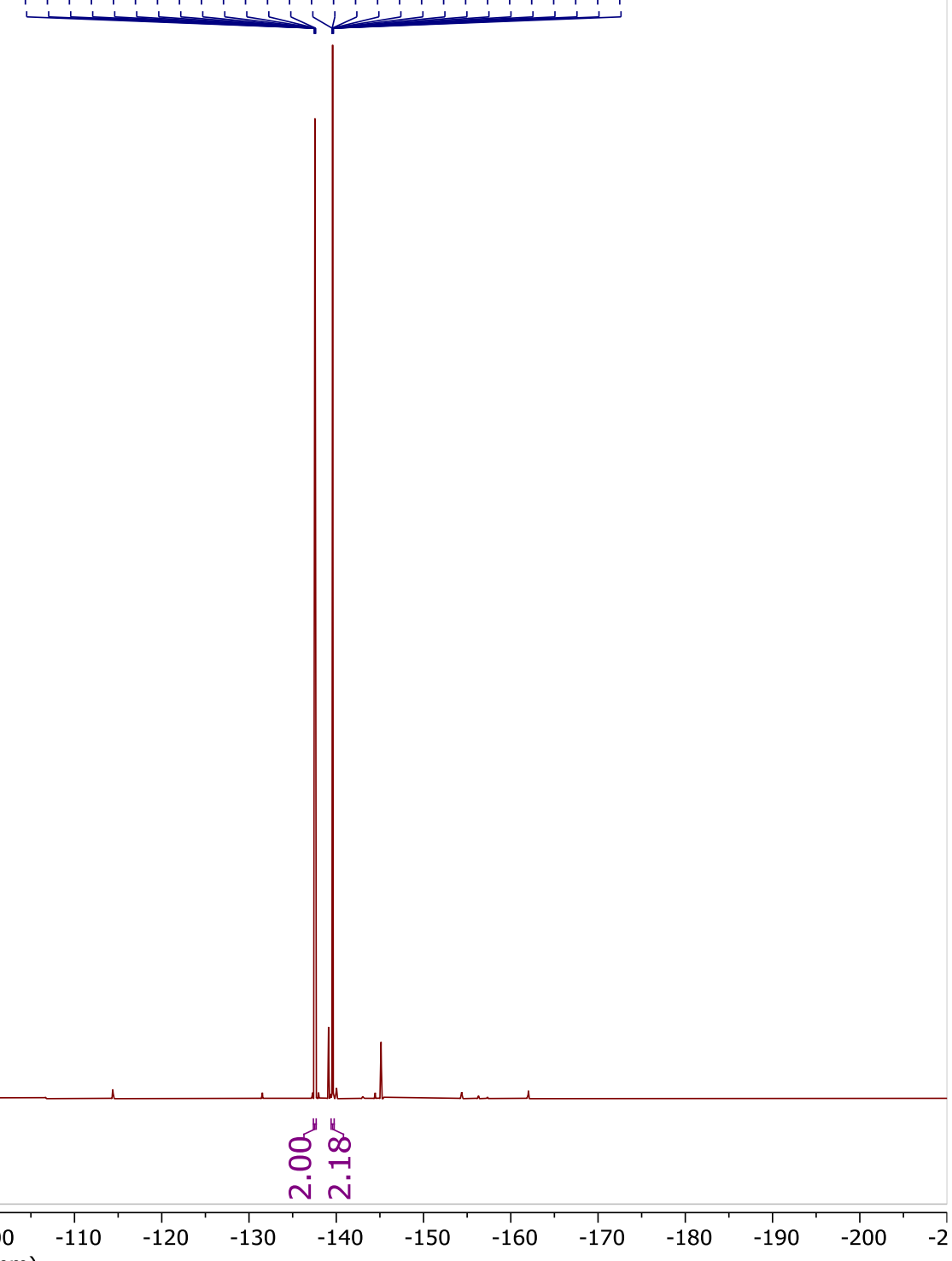




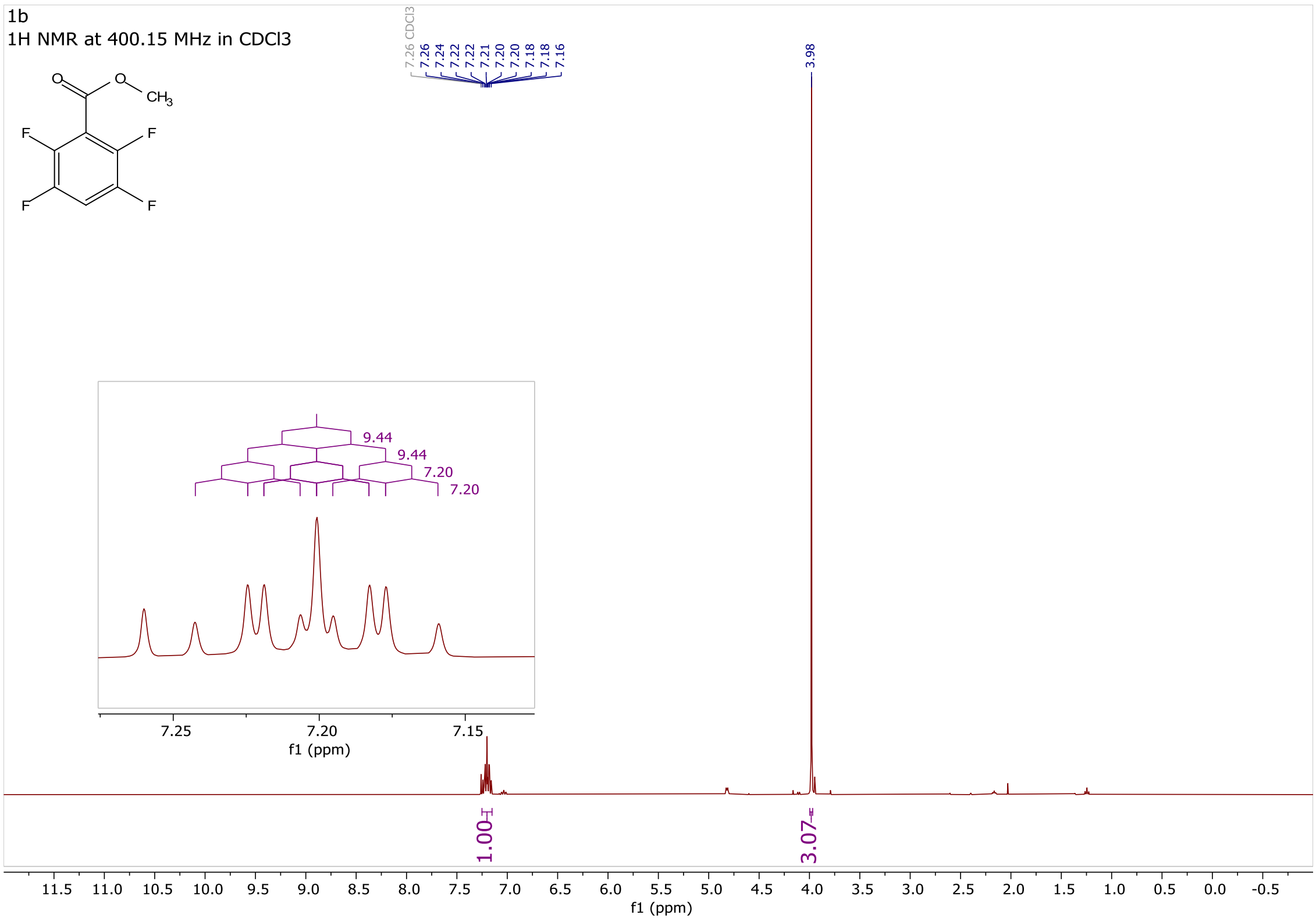


$2 b$

$19 F$ NMR at $376.48 \mathrm{MHz}$ in $\mathrm{CDCl} 3$

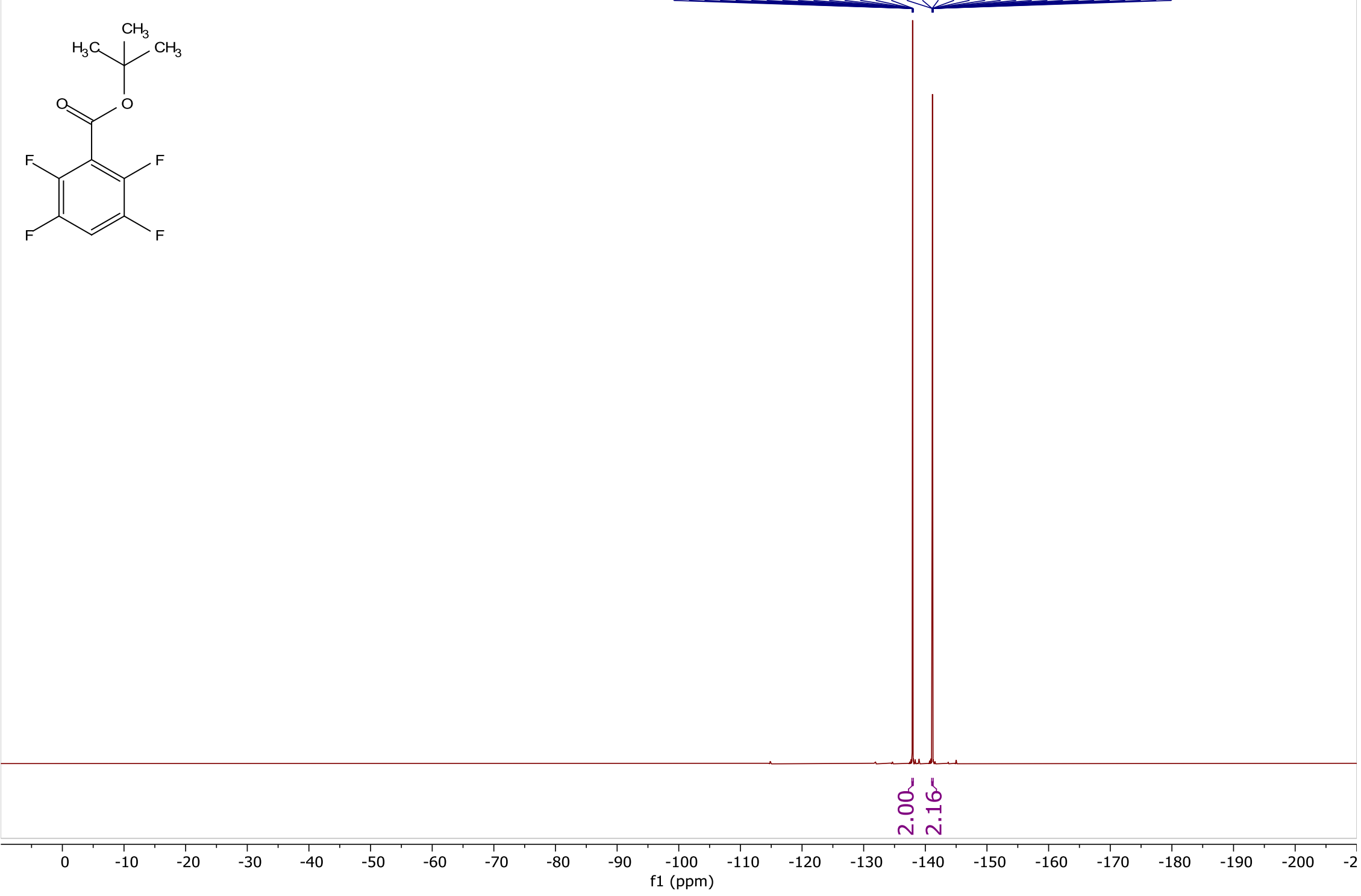



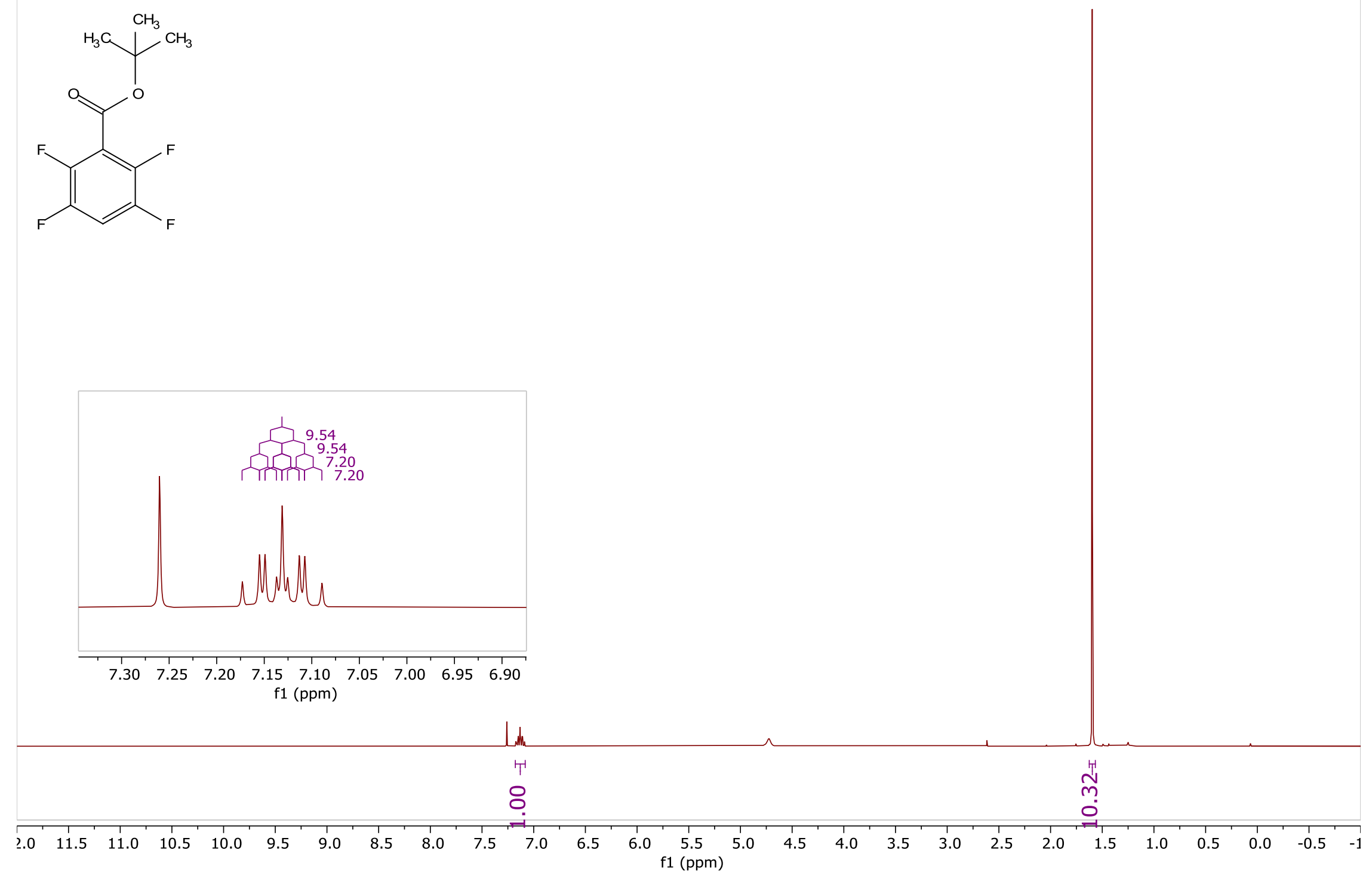

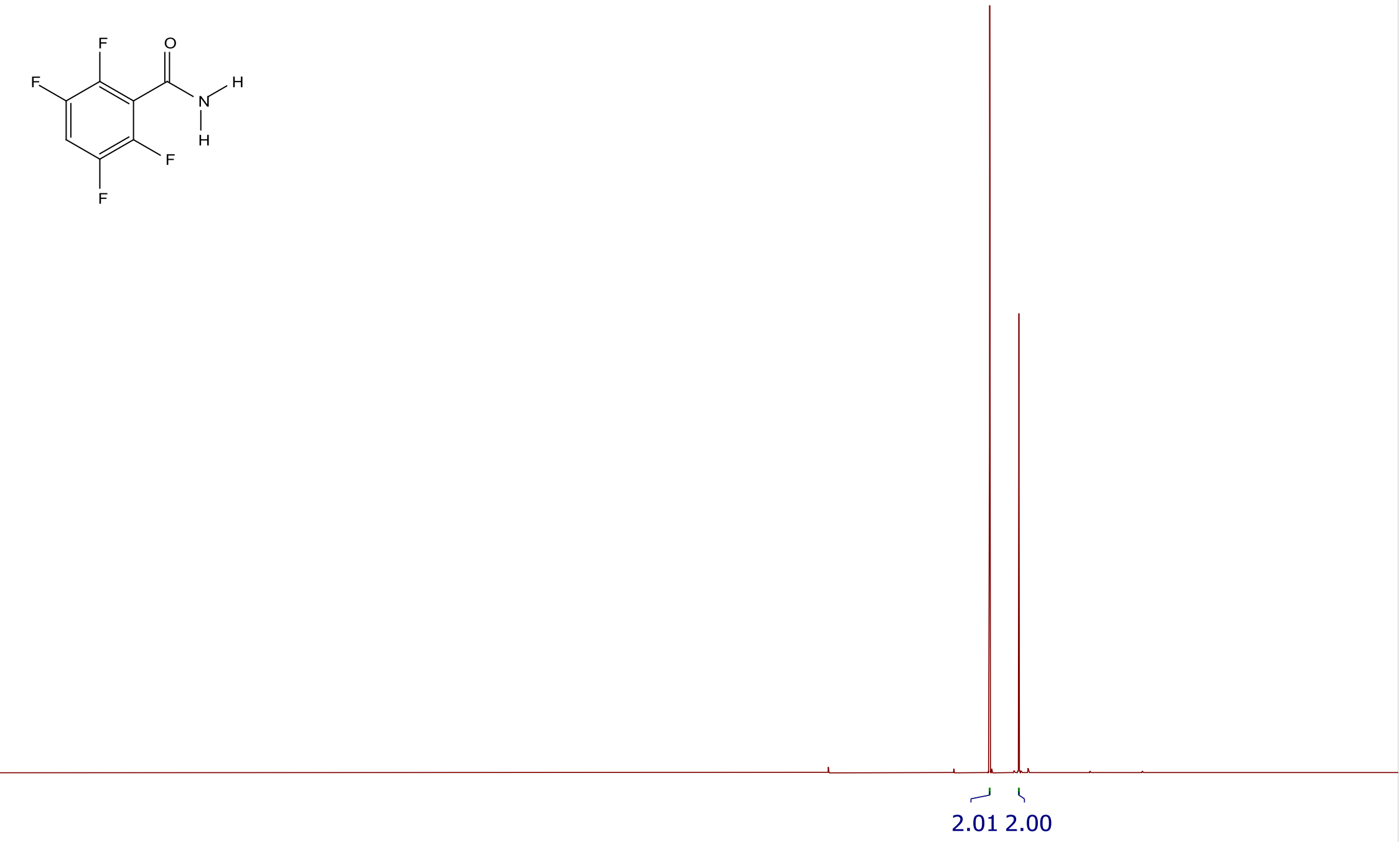

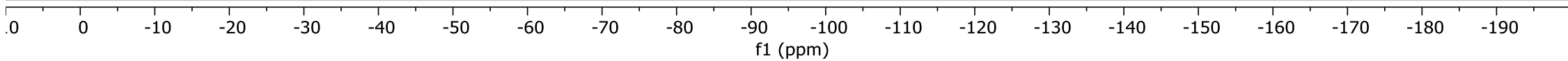


$1 \mathrm{H} \mathrm{NMR}$ at $599.05 \mathrm{MHz}$ in DMSO

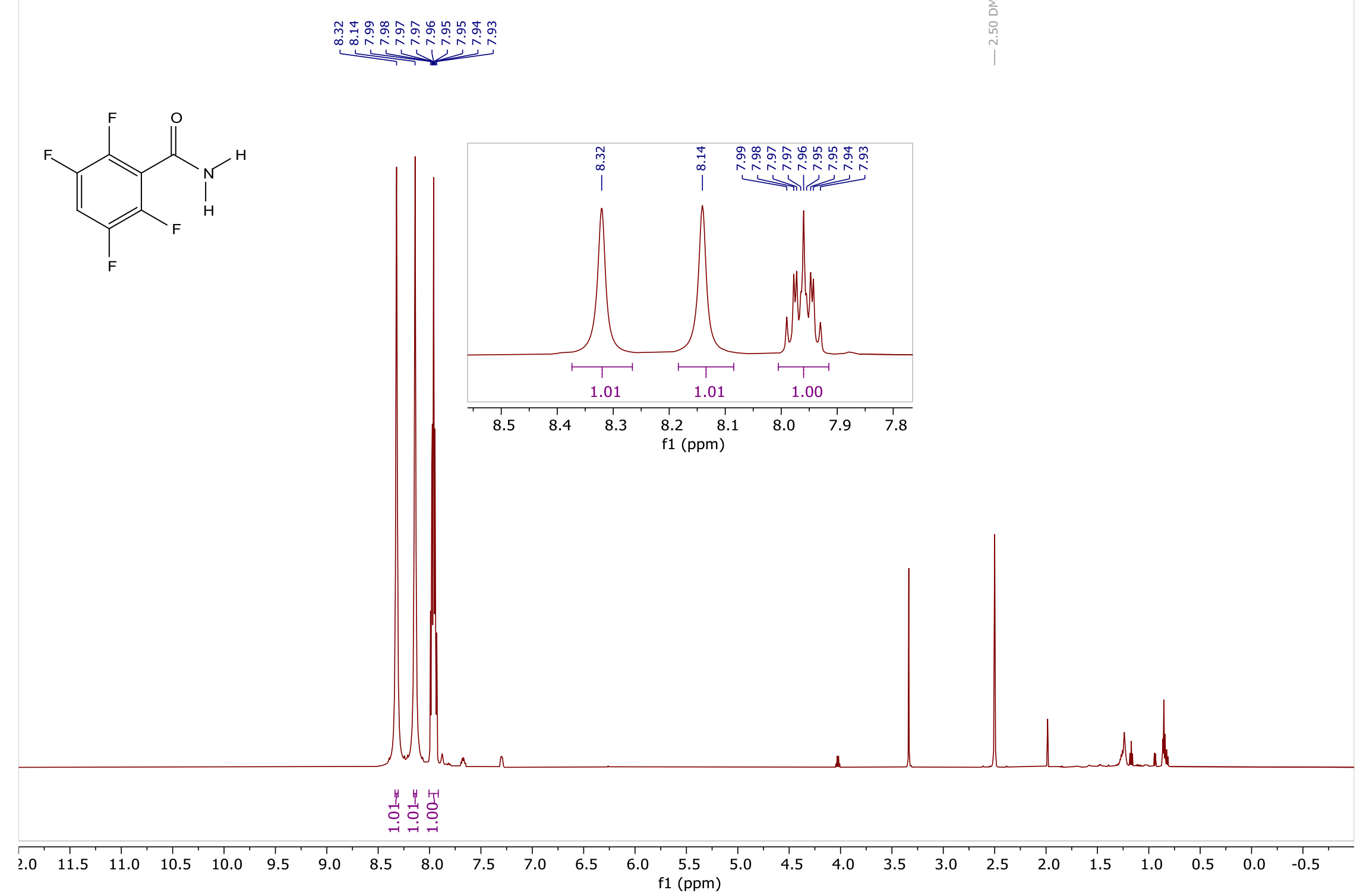


$3 \mathrm{~b}$

$13 \mathrm{C} \mathrm{NMR}$ at $150.65 \mathrm{MHz}$ in DMSO
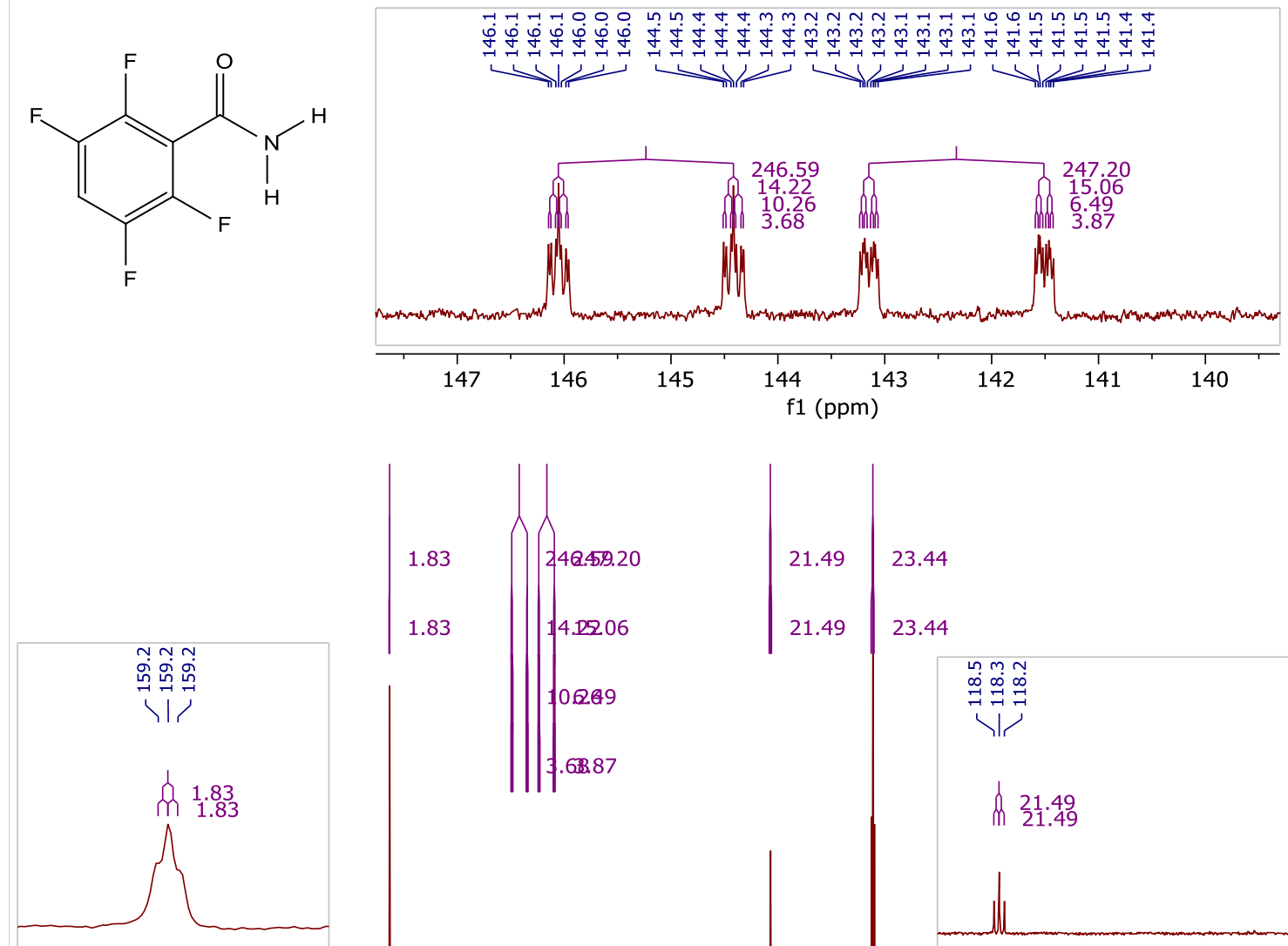

$\begin{array}{llll}159.3 & 159.2 & 159.1 & 159.0\end{array}$ f1 (ppm)

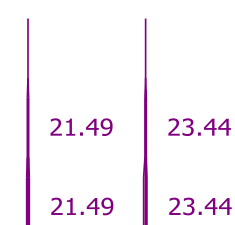

23.44
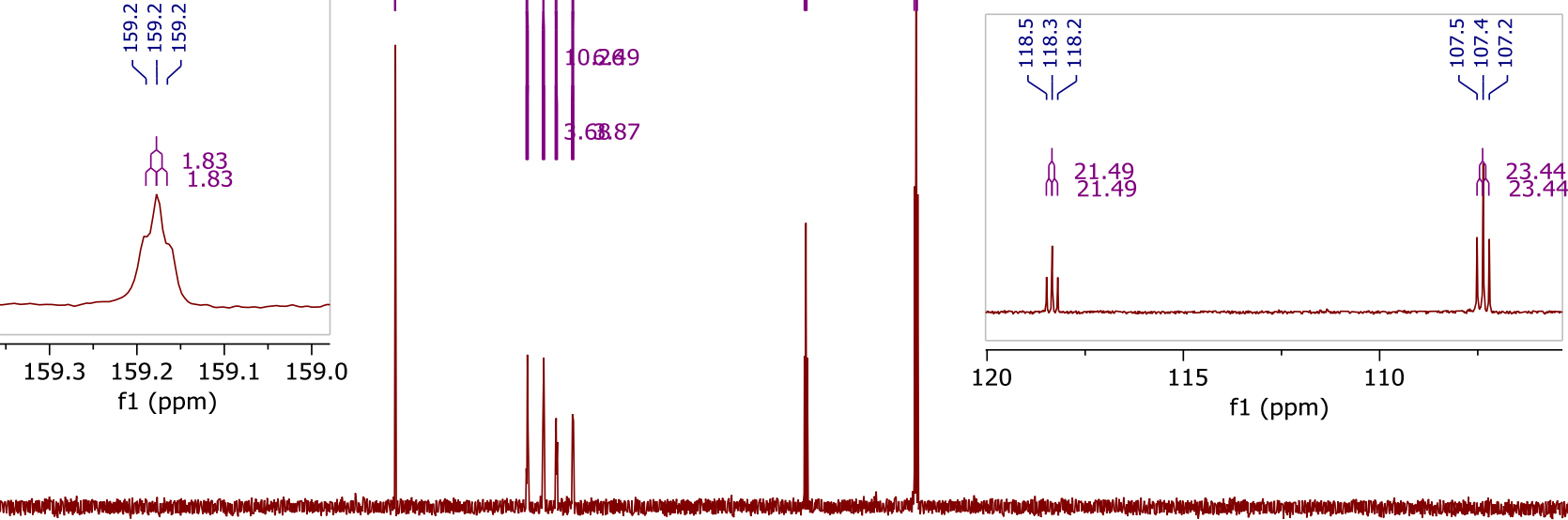

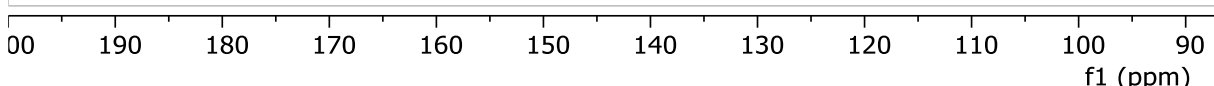



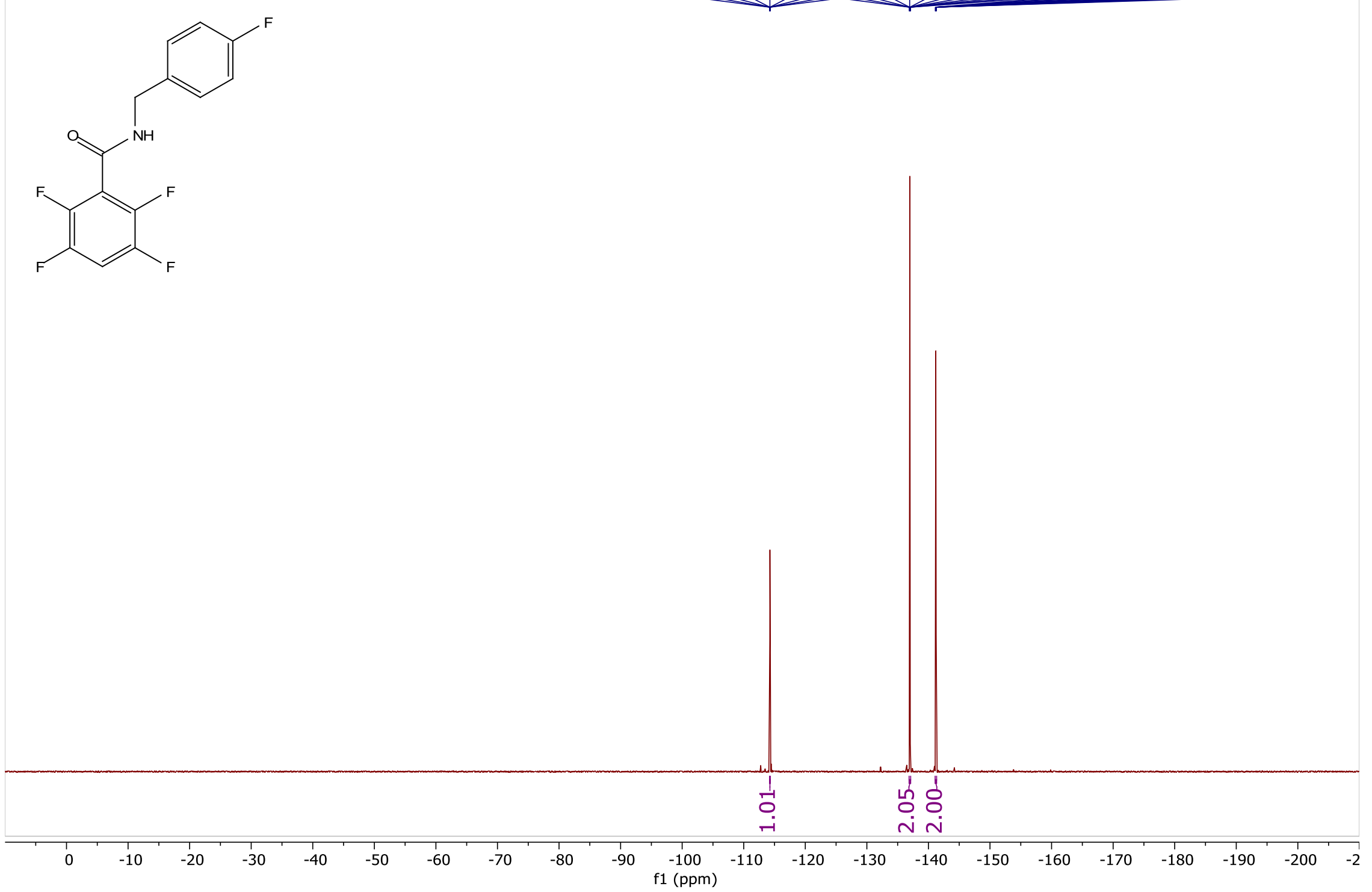
$1 \mathrm{H} N M R$ at $400.15 \mathrm{MHz}$ in $\mathrm{CDCl} 3$
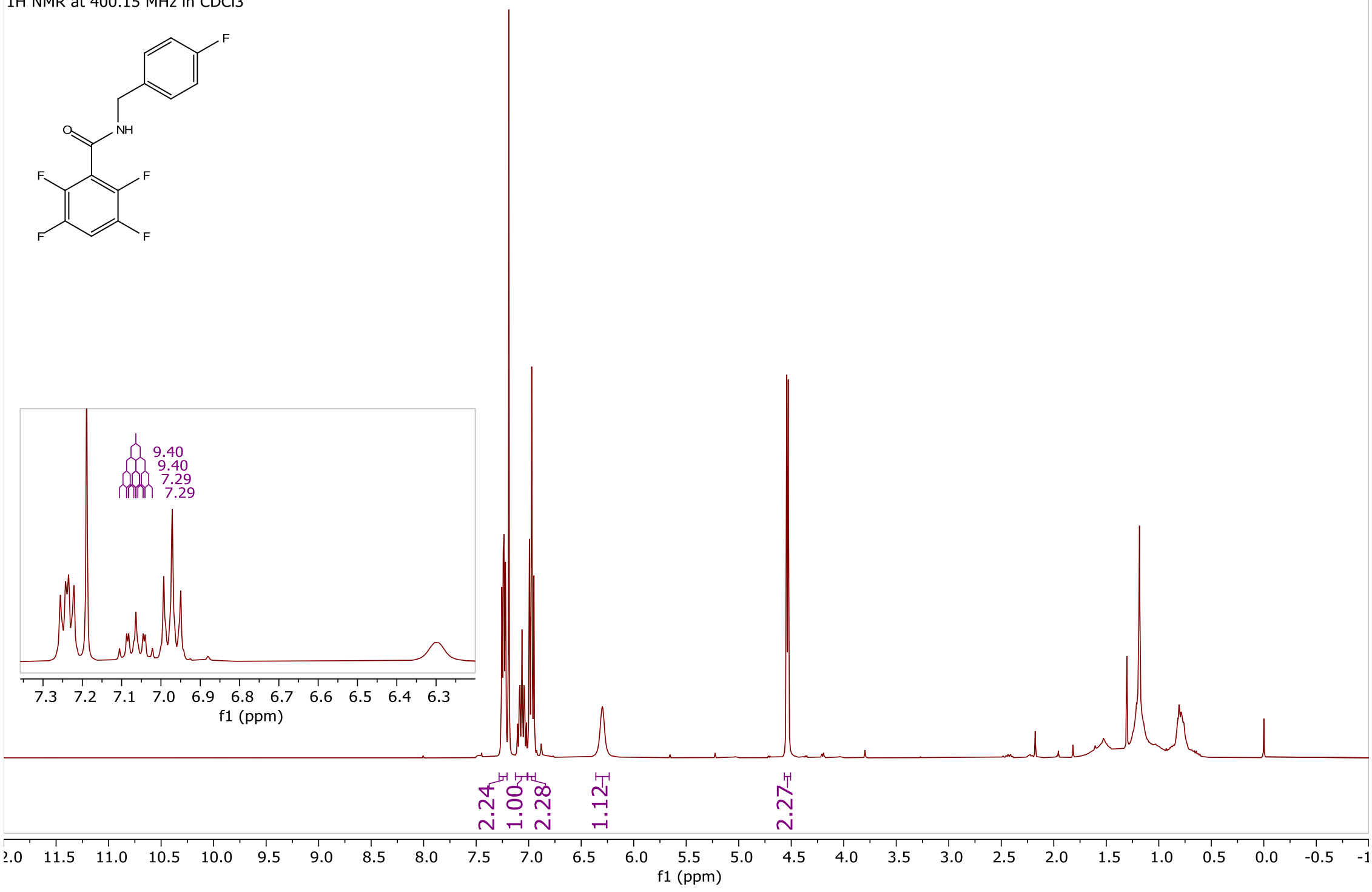
19F NMR at $376.48 \mathrm{MHz}$ in $\mathrm{CDCl} 3$

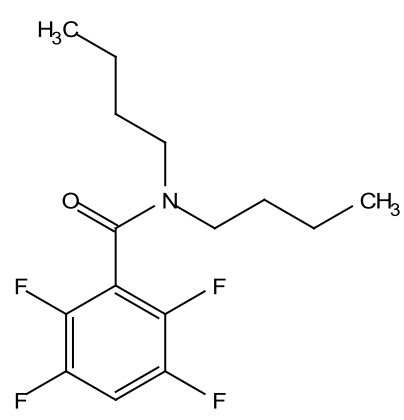

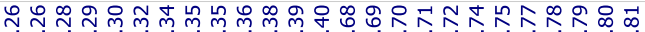

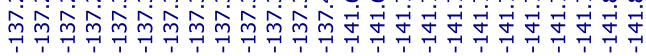

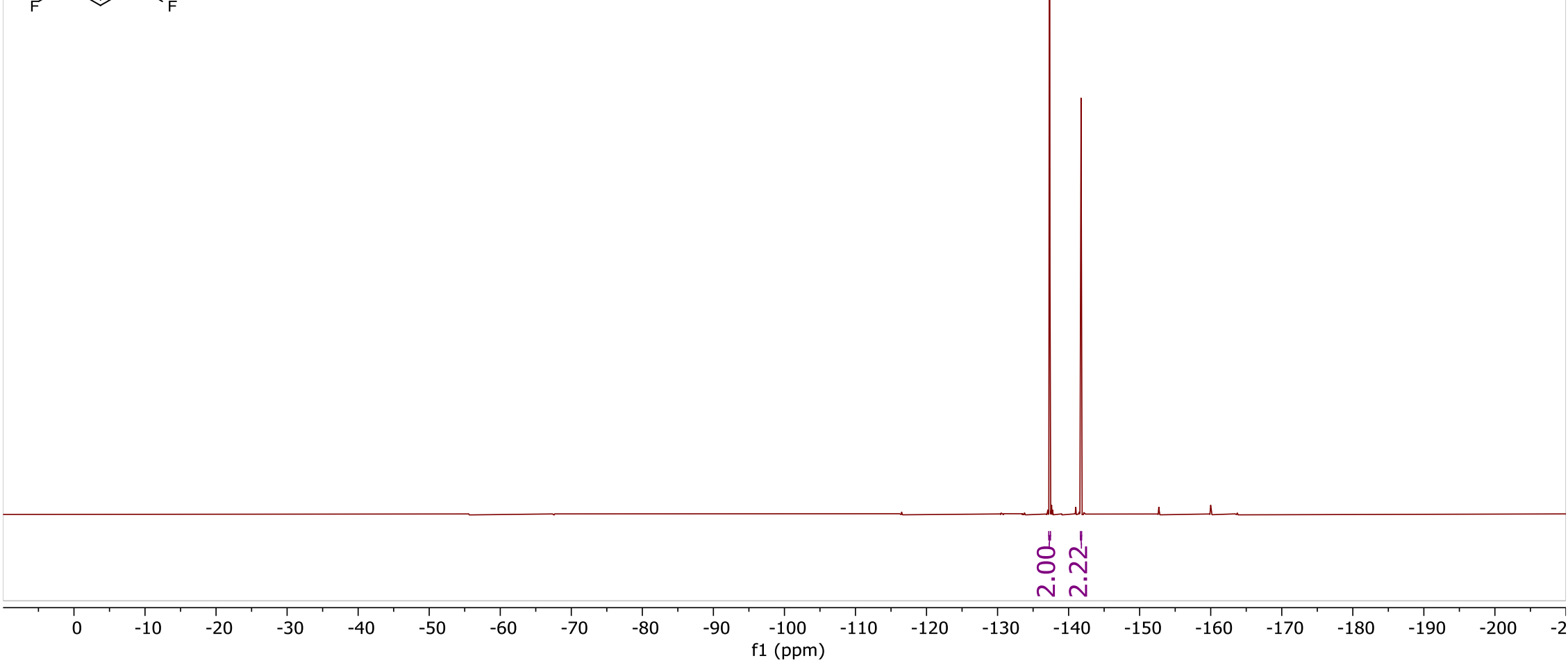


$\mathrm{H}_{3} \mathrm{C}$<smiles>CCCCN(CCCC)C(=O)c1c(F)c(F)cc(F)c1F</smiles>

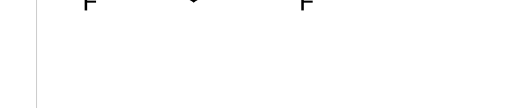

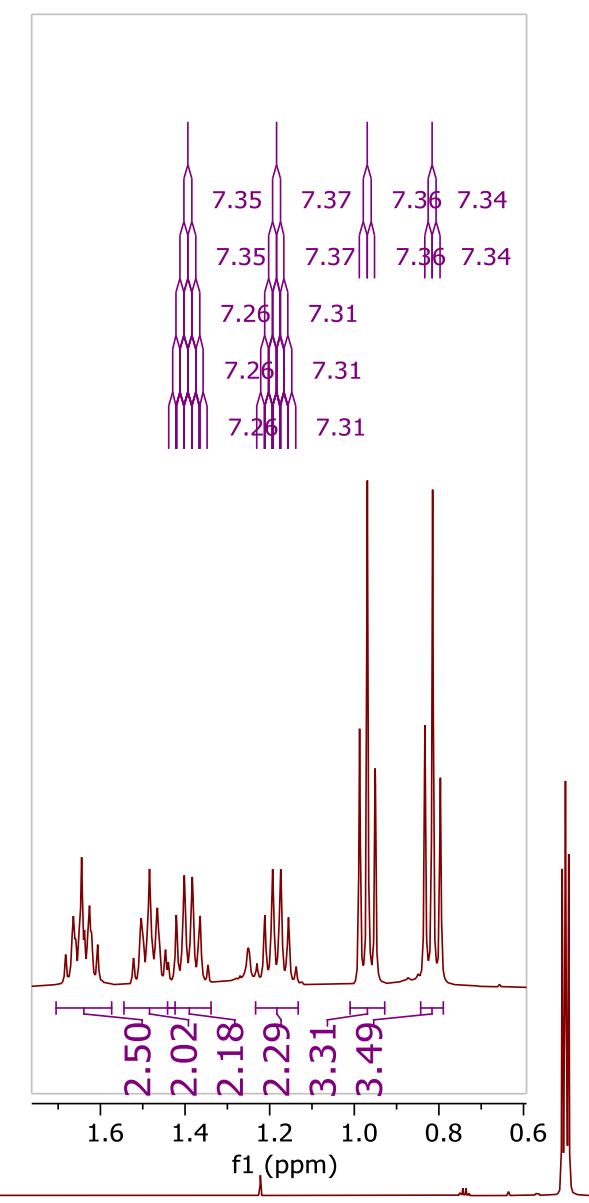

"
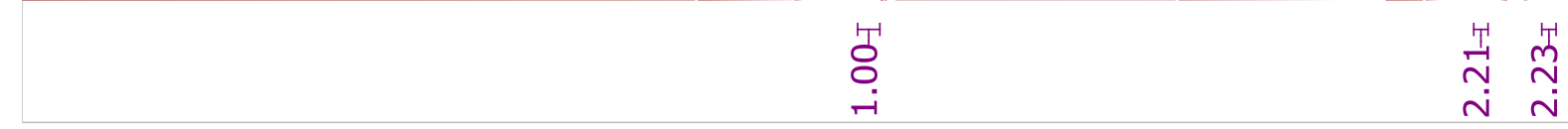

\begin{tabular}{lllllllll}
\hline 2.0 & 11.5 & 11.0 & 10.5 & 10.0 & 9.5 & 9.0 & 8.5 & 8.0
\end{tabular}

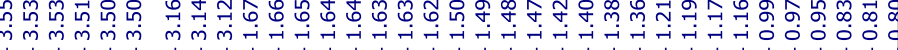
min

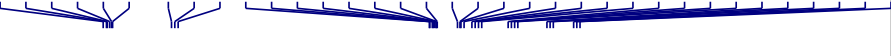


$6 b$

$19 F \mathrm{NMR}$ at $376.48 \mathrm{MHz}$ in DMSO

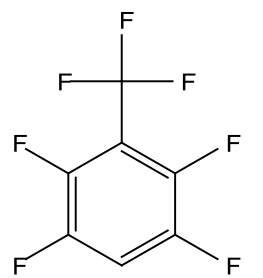

500 microliter aliquot of $5 \mathrm{~mL}$ total volume

fluorobenzene peak normalized to 213 micromoles

$(10)((129.5+87.49+88.80) / 7) / 466=94 \%$ yield

129.50

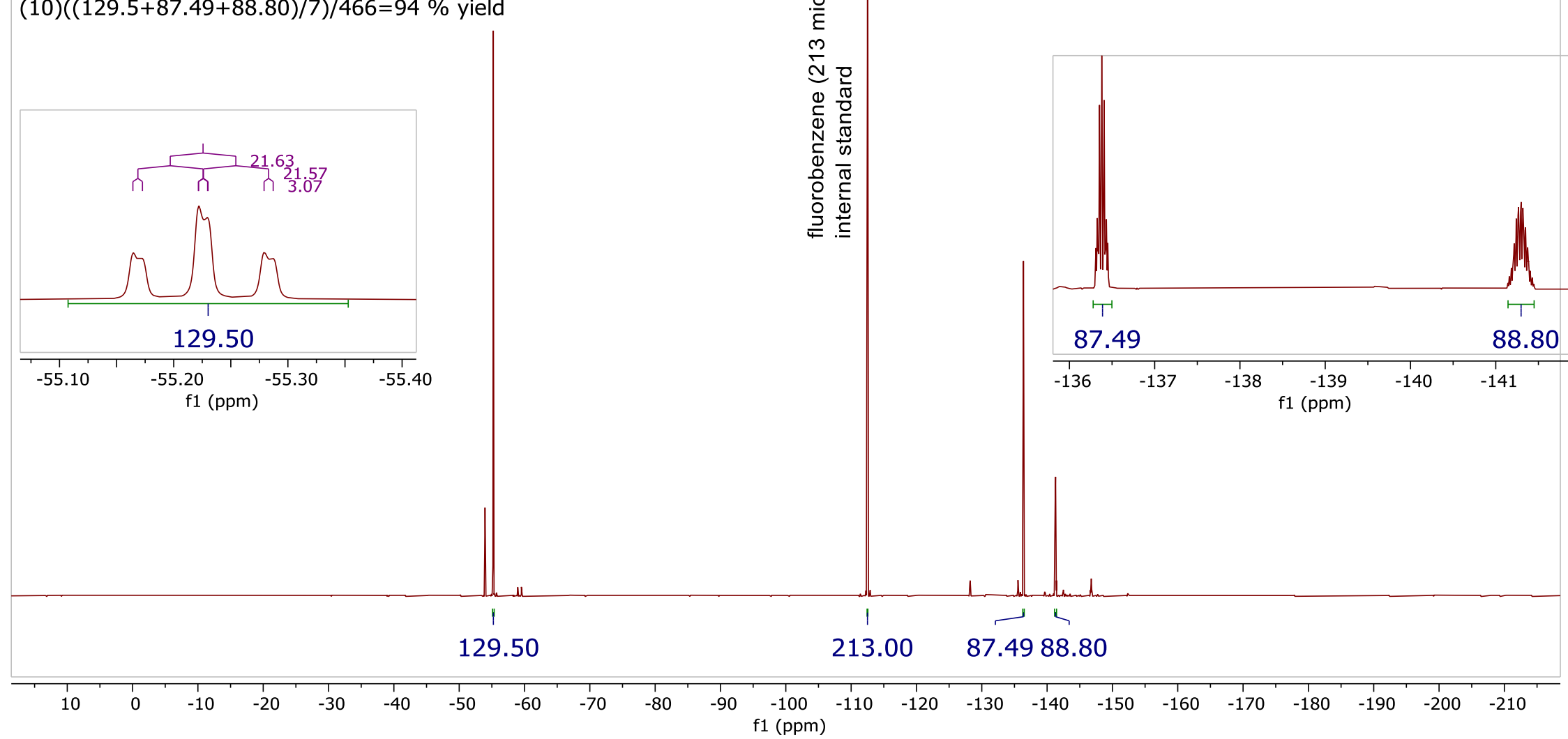

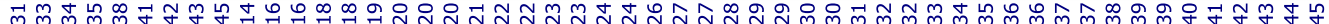

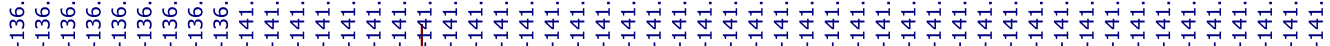
ถุำน 4 
$7 b$

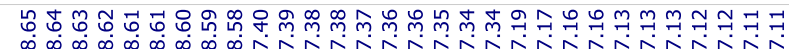

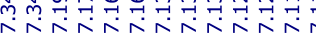

$1 \mathrm{H} N M R$ at $400.15 \mathrm{MHz}$ in DMSO

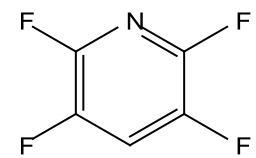

500 microliter aliquot from $5 \mathrm{~mL}$ total crude reaction with 213 micromole fluorobenzene internal standard

$54.22 \times 10 / 592=92 \%$ yield
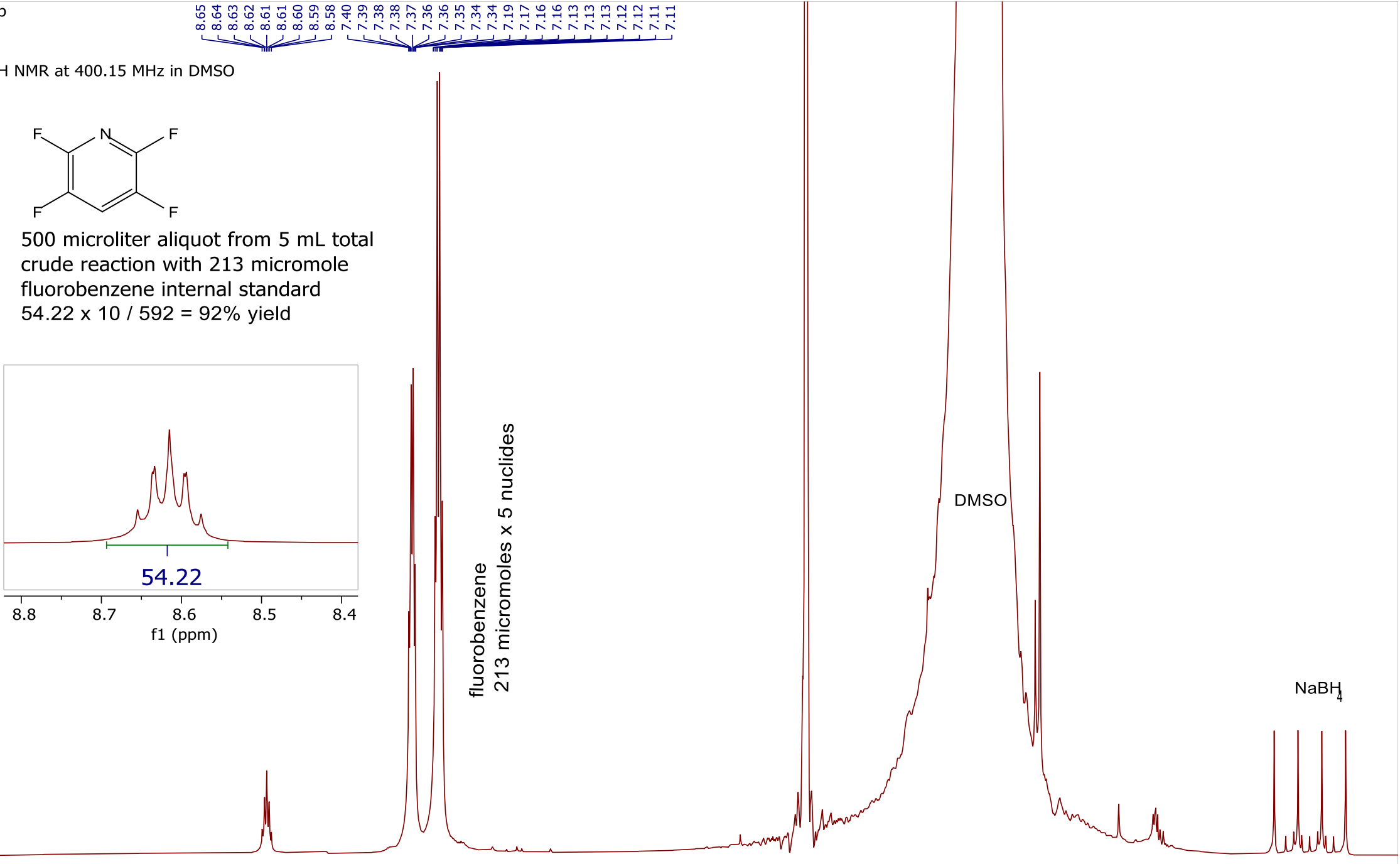

54.22

1065.00

\begin{tabular}{lllllll}
\hline 1.0 & 10.5 & 10.0 & 9.5 & 9.0 & 8.5 & 8.0
\end{tabular}

$\begin{array}{ll}7.5 & 7.0\end{array}$

6.5

6.0

$5.5 \quad 5.0$

$\begin{array}{ll}4.0 & 3.5\end{array}$

$3.0 \quad 2.5$

2.0

$1.5 \quad 1.0$

0.5

$0.0 \quad-0.5 \quad-1$ 
$8 \mathrm{~b}$

$19 F \mathrm{NMR}$ at $563.61 \mathrm{MHz}$ in $\mathrm{CDCl} 3$

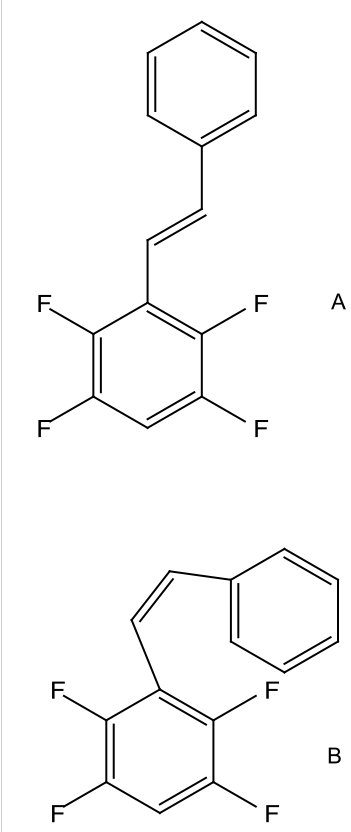

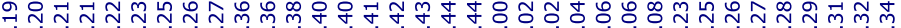

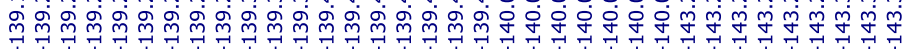

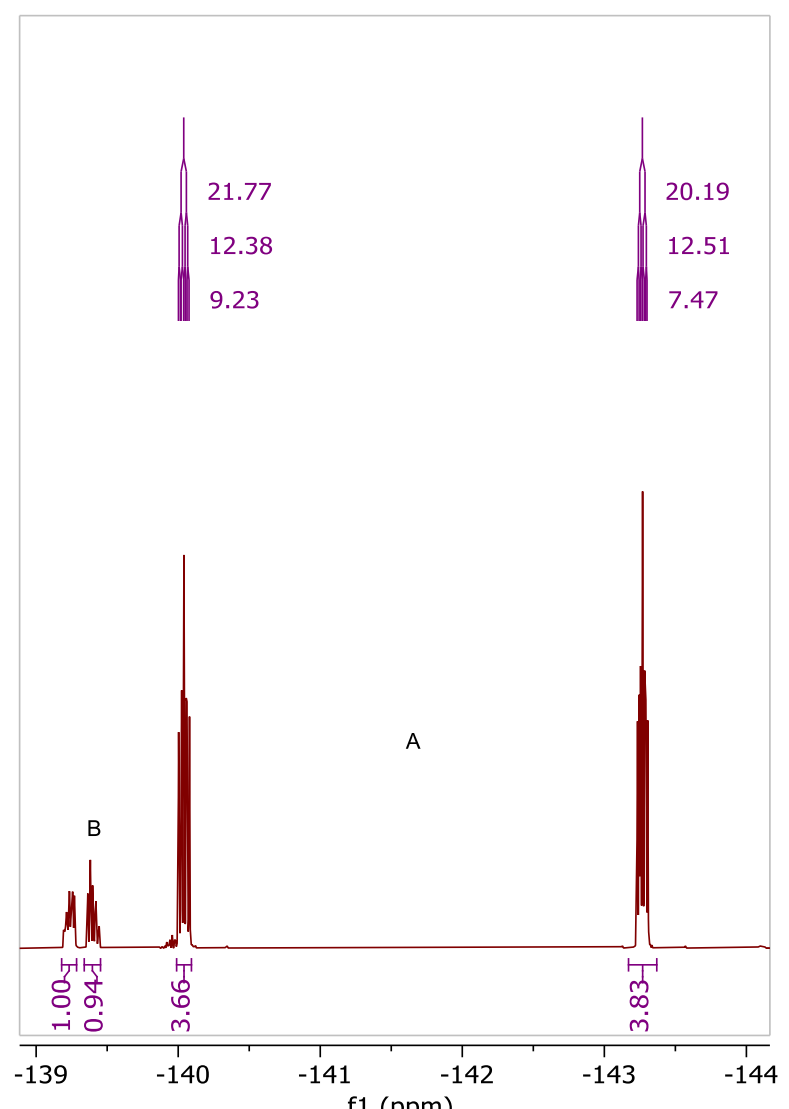

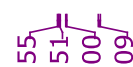

\begin{tabular}{|c|c|c|c|c|c|c|c|c|c|c|c|c|c|c|c|c|c|c|c|c|c|}
\hline & 1 & $\begin{array}{r}10 \\
-10\end{array}$ & -20 & -30 & -40 & $\frac{1}{-50}$ & $\begin{array}{c}1 \\
-60\end{array}$ & -70 & $\begin{array}{l}1 \\
-80\end{array}$ & 190 & 1 & 110 & 120 & 1 & -140 & -150 & -160 & -170 & -180 & -190 & $\begin{array}{ll}-200 & -2\end{array}$ \\
\hline
\end{tabular}




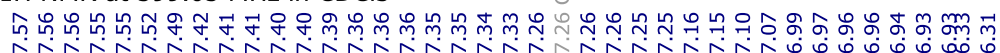
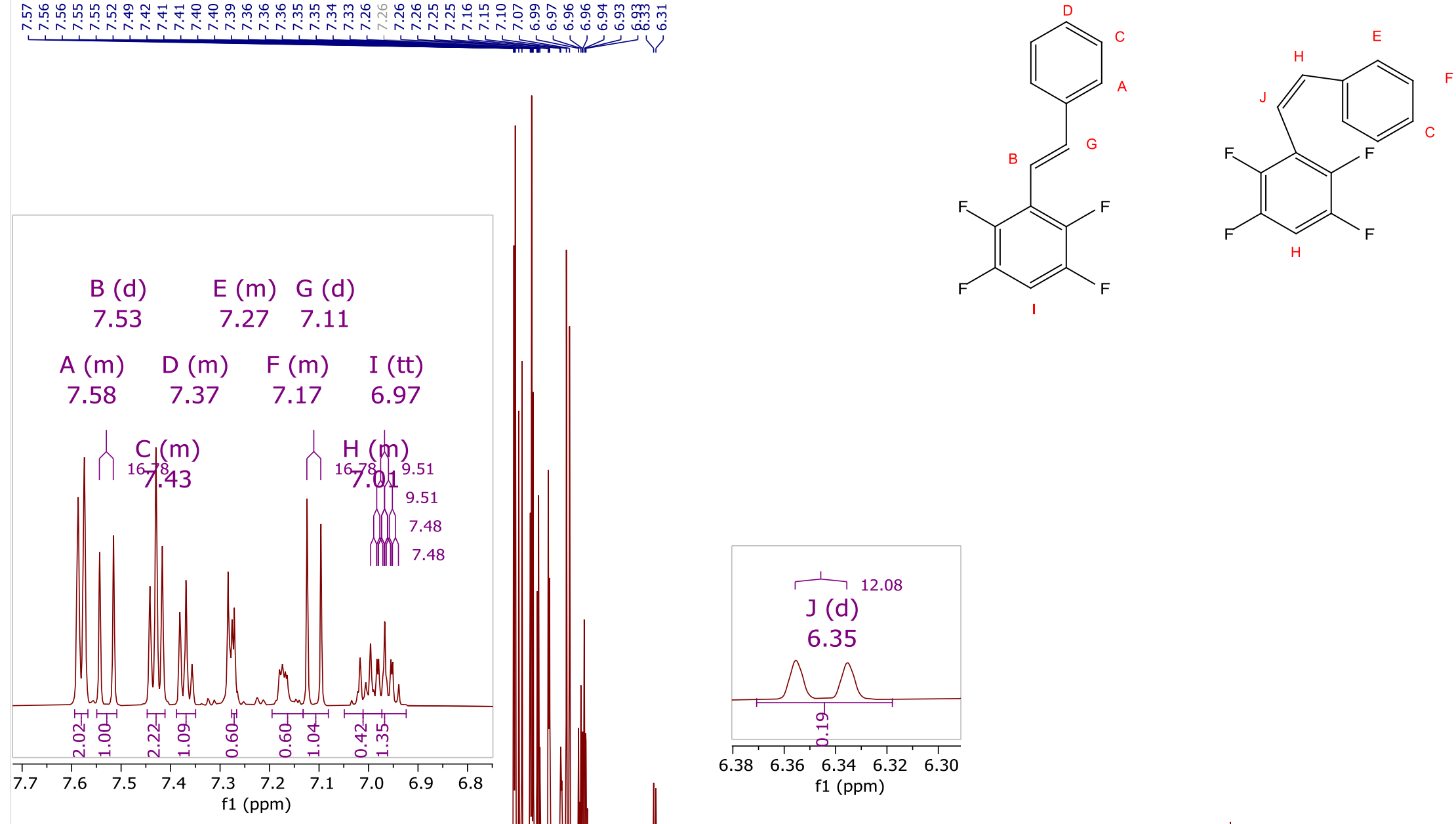

7.53

$\mathrm{A}(\mathrm{m}) \quad \mathrm{D}(\mathrm{m}) \quad \mathrm{F}(\mathrm{m}) \quad \mathrm{I}(\mathrm{tt})$

.01 9.51

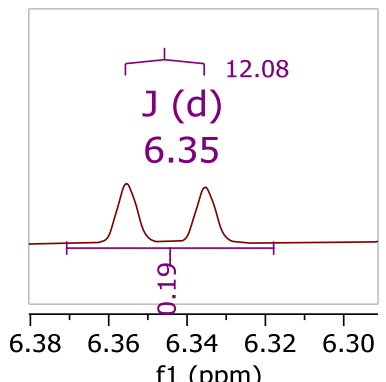

f1 (ppm)

तo

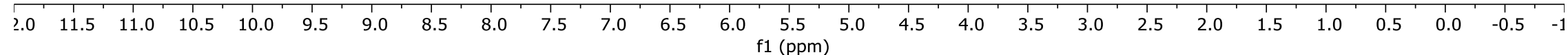


$9 \mathrm{~b}$

$19 \mathrm{~F} \mathrm{NMR}$ at $376.48 \mathrm{MHz}$ in $\mathrm{CDCl} 3$

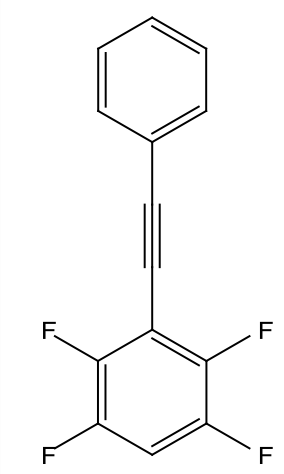

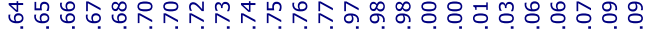

mim

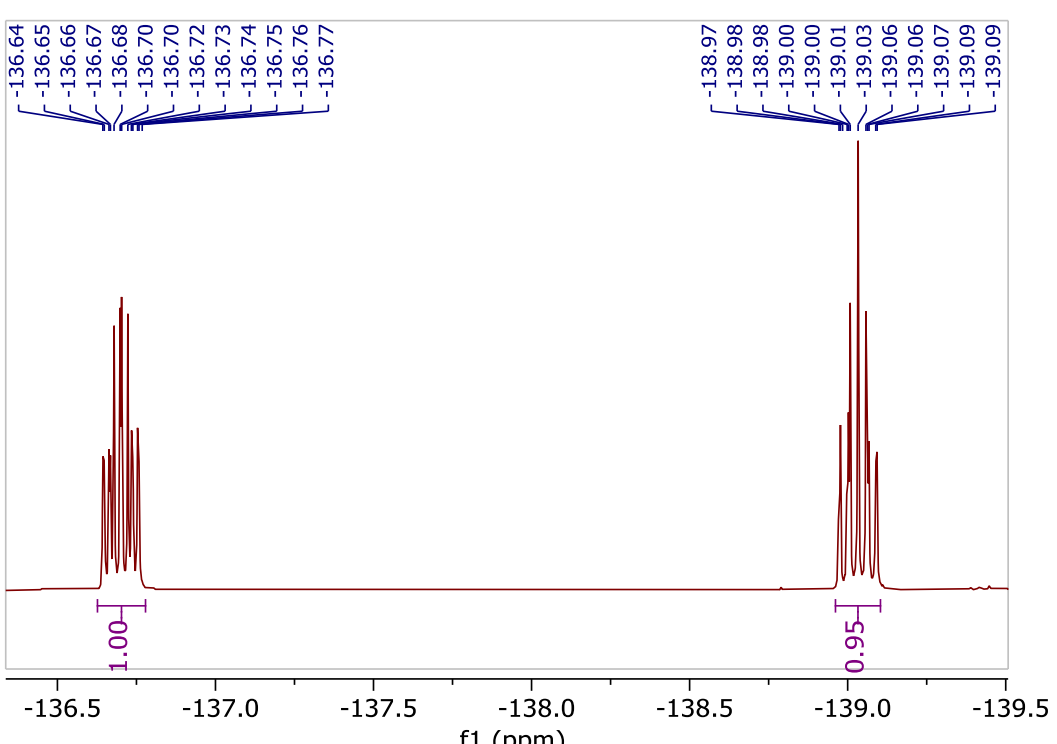

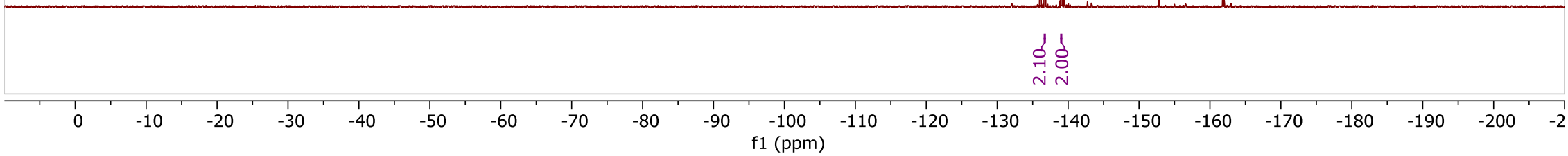




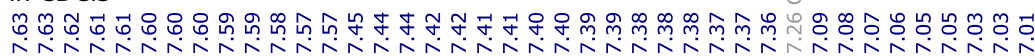
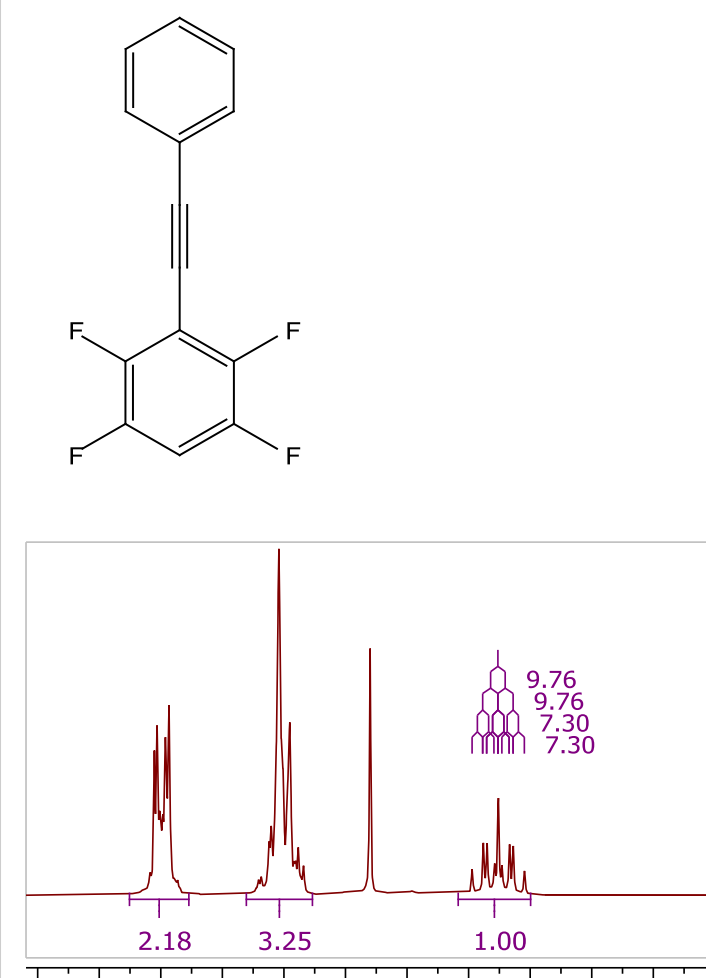

$\begin{array}{llllllllllllll}7.8 & 7.7 & 7.6 & 7.5 & 7.4 & 7.3 & 7.2 & 7.1 & 7.0 & 6.9 & 6.8\end{array}$ f1 (ppm)

DME (n)

然客足

\begin{tabular}{lllllllllll}
\hline .0 & 11.5 & 11.0 & 10.5 & 10.0 & 9.5 & 9.0 & 8.5 & 8.0 & 7.5 & 7.0
\end{tabular} $\begin{array}{llll}7.0 & 6.5 & 6.0 & 5.5 \\ & & & \end{array}$ $\begin{array}{llllllllllllll}5.0 & 4.5 & 4.0 & 3.5 & 3.0 & 2.5 & 2.0 & 1.5 & 1.0 & 0.5 & 0.0 & -0.5 & -1\end{array}$ 
$9 b$

$13 \mathrm{C}$ NMGR at $150.65_{\infty} \mathrm{MHz}$ in $\mathrm{CDCl}$

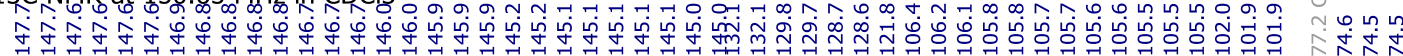

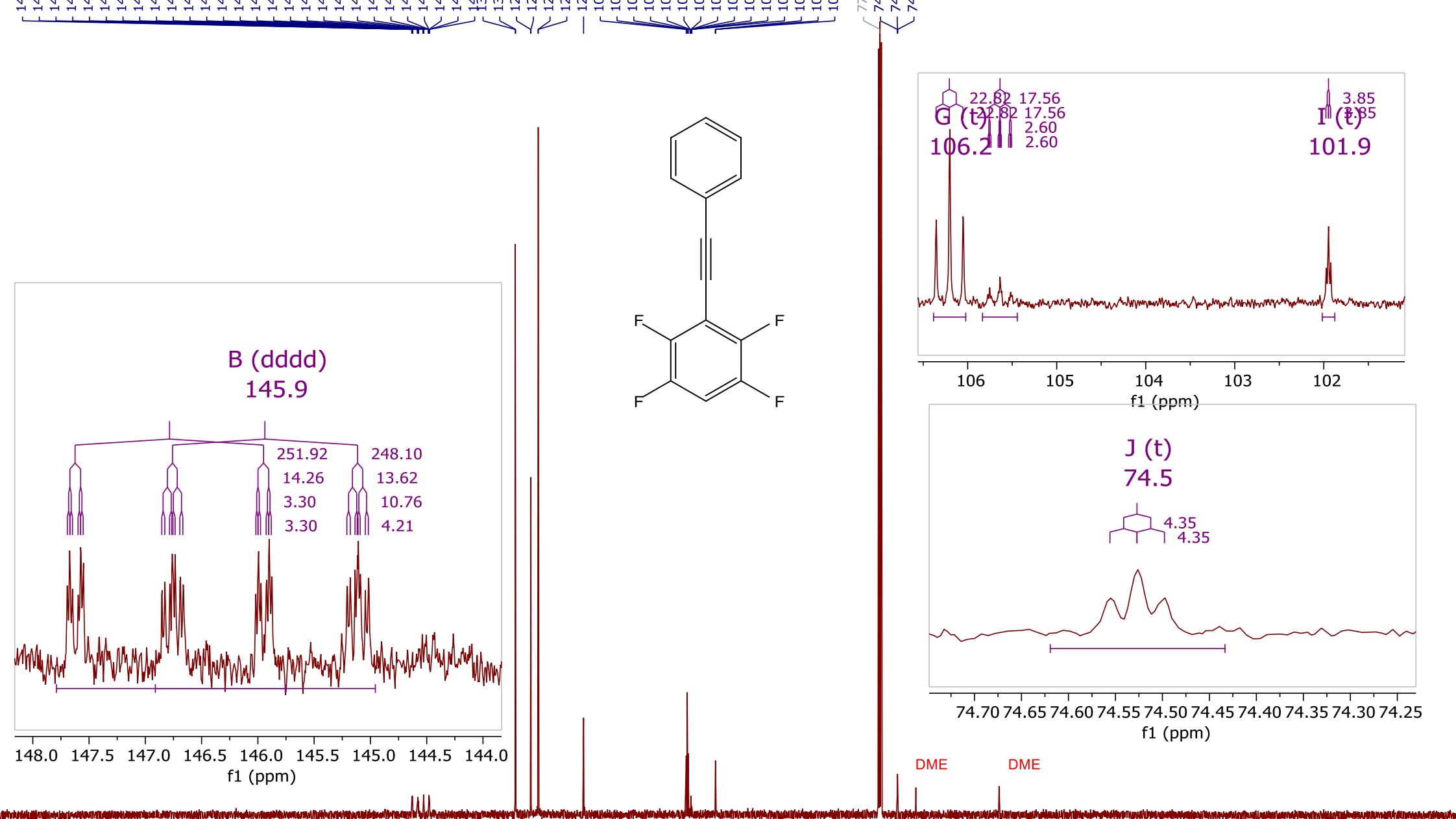

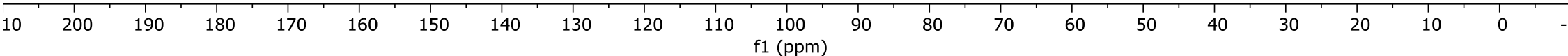


$10 \mathrm{~b}$

$19 \mathrm{~F} \mathrm{NMR}$ at $376.48 \mathrm{MHz}$ in $\mathrm{CDCl} 3$

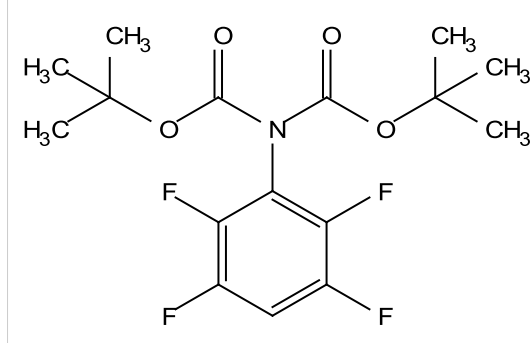

ที่

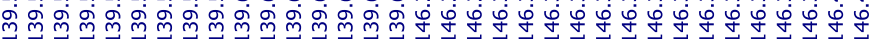

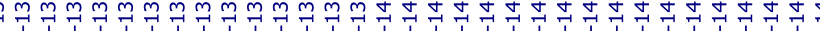

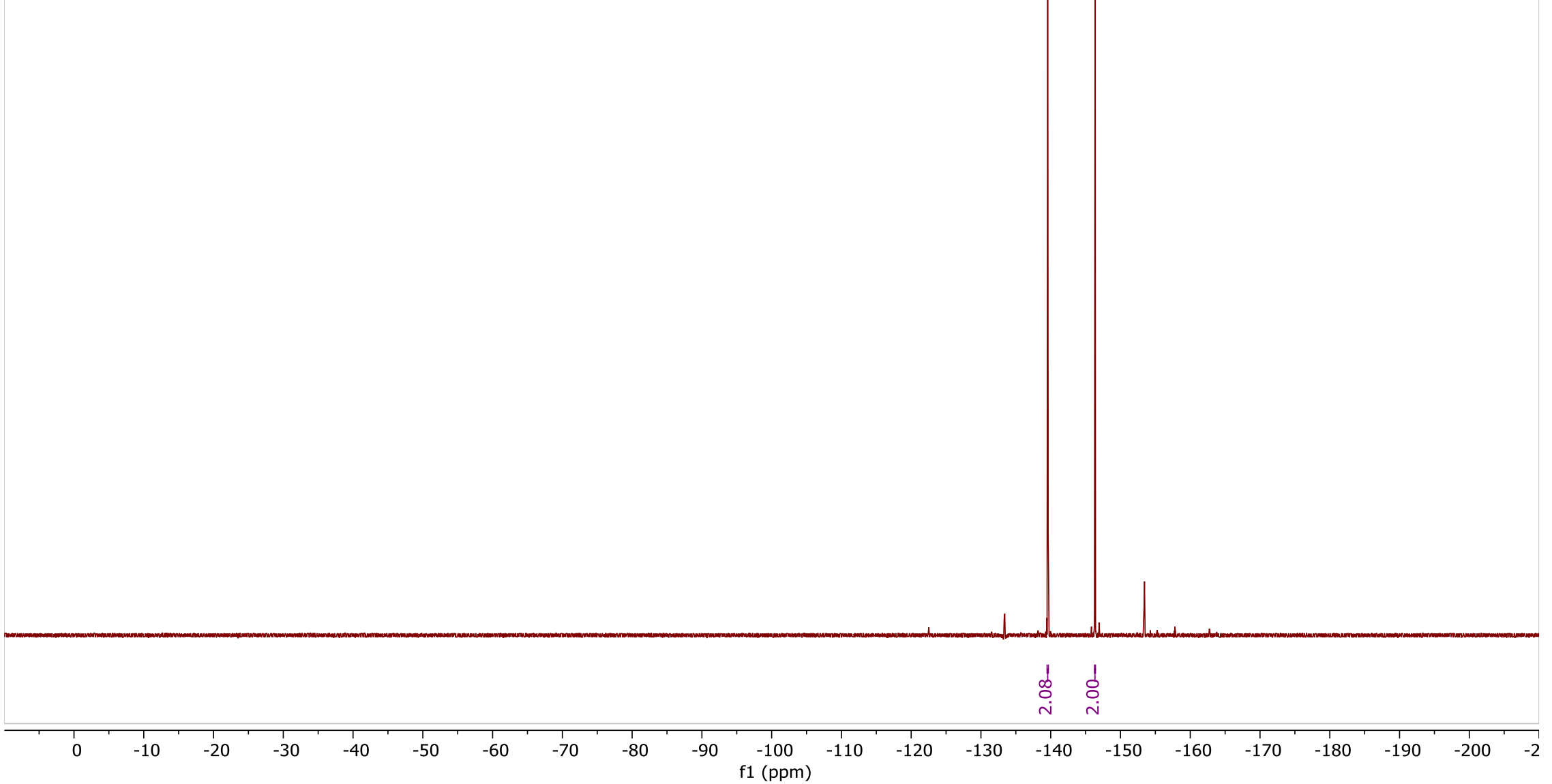


$1 \mathrm{H} \mathrm{NMR}$ at $400.15 \mathrm{MHz}$ in $\mathrm{CDCl}$

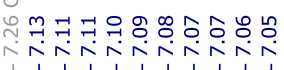
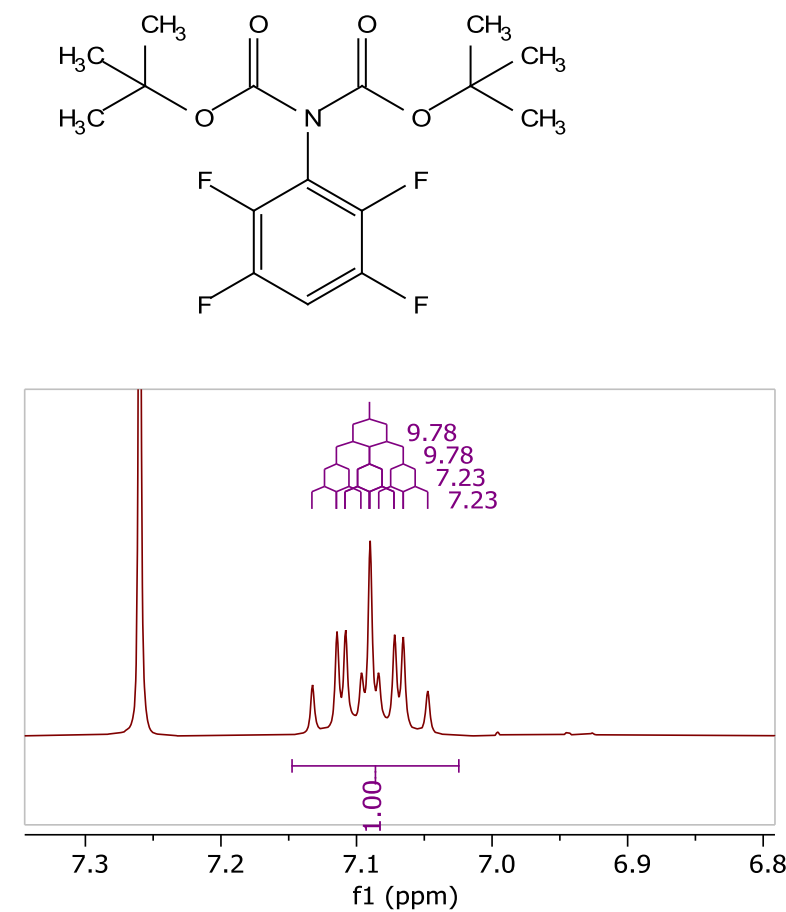

定

$+$

$\mathrm{H}_{3}$

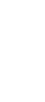


$11 \mathrm{~b}$

19F NMR at $376.48 \mathrm{MHz}$ in $\mathrm{CDCl} 3$

(c)

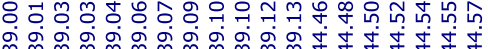

m̧ m m m m m m

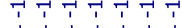

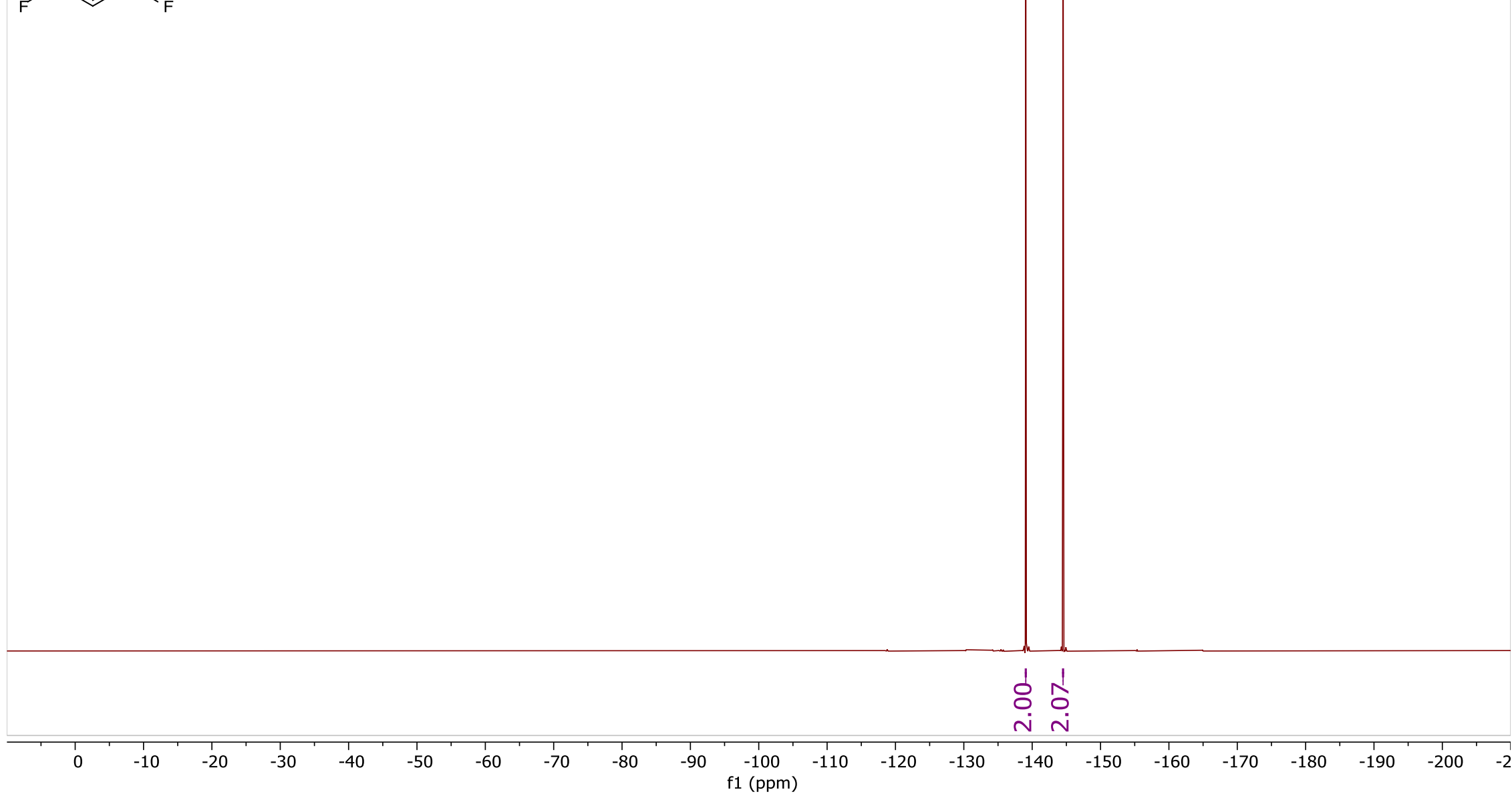




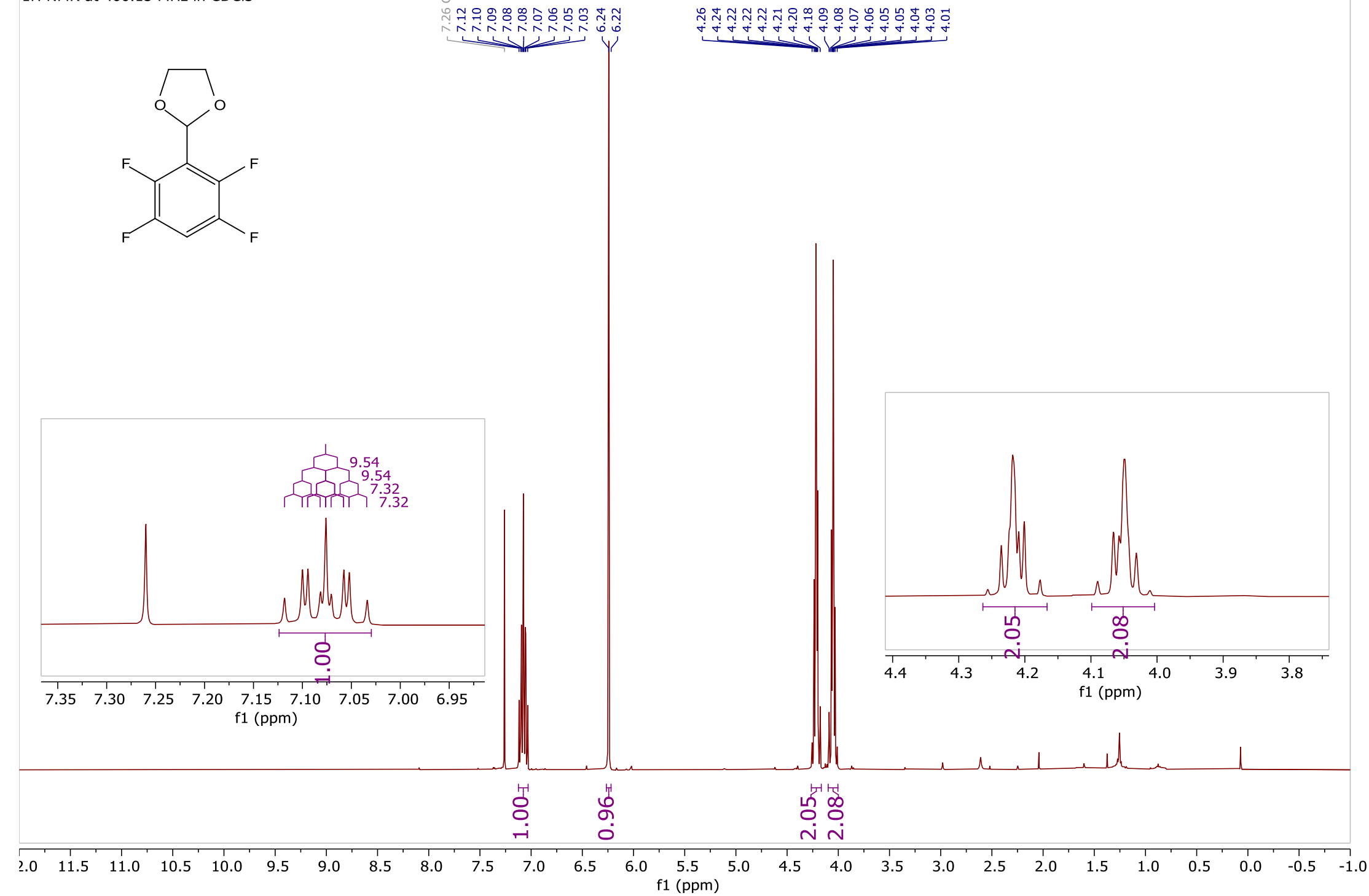




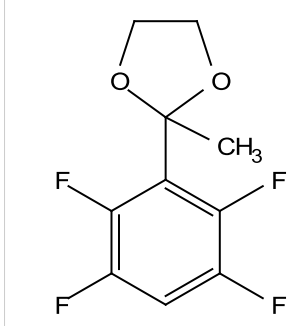

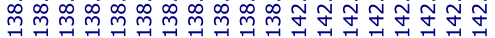
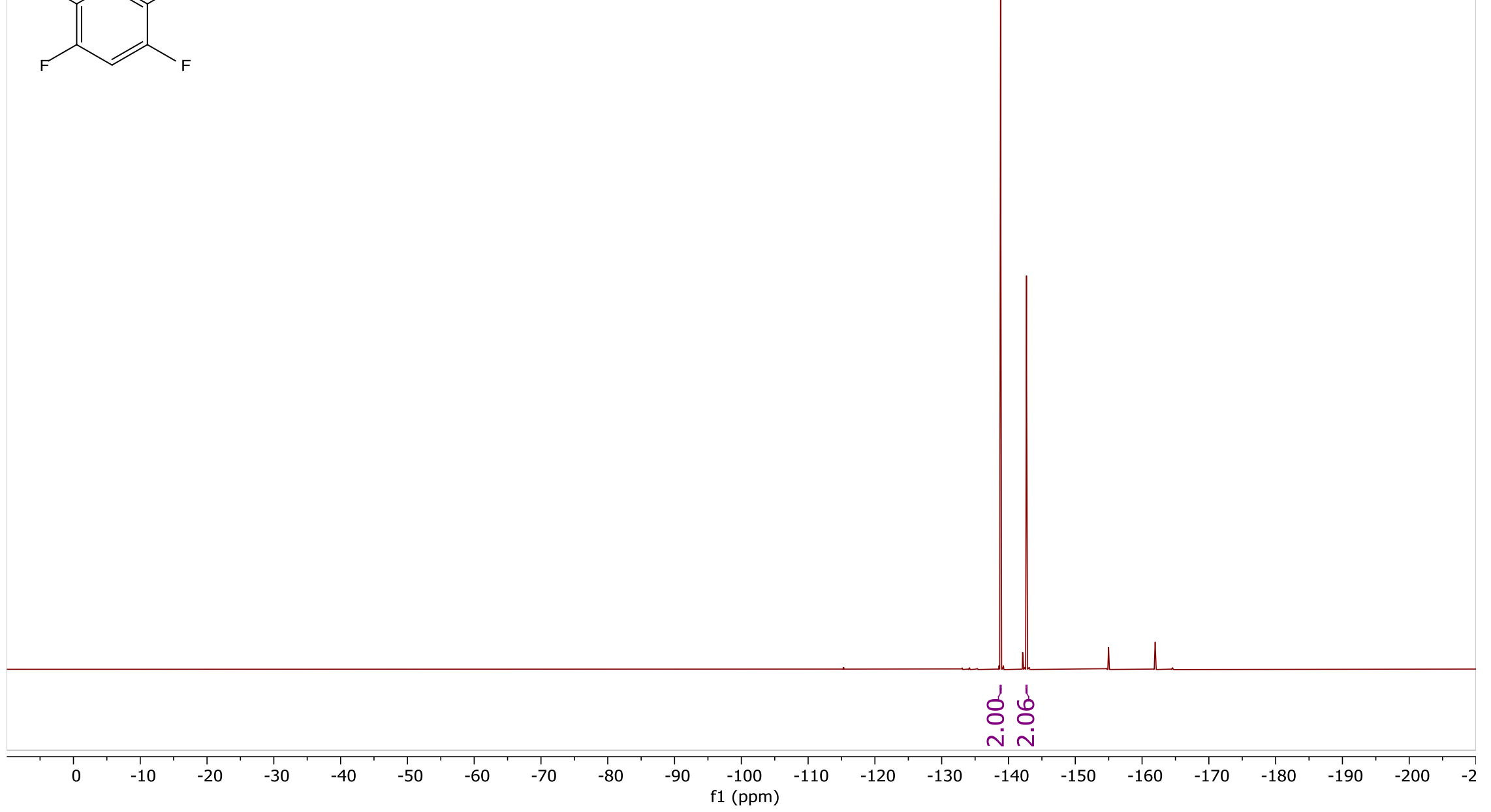


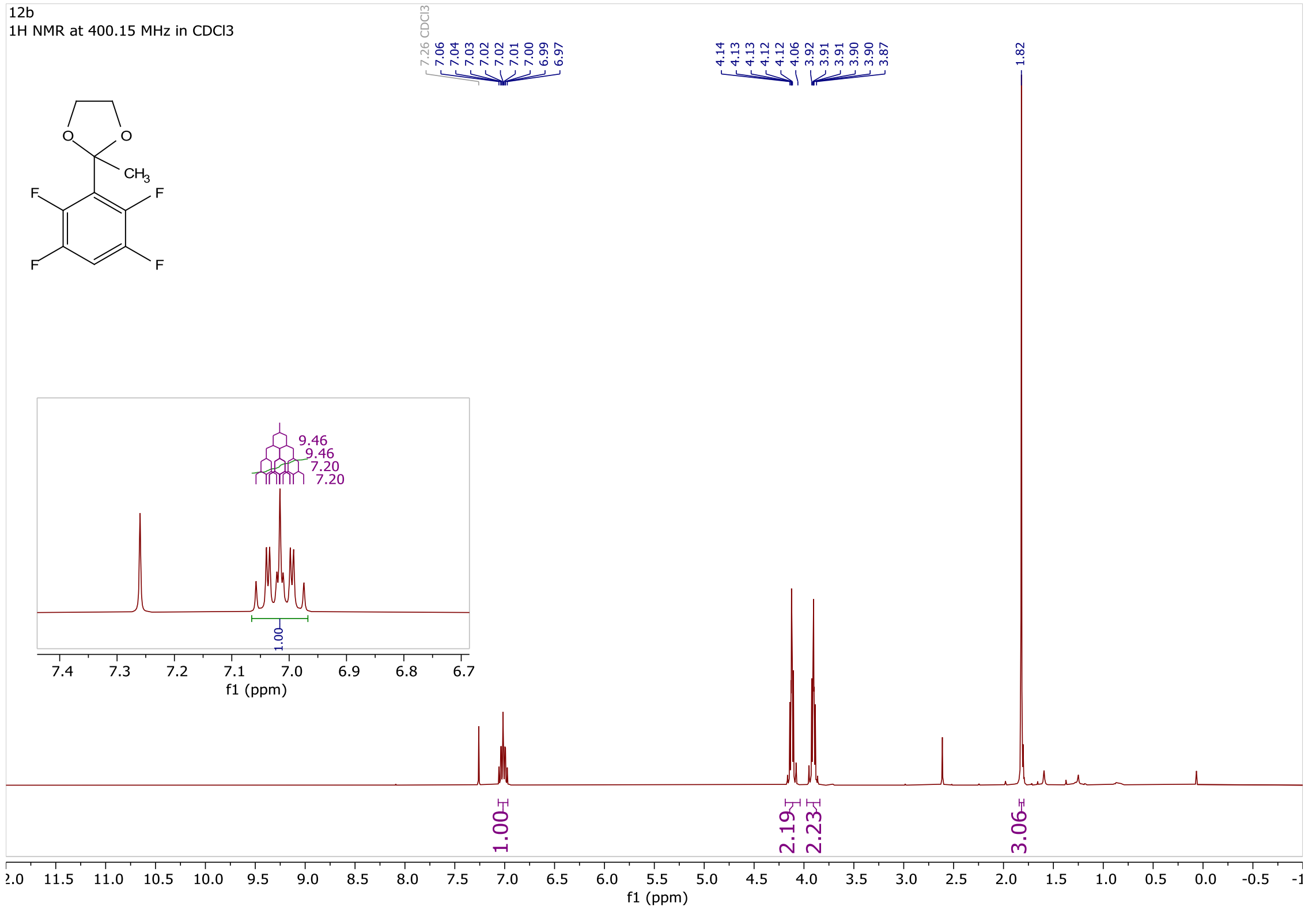




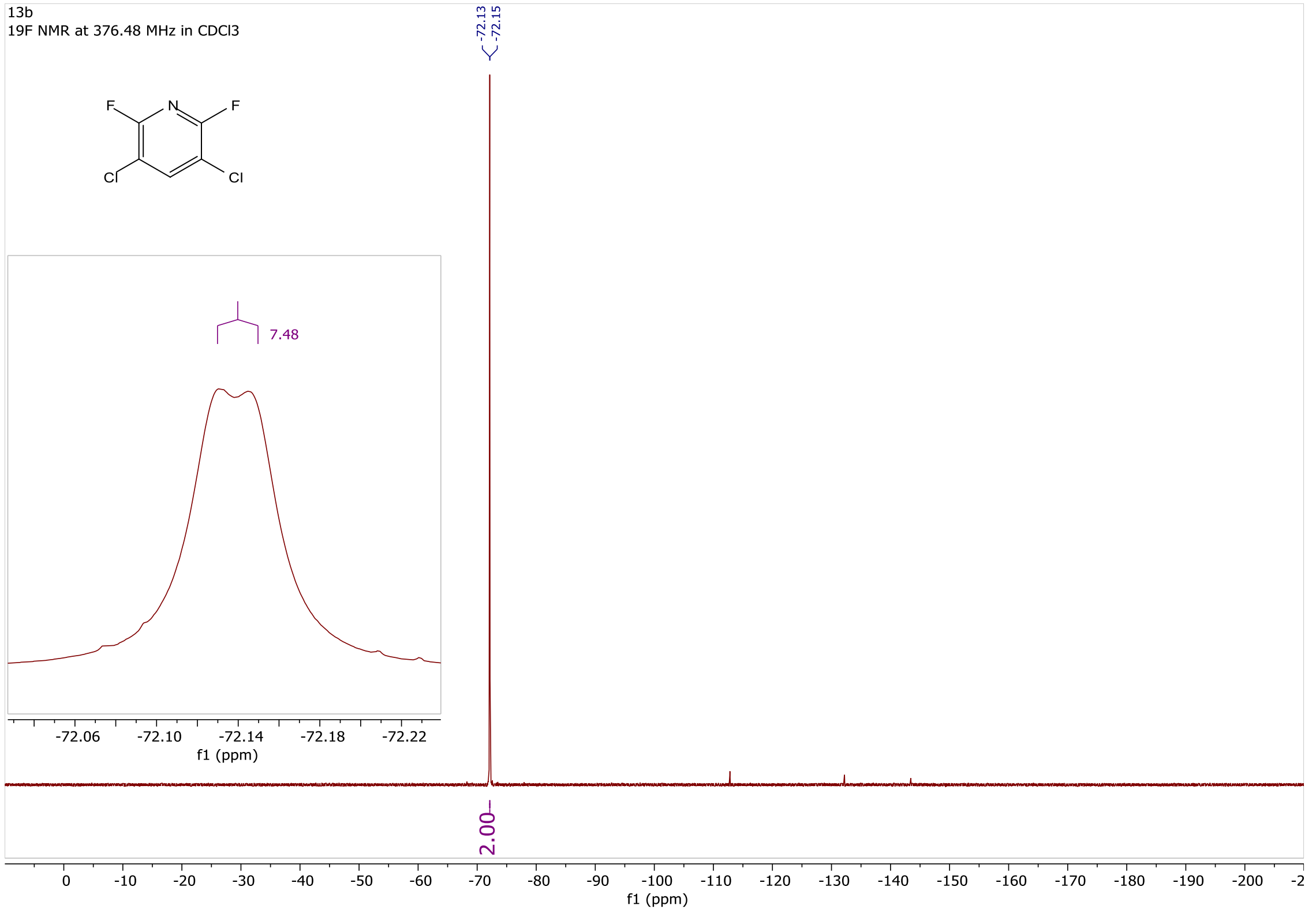


$1 \mathrm{H} \mathrm{NMR}$ at $400.15 \mathrm{MHz}$ in $\mathrm{CDCl} 3$

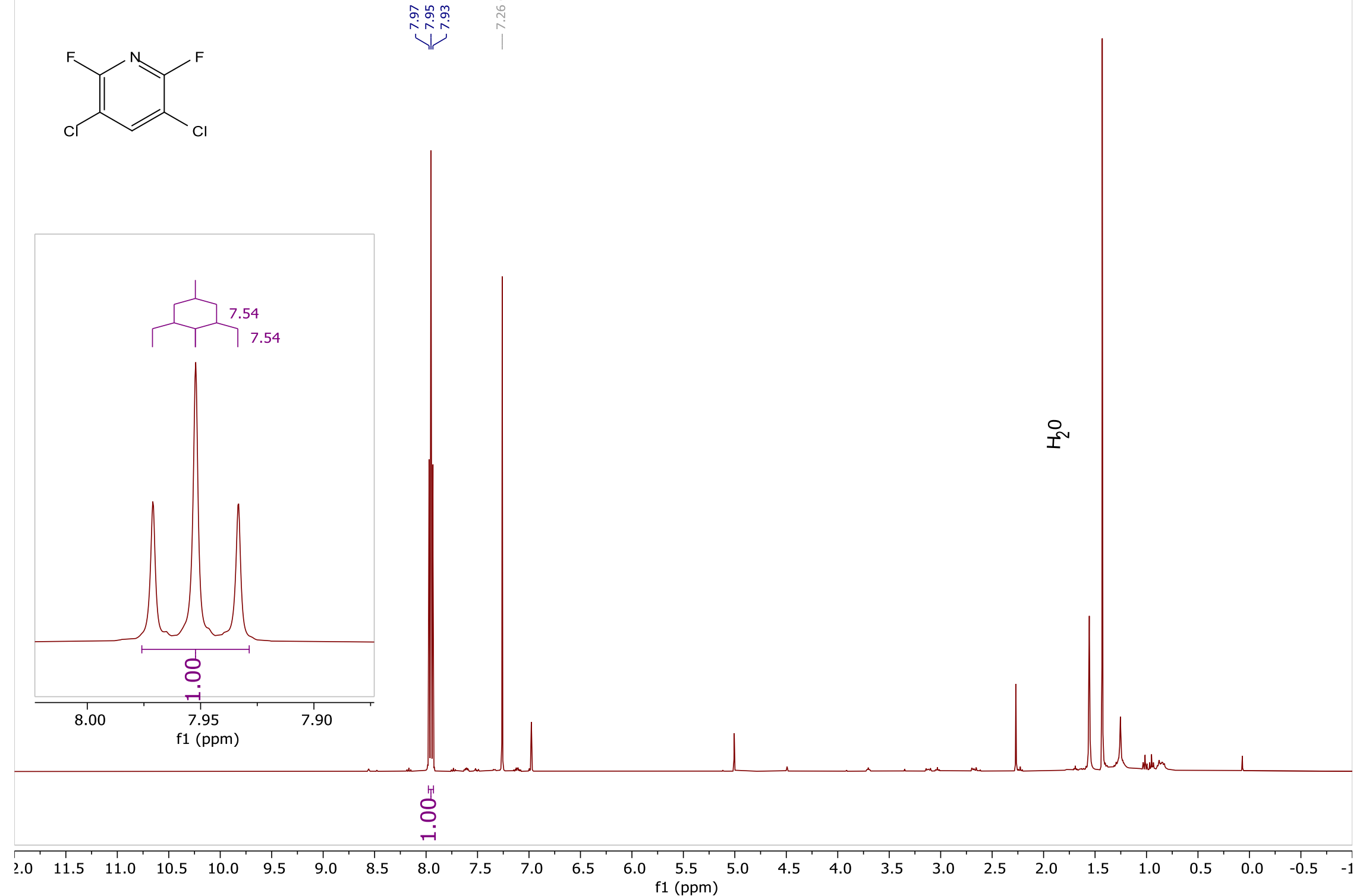


$14 \mathrm{~b}$

19F NMR at $376.48 \mathrm{MHz}$ in $\mathrm{CDCl} 3$

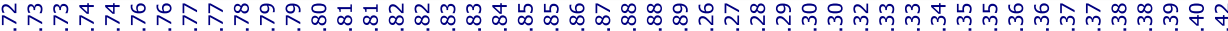

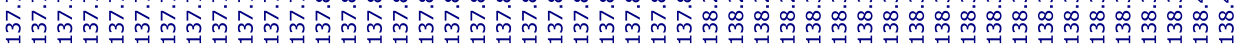

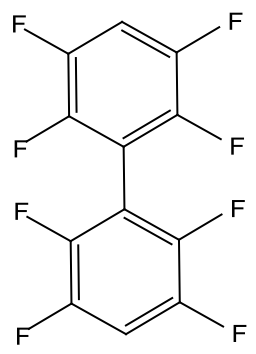

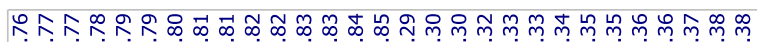

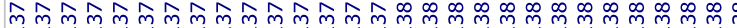

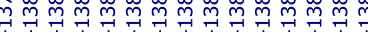

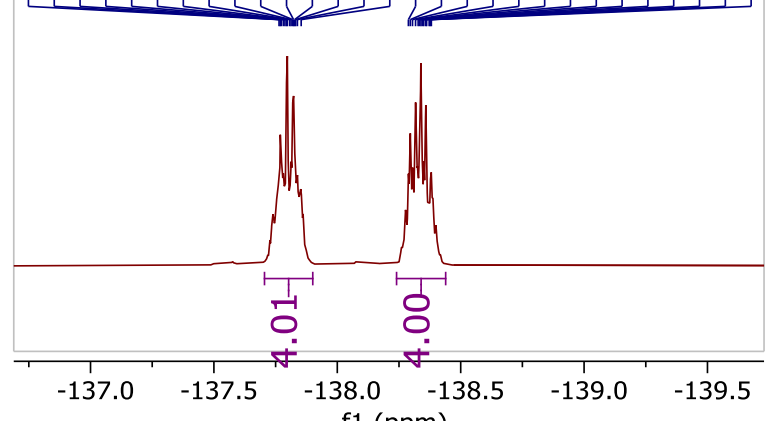

f1 (ppm)

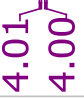

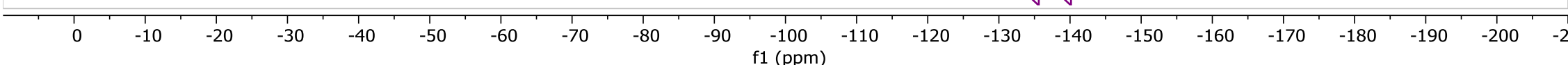


$1 \mathrm{H} \mathrm{NMR}$ at $400.15 \mathrm{MHz}$ in $\mathrm{CDCl}$

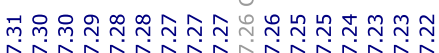
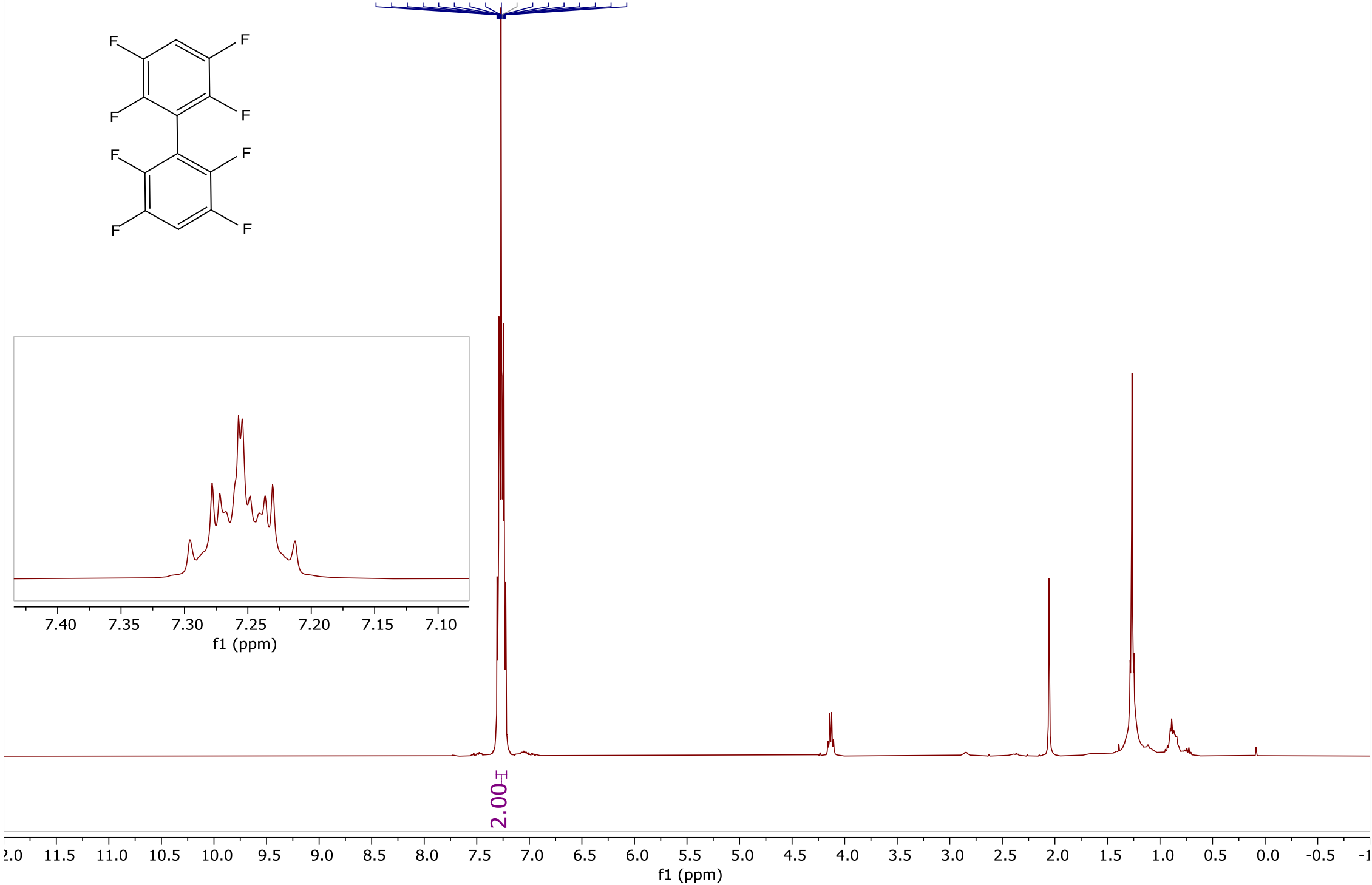


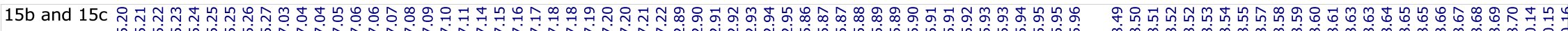

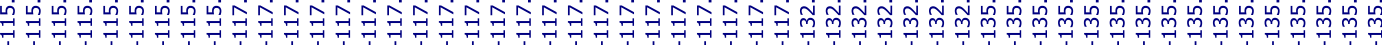

$19 F \mathrm{NMR}$ at $563.61 \mathrm{MHz}$ in $\mathrm{CDCl} 3$

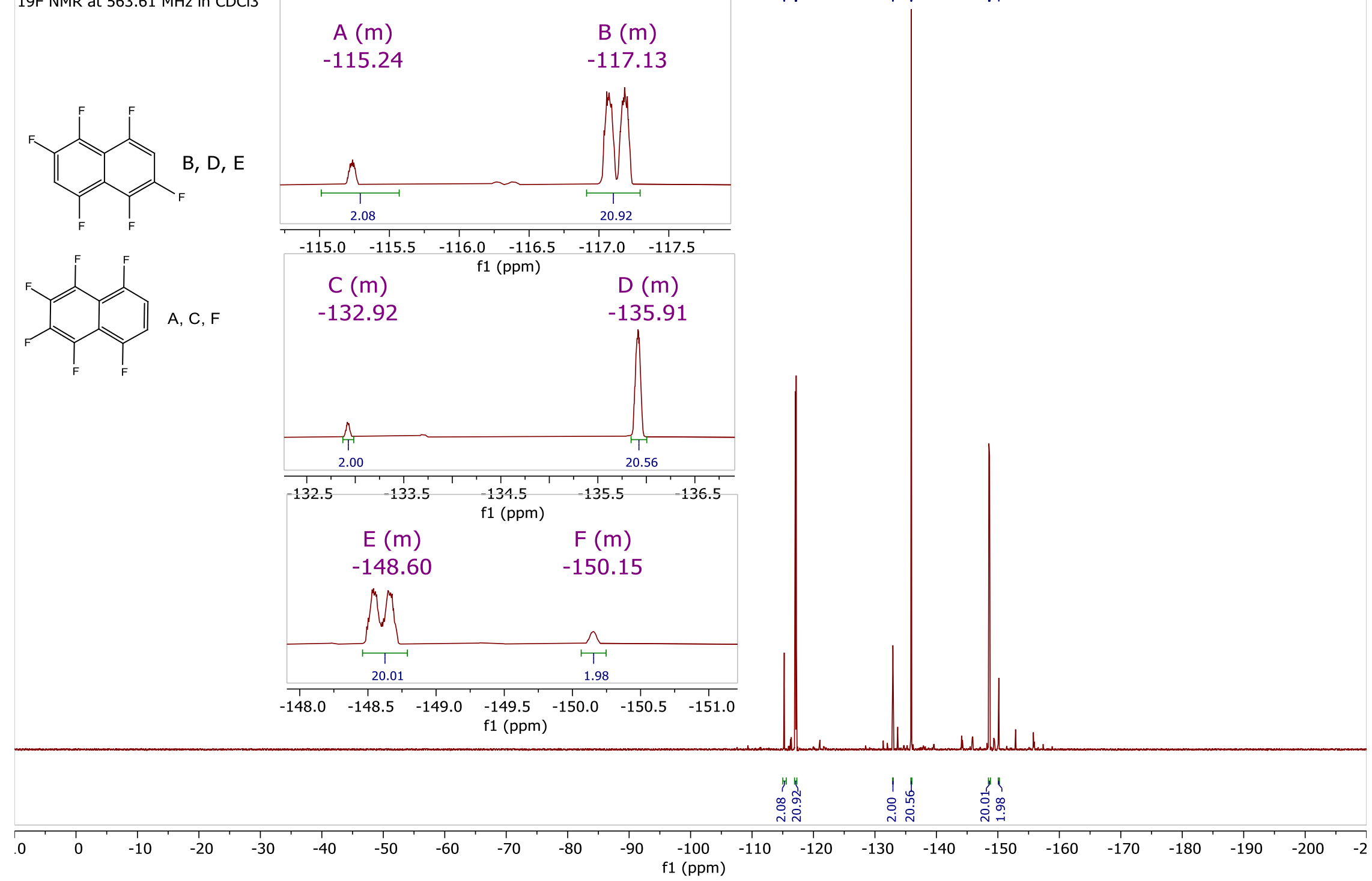


$15 b$ and $15 c$

$1 \mathrm{H} \mathrm{NMR}$ at $599.05 \mathrm{MHz}$ in $\mathrm{CDCl} 3$

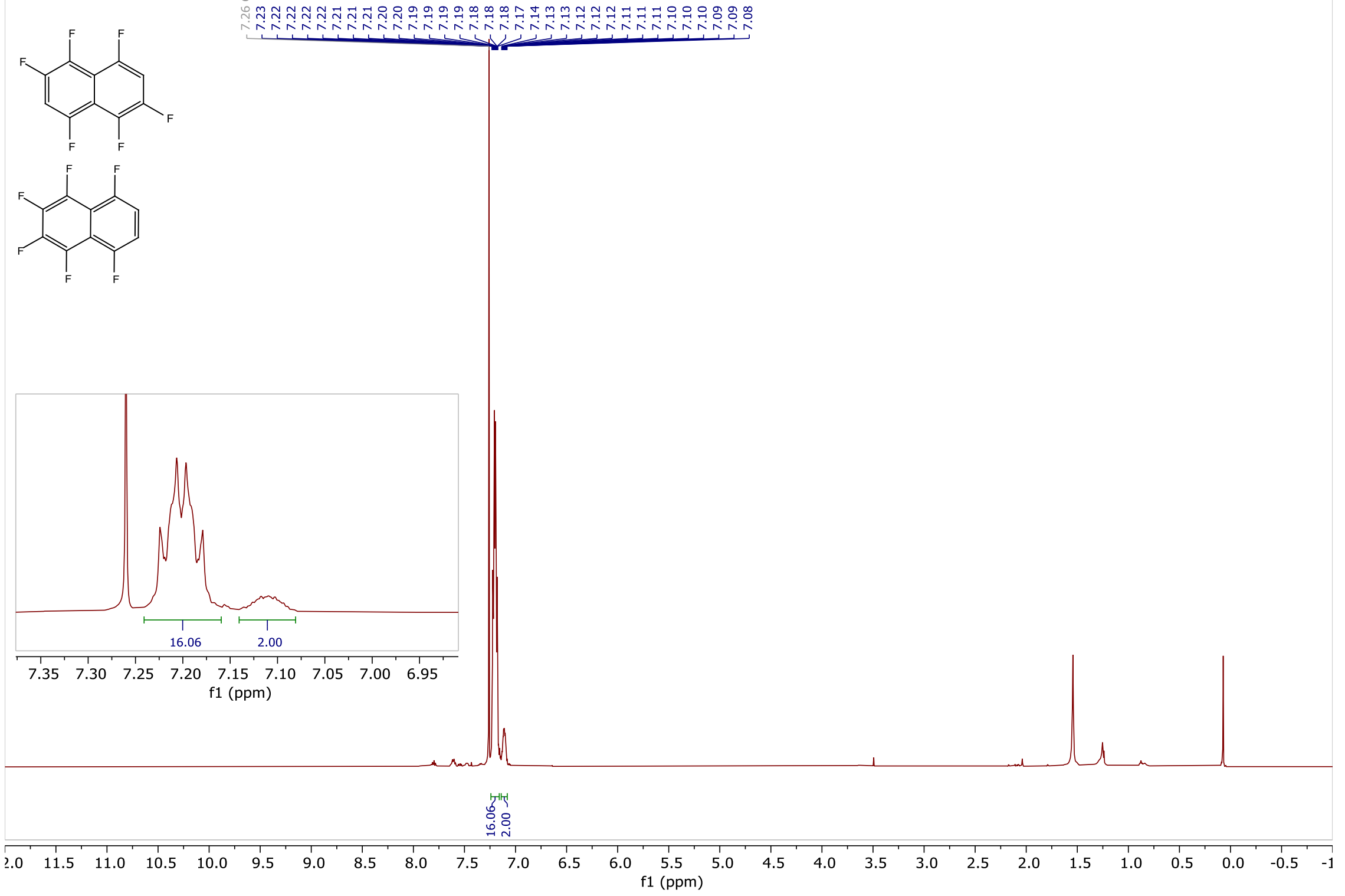


$16 \mathrm{~b}$

$19 F$ NMR at $376.48 \mathrm{MHz}$ in $\mathrm{CDCl} 3$

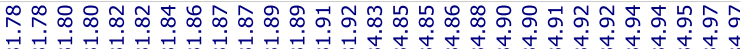

(N)
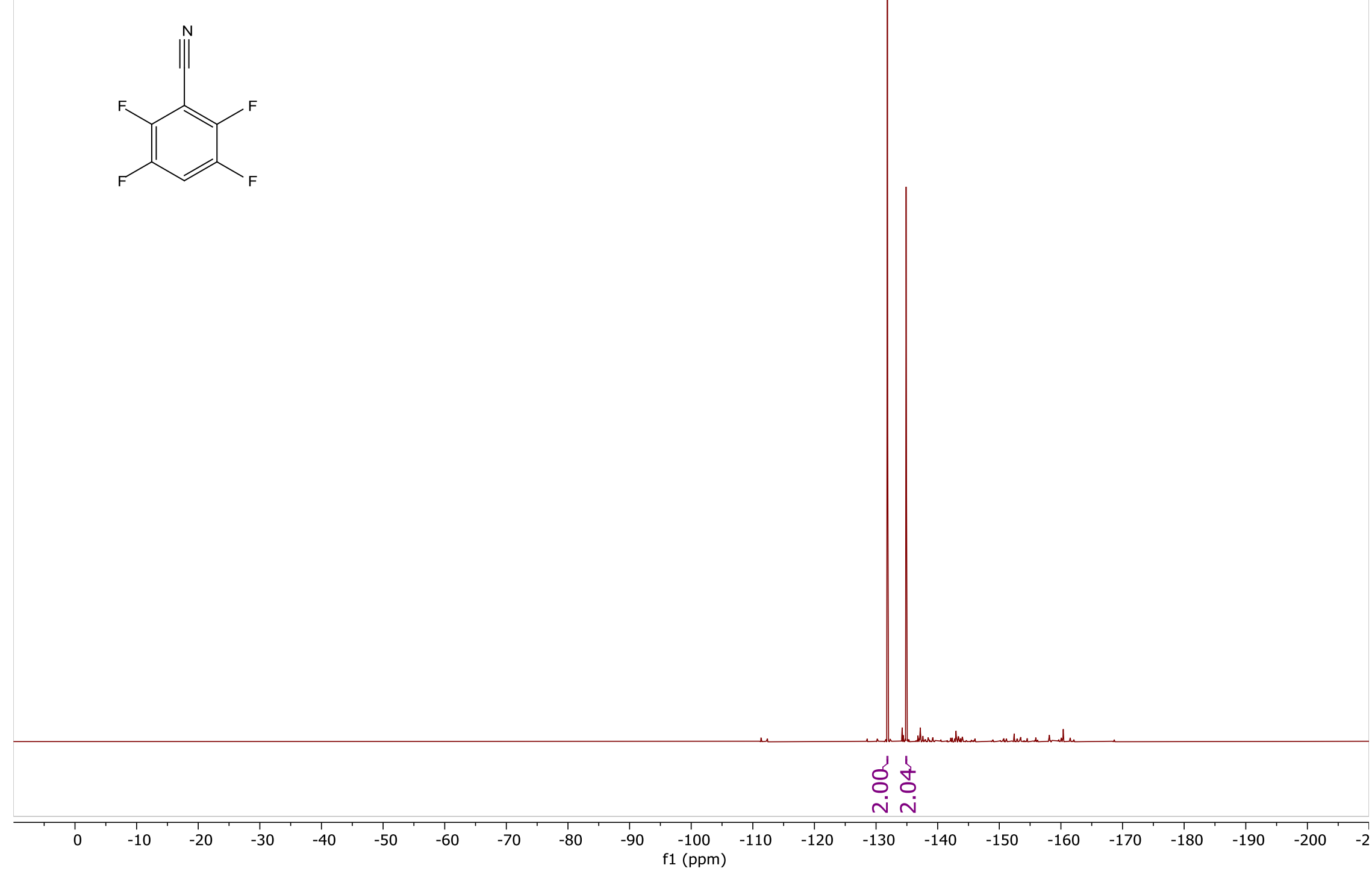
$16 \mathrm{~b}$

$1 \mathrm{H} N M R$ at $400.15 \mathrm{MHz}$ in $\mathrm{CDCl} 3$

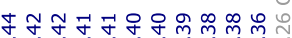

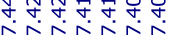
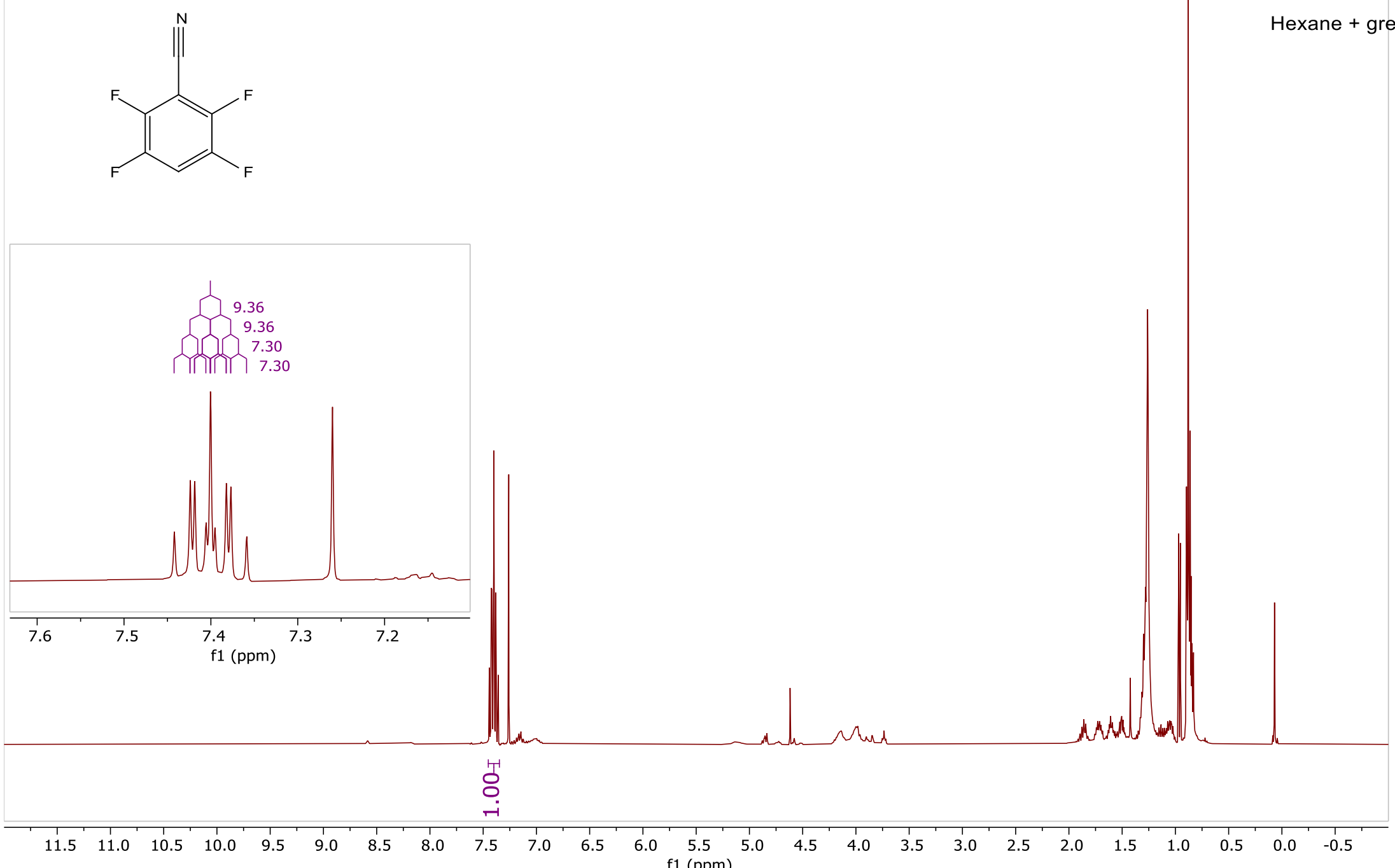


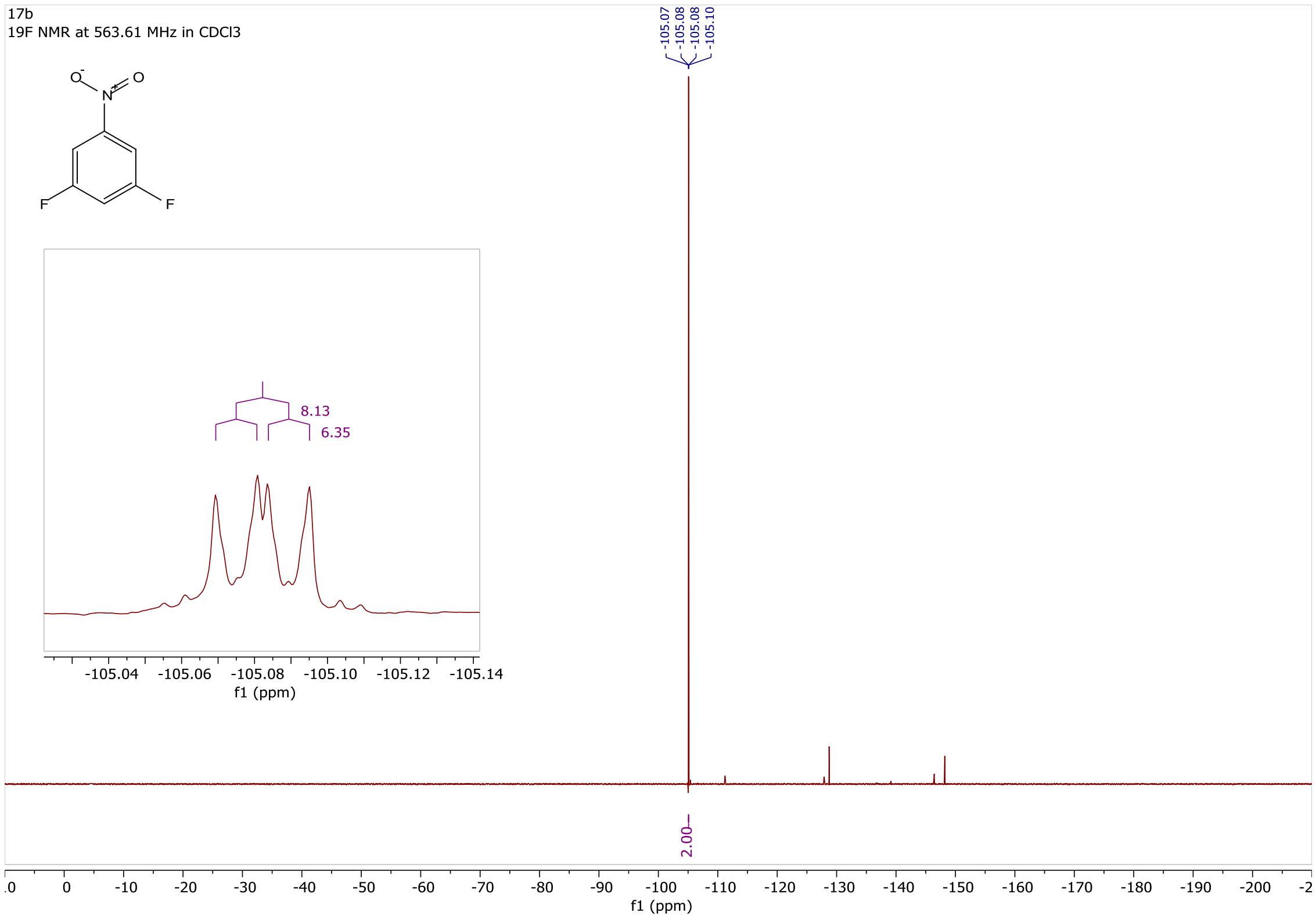




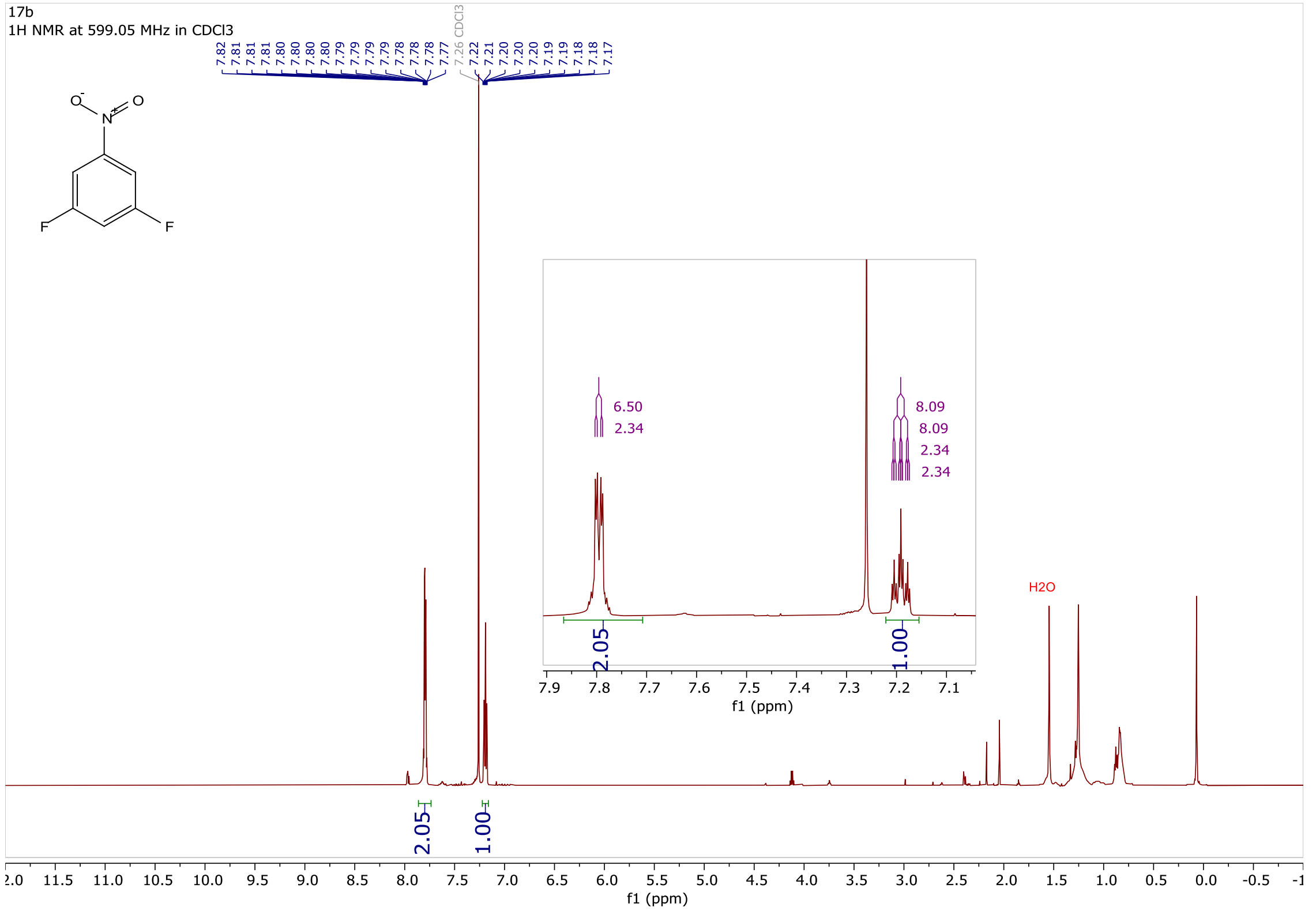


$18 \mathrm{~b}$

19F NMR at $563.61 \mathrm{MHz}$ in $\mathrm{CDCl} 3$
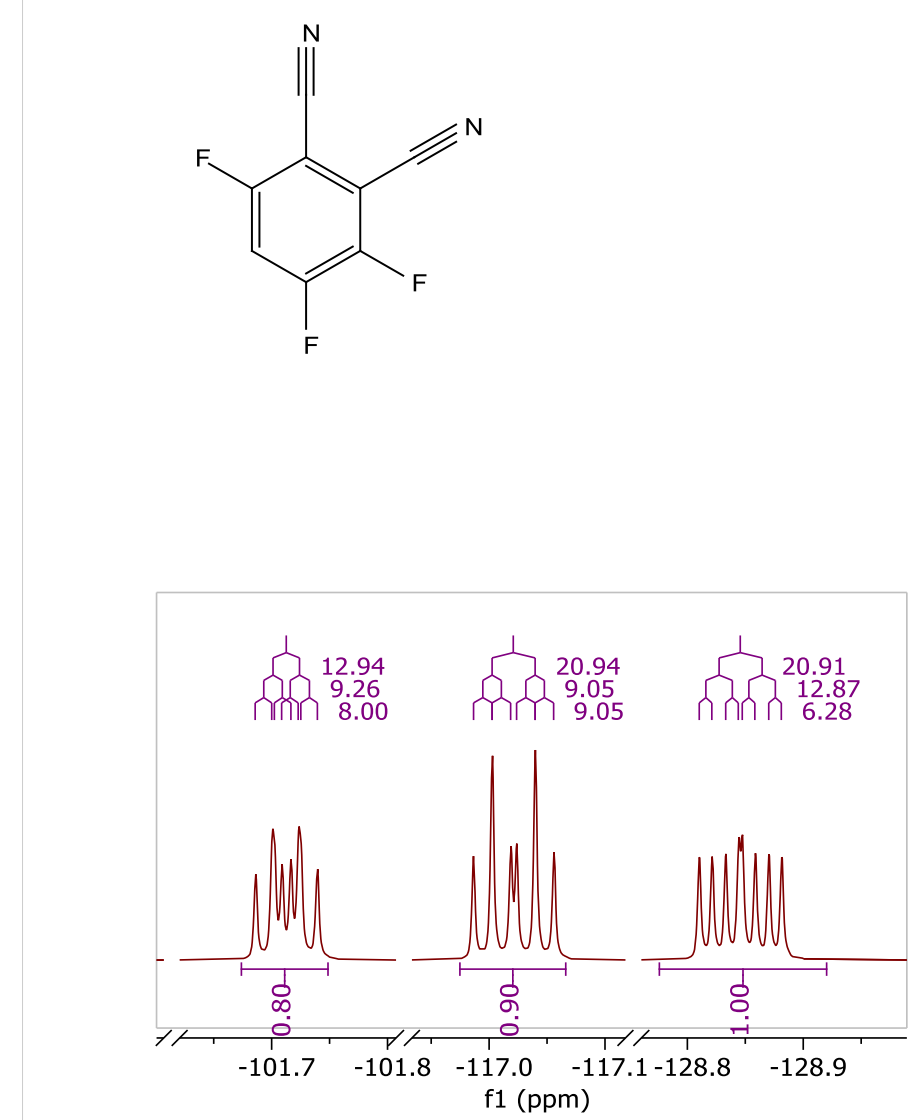

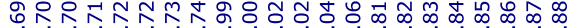

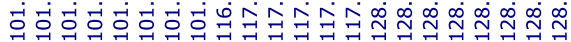

作

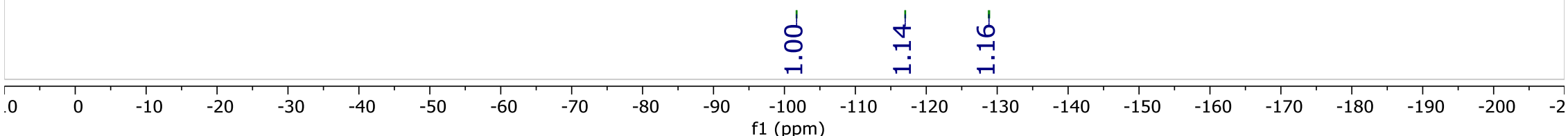




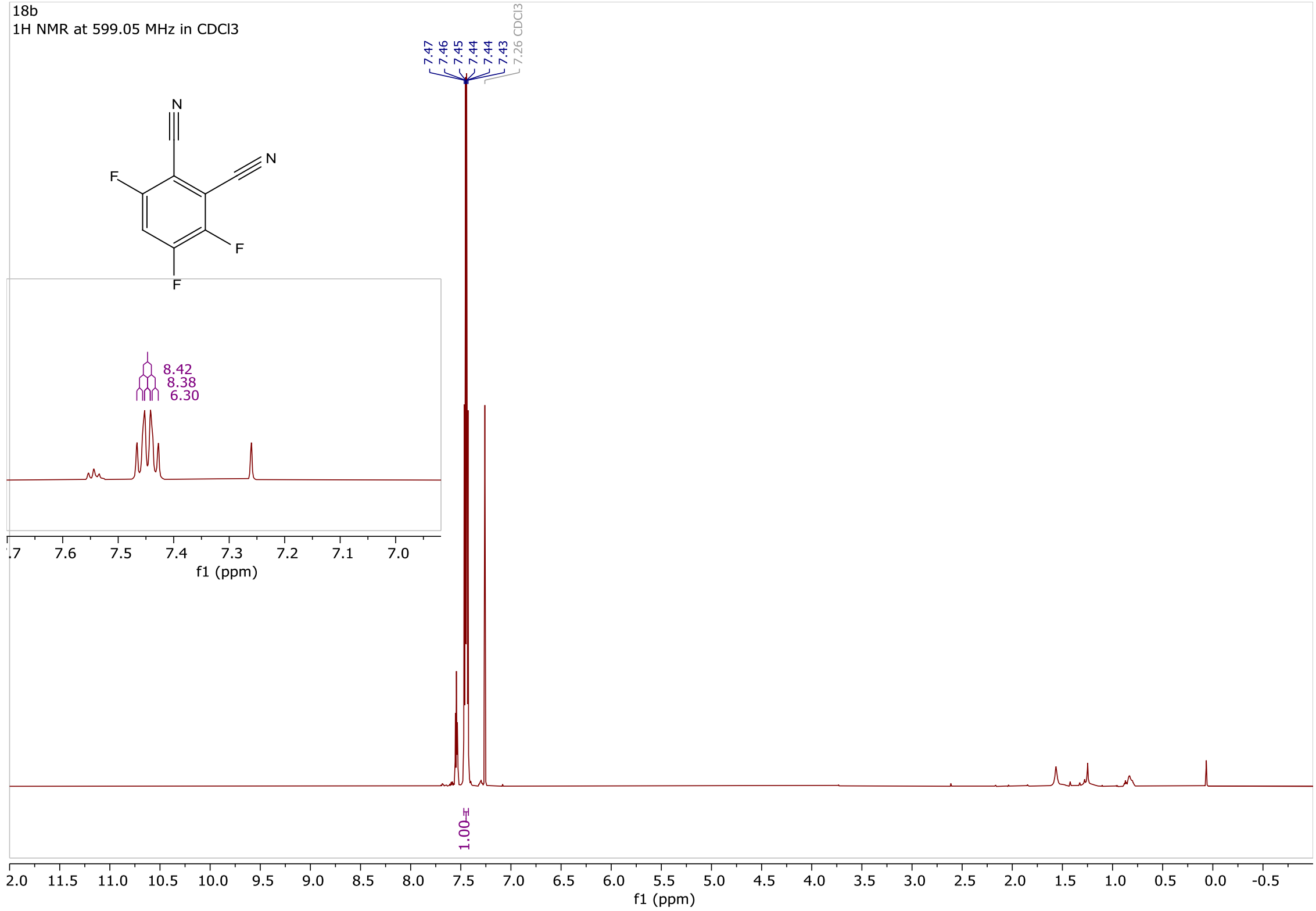


$18 \mathrm{~b}$

13C NMg at $150.65 \mathrm{MHz}$ in $\mathrm{CDCl}$

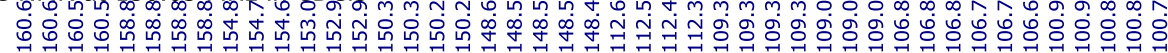

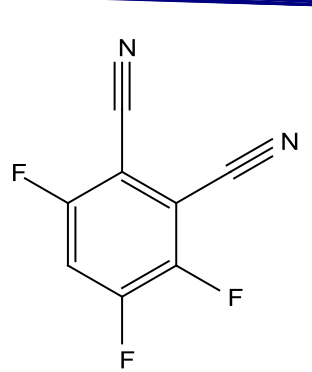

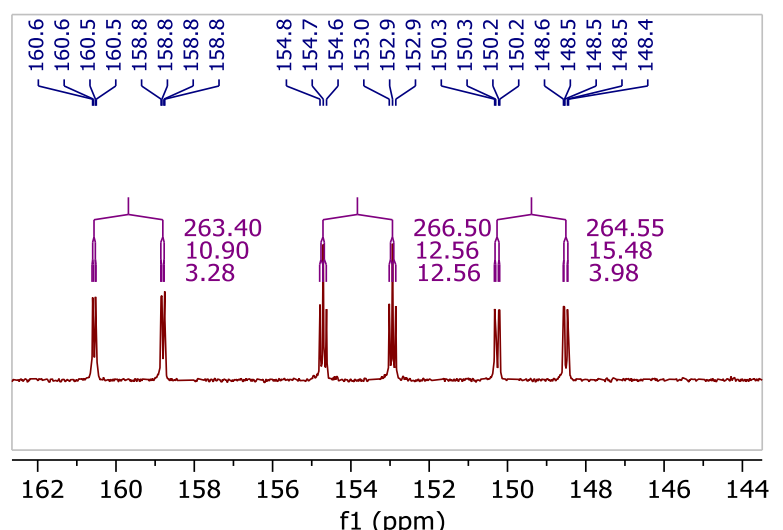

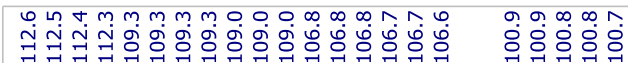
W W
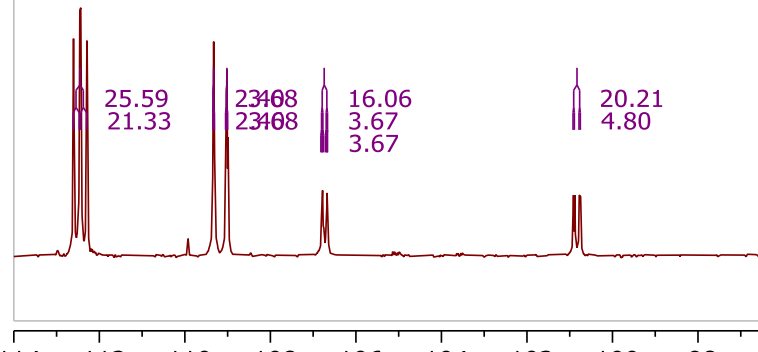

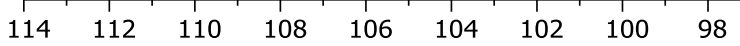
f1 (ppm)

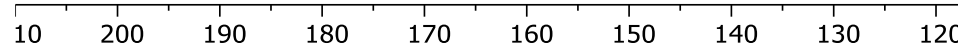

$110 \quad 100$

90

80

70

60

50

40

$30 \quad 20$

10

0 

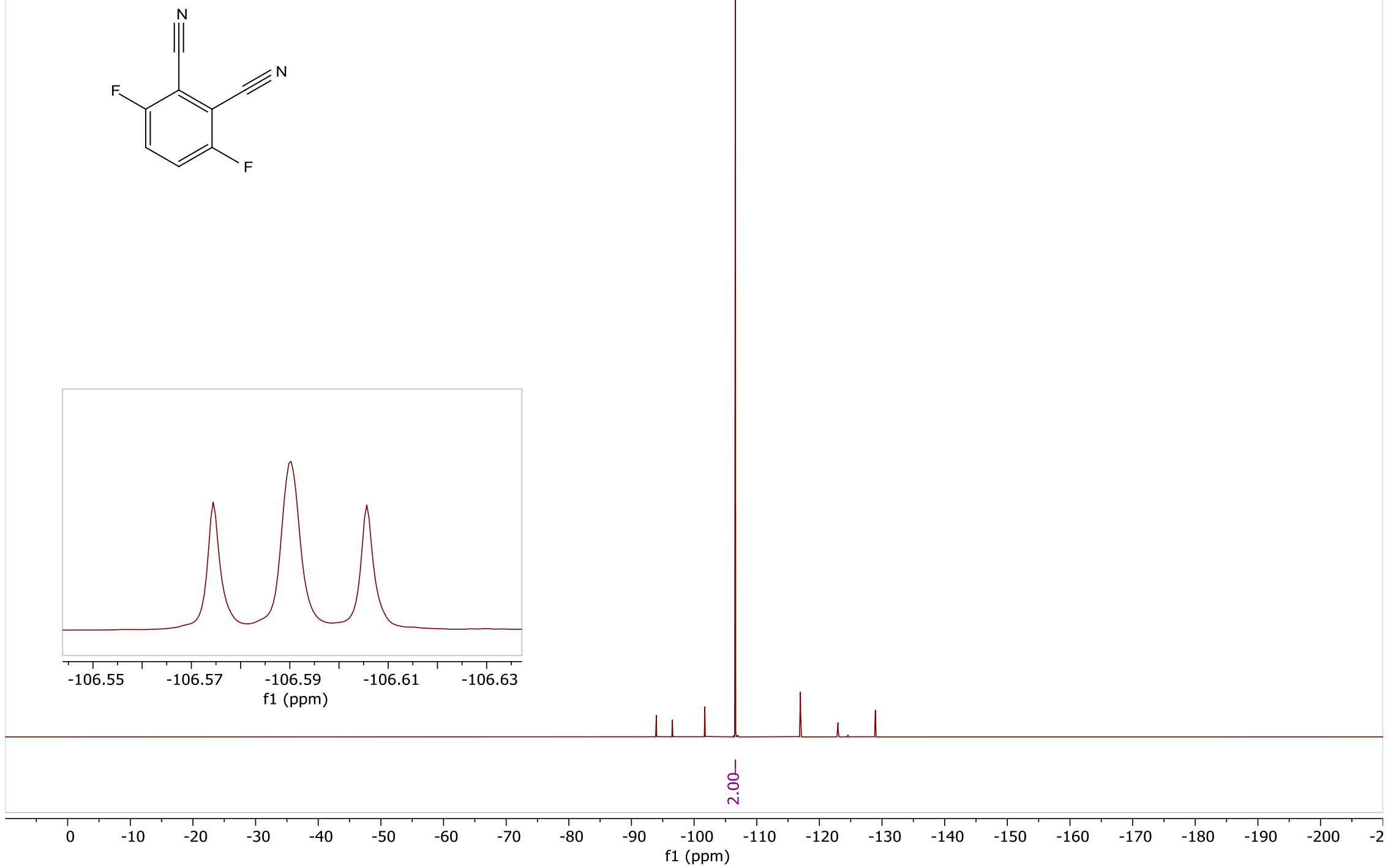


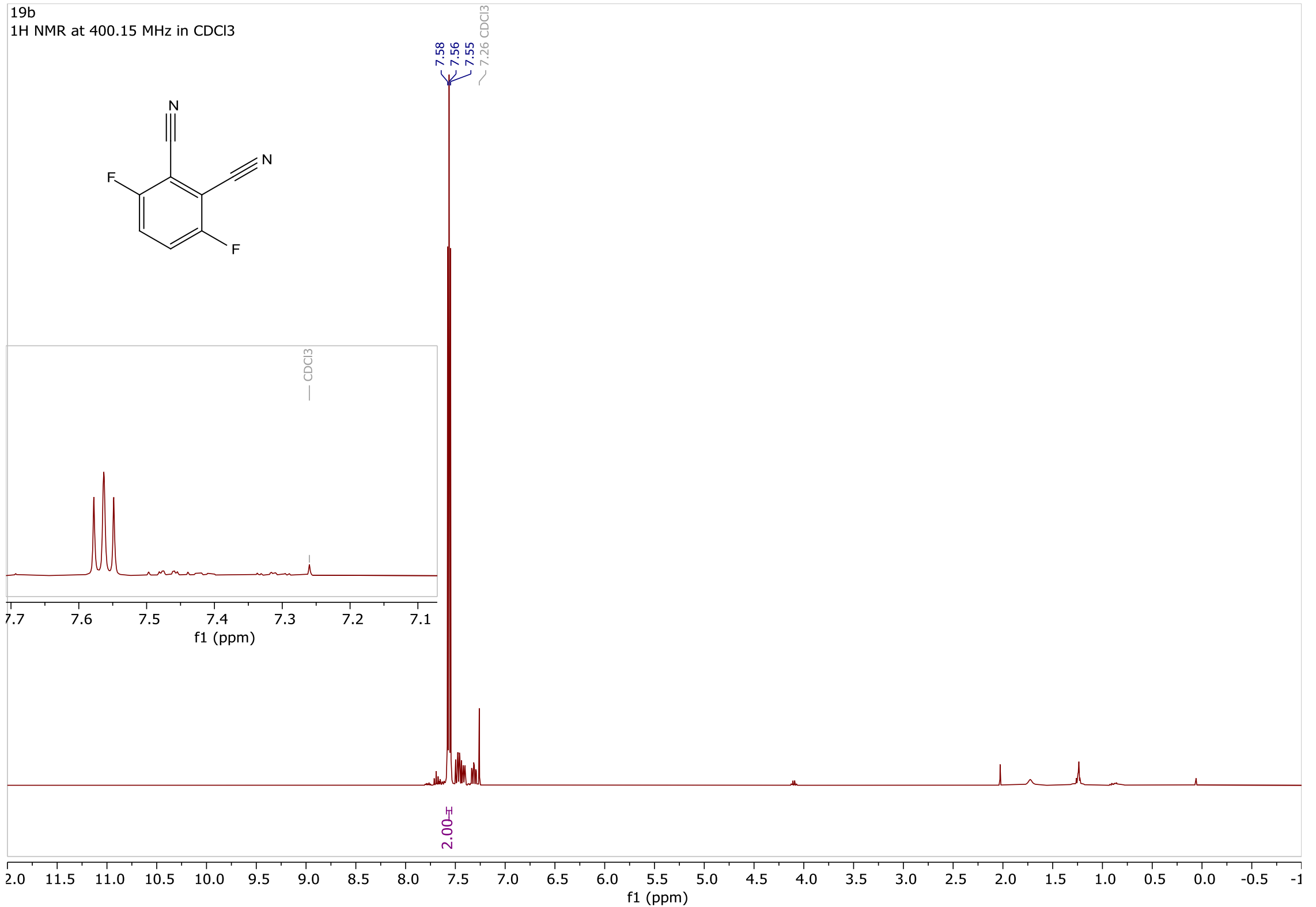


19F NMR at $376.48 \mathrm{MHz}$ in $\mathrm{CDCl} 3$
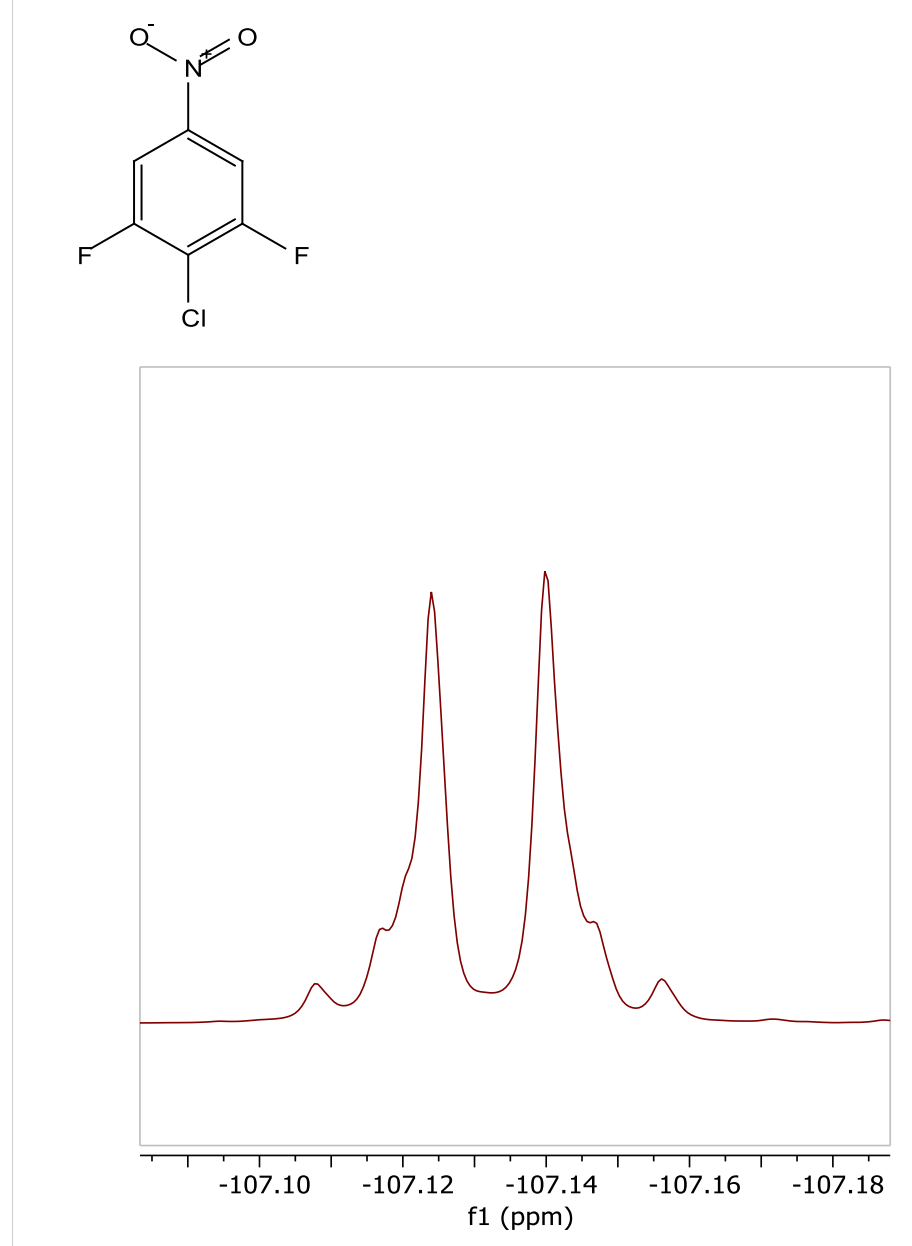

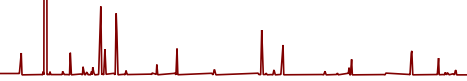

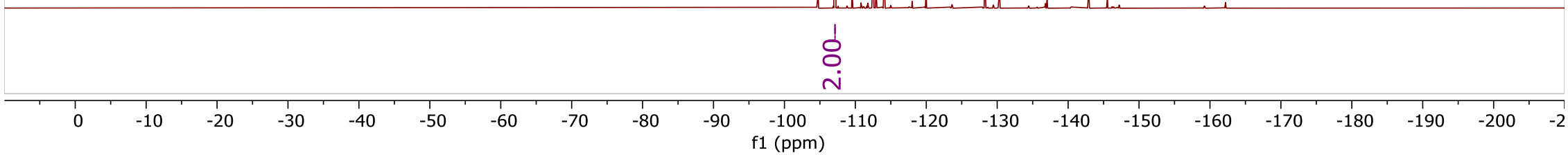


20b

$1 \mathrm{H} \mathrm{NMR}$ at $400.15 \mathrm{MHz}$ in $\mathrm{CDCl}$

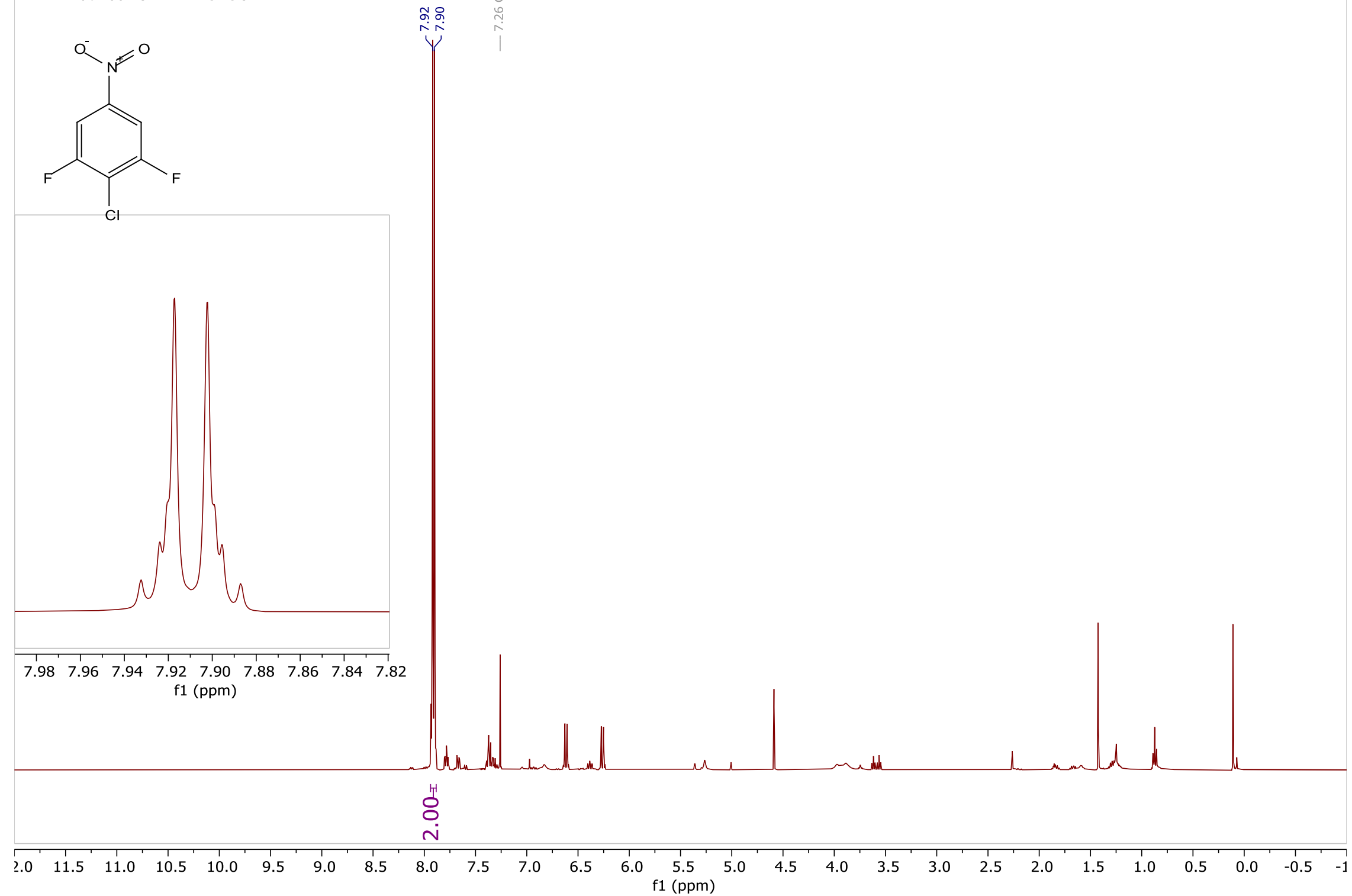




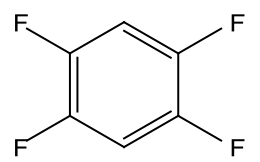

$1 \mathrm{~mL}$ aliquot of $5 \mathrm{~mL}$ total reaction volume fluorobenzene normalized to 213 micromoles $(350 \times 5) /(4 \times 537)=81 \%$ yield
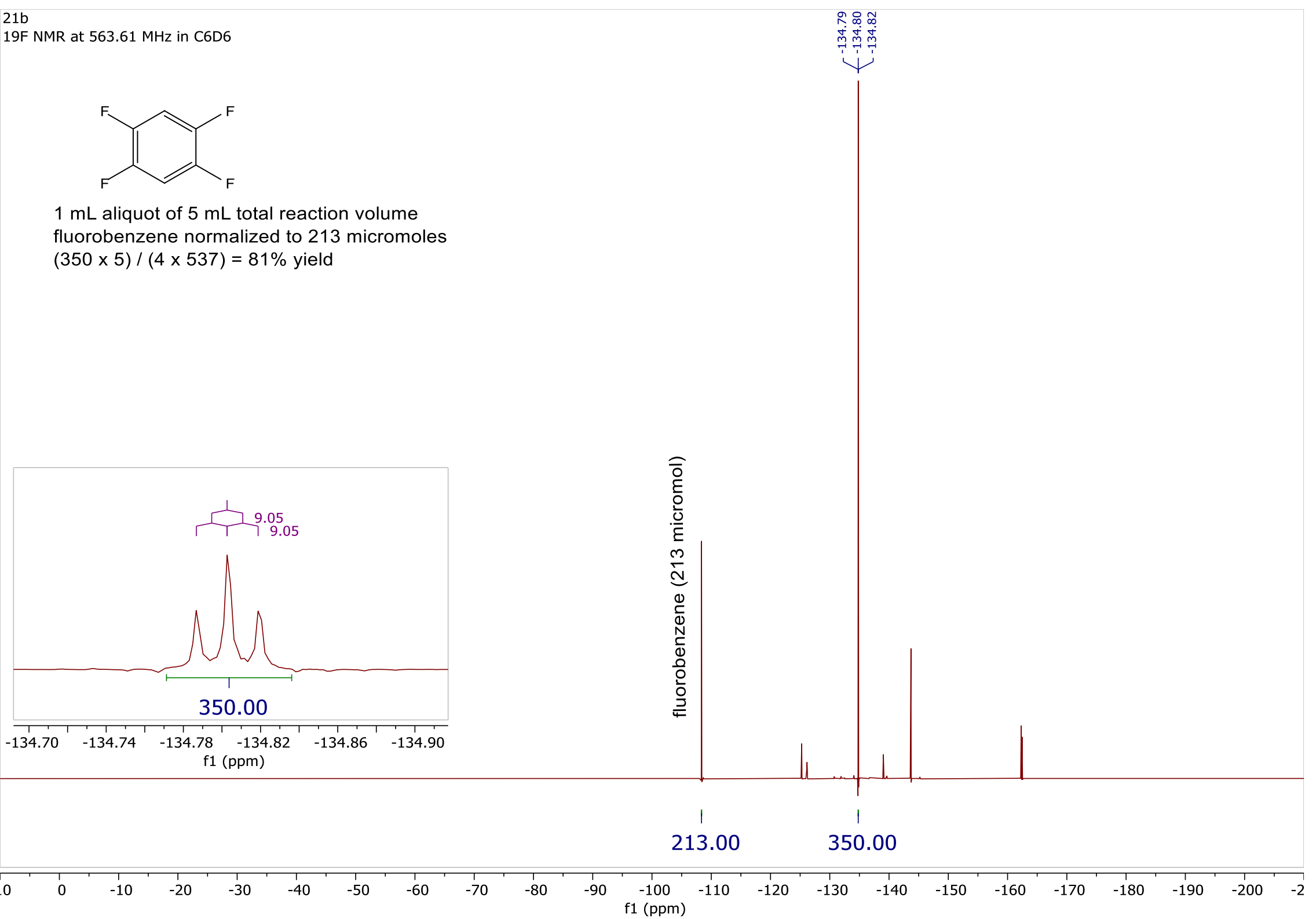
$22 \mathrm{~b}$

19F NMR at $376.48 \mathrm{MHz}$ in DMSO<smiles>Cc1c(F)c(F)cc(F)c1F</smiles>

500 microliter aliquot from $5 \mathrm{~mL}$ total reaction volume fluorobenzene normalized to 213 micromoles $(10 \times(78.32+78.95) /(4 \times 550)=72 \%$ yield

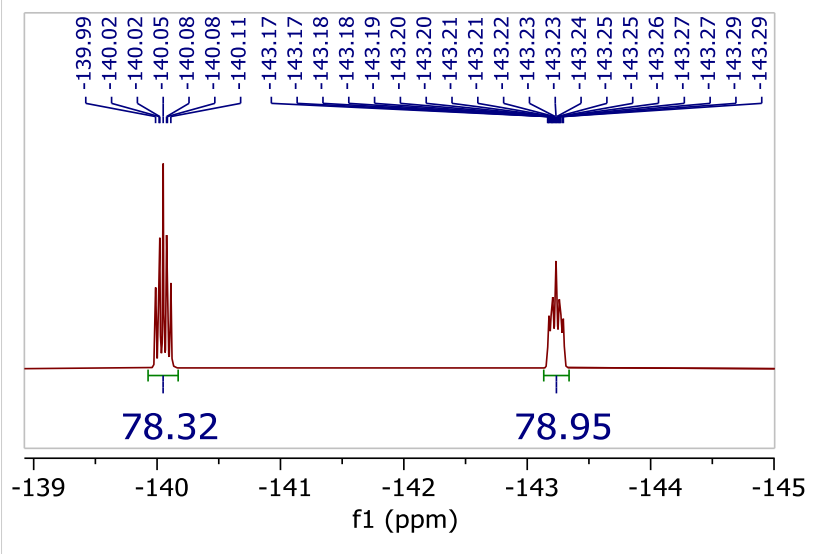

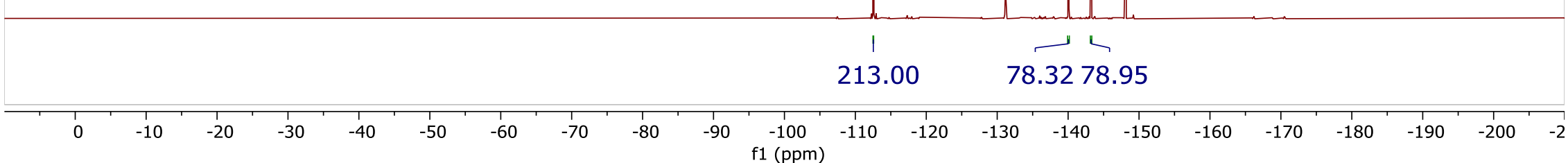

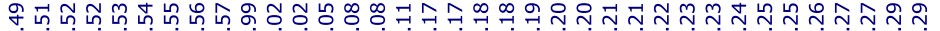

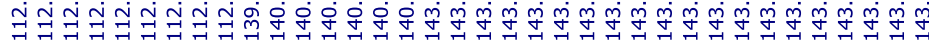

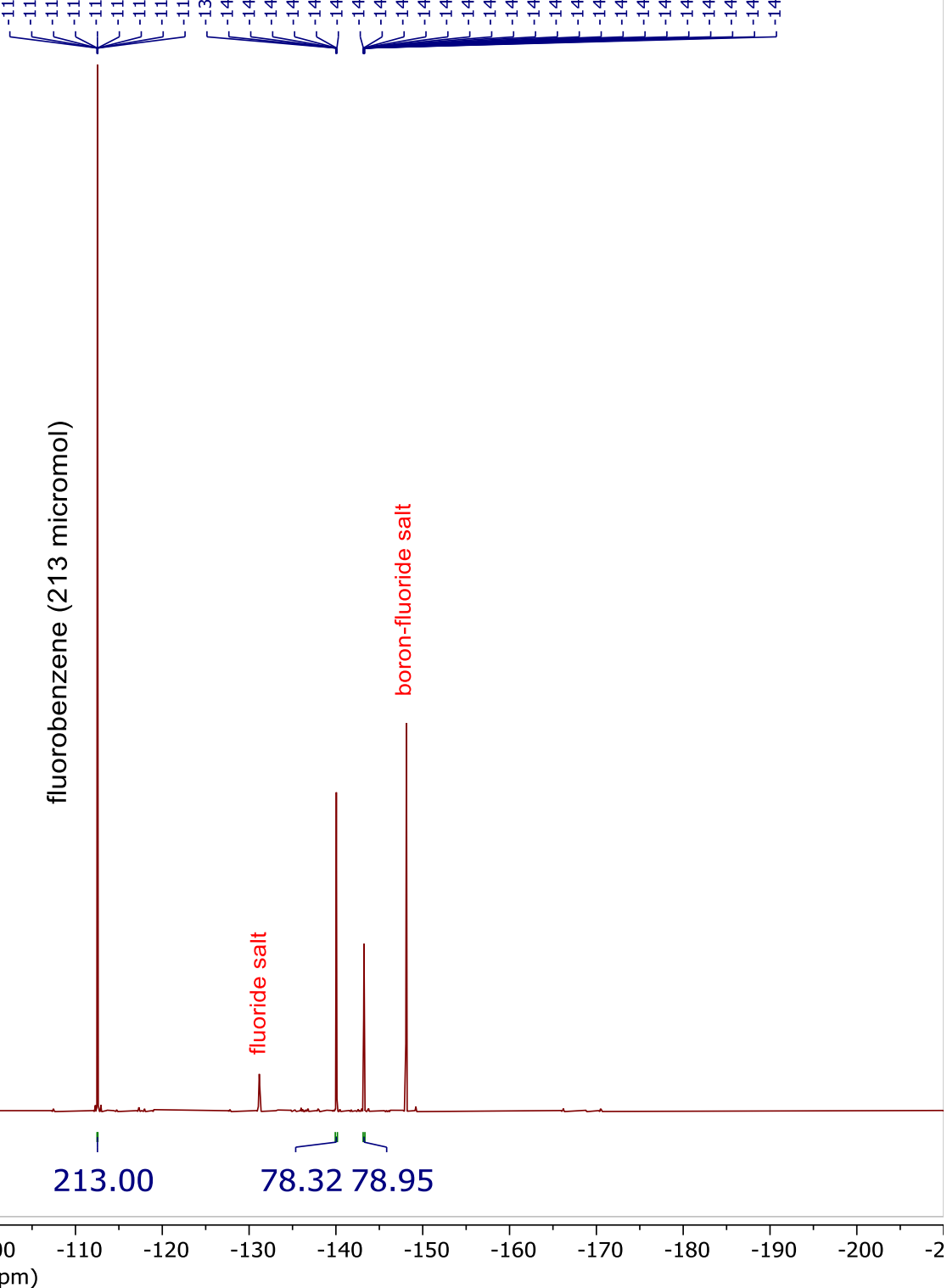




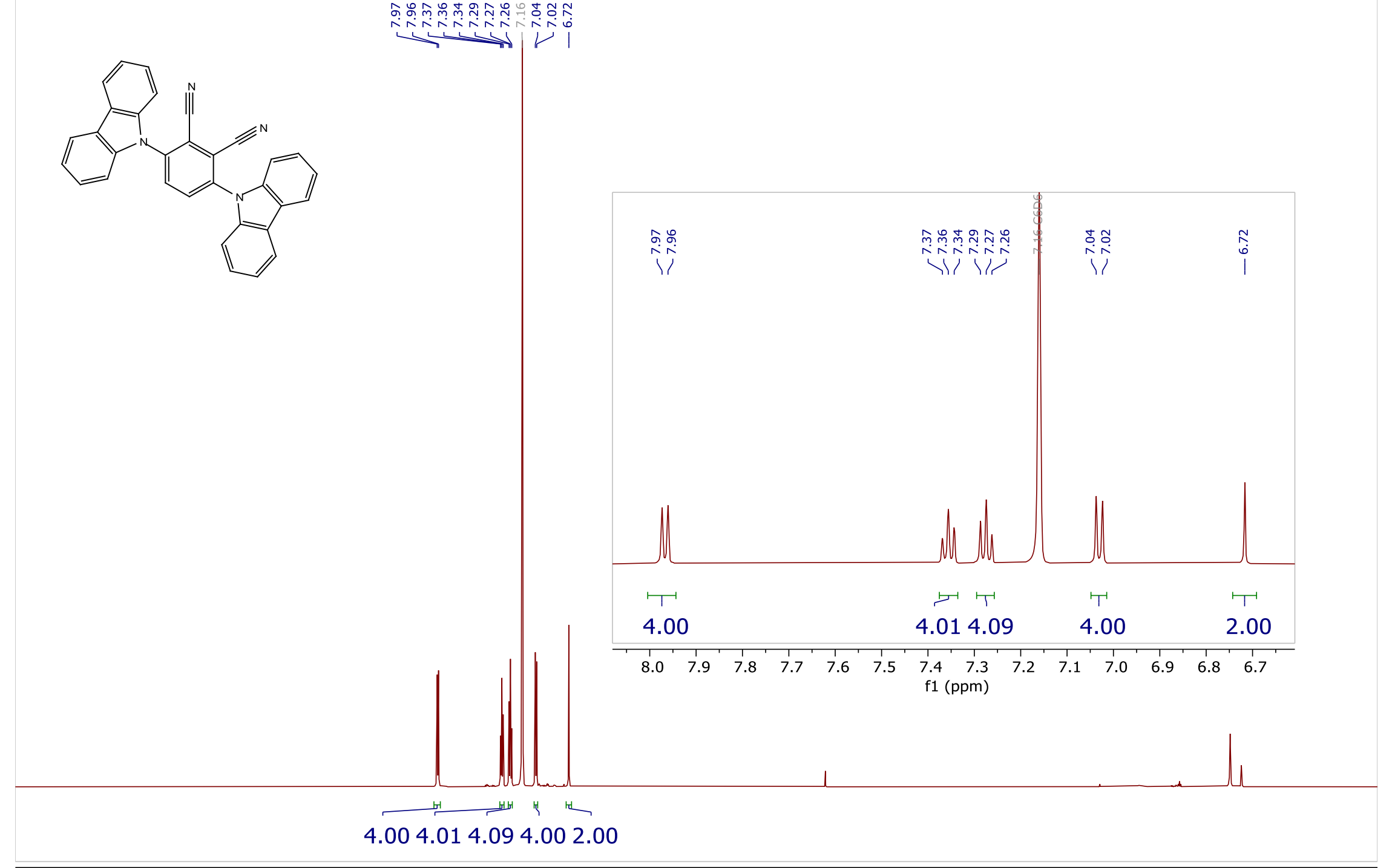

$6.0 \quad 5.5$

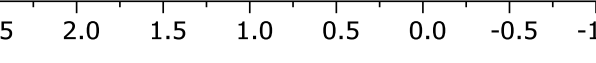


$19 \mathrm{c}$

13C NMR at $150.65 \mathrm{MHz}$ in C6D6

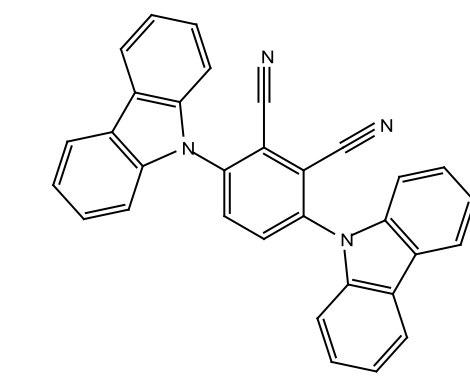

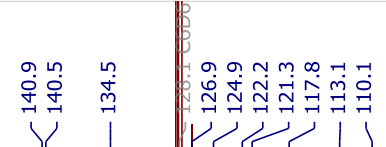

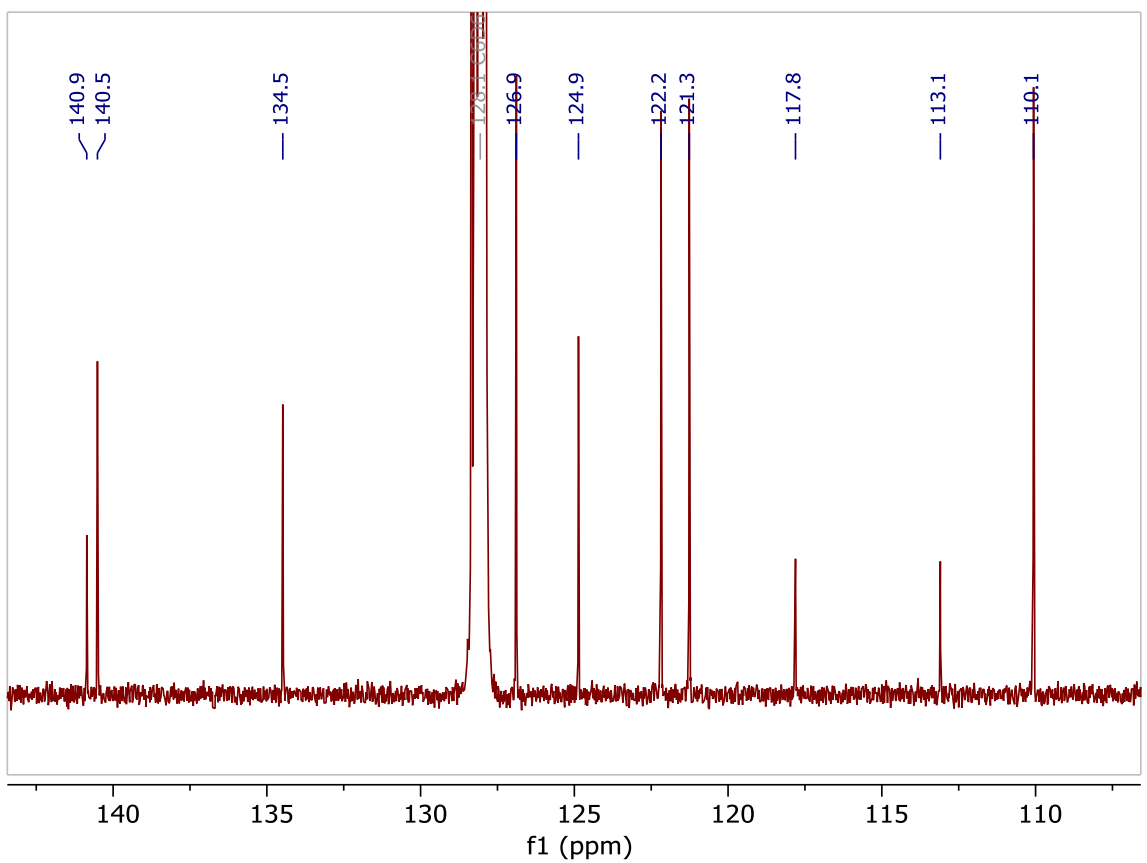

$\begin{array}{llllll}00 & 190 & 180 & 170 & 160 & 150\end{array}$

140

130

120

110

$100 \quad 90$

80

$70 \quad 60$

50

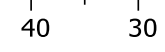

20

$10 \quad 0$

$0 \quad-$ 